\title{
FLUXOS DE DIÓXIDO DE CARBONO EM UMA ÁREA DE FLORESTA NA AMAZÔNIA CENTRAL.
}

\author{
RAFAEL FERREIRA DA COSTA \\ Meteorologista
}

Orientador: Prof. ANTONIO ROBERTO PEREIRA

\begin{abstract}
Disserțação apresentada à Escola Superior de Agricultura "Luiz de Queiroz", Universidade de São Paulo, para obtenção do Título de Mestre em Agronomia, Área de Concentração: Agrometeorologia.
\end{abstract}

\section{PIRACICABA}

Estado de São Paulo - Brasil 
Dados Internacionais de Catalogação na Publicação (CIP)

DIVISĀo DE BIBLIOTECA E DOCUMENTAÇĀO - Campus "Luiz de Queiroz"/USP

Ferreira da Costa, Rafael

Fluxos de dióxido de carbono em uma área de floresta na Amazônia Central /

Rafael Ferreira da Costa. - - Piracicaba, 2000.

97 p. : il.

Dissertação (mestrado) - Escola Superior de Agricultura Luiz de Queiroz, 2000.

Bibliografia.

1. Climatologia florestal 2. Dióxido de carbono 3. Ecologia florestal 4. Floresta amazônica 5. Relação solo-planta-atmosfera l. Título

CDD 634.94

"Permitida a copia total ou parcial deste documento, desde que citada a fonte - $O$ autor" 


\section{ERRATAS}

Página $2,2^{\circ}$ parágrafo, linha 11 , onde se lề "...opera em escala de tempo de alguns segundos até vários anos, sendo possível relacionar ..." leia-se “...opera em escala de tempo de alguns segundos, sendo possível relacionar..."

Página $52,3^{\circ}$ parágrafo, linha 6 , onde se lê "O dia 19 mesmo tendo de ocorrência de chuvas só às registrou significativamente às 17 h,..." leia-se "O dia 19 mesmo com a ocorrência de chuvas só as registrou significativamente após 17 h,...." 
Para Nair, minha mãe

e para Ana que é a melhor metade de mim, fontes eternas de incentivo, amor e compreensão, e sumidouros de dúvidas, tristezas e desânimos.

Apenas uma góta de luz sobre of mistérios do clorofitado oceano amazônico. 


\section{AGRADECIMENTOS}

Ao Professor Antonio Roberto Pereira, pela orientação neste trabalho e pela confiança depositada.

Aos professores e funcionários do Departamento de Ciências Exatas, curso de Agrometeorologia da ESALQ/USP pelos ensinamentos, em especial aos Doutores: Nilson Augusto Villanova e Paulo Cesar Sentelhas.

Aos companheiros do curso de Mestrado; Evandro, Glauco, Karen, Késia, Marcius, e Sylvia e aos novos amigos; Cristina, Marcelino e Cláudia, Norberto, Betânia e Rosa.

Ao Gilberto Fisch pesquisador do IAE/CTA de São José dos Campos, SP, pela amizade e valiosa contribuição na elaboração deste trabalho

À CAPES, pela concessão da bolsa de estudos

A tọdos aqueles que direta ou indiretamente, contribuíram para a realização deste trabalho. 


\section{SUMÁRIO}

LISTA DE FIGURAS

Página

RESUMO

$\mathrm{V}$

SUMMARY

1.

INTRODUÇÃO..

VI

VIII

2. REVISÃO DE LITERATURA ……................................................

$2.1 \mathrm{O}$ passado e o presente do $\mathrm{CO}_{2}$ atmosférico

2.2 Emissões globais e regionais de $\mathrm{CO}_{2}$.

2.3. Mudanças no uso da terra.

2.4 As interações do carbono atmosférico.

2.5 Técnicas de medidas de $\mathrm{CO}_{2}$

2.6 Alguns estudos de $\mathrm{CO}_{2}$ em florestas.

2.7 Estudos de $\mathrm{CO}_{2}$ na Amazônia.

3. MATERIAL E MÉTODOS

3.1 Localização.

3.2 Características do solo.

3.3 Vegetação.

3.4 Torre micrometeorológica.

3.5 Covariância dos fluxos turbulentos.

3.6 Análise dos dados

4. RESULTADOS E DISCUSSÃO …………………………........

4.1 Precipitação pluviométrica. ................................................................. 34

4.2 Fluxos de $\mathrm{CO}_{2}$...................................................................... 38

4.3 Concentrações de $\mathrm{CO}_{2}$................................................................ 45

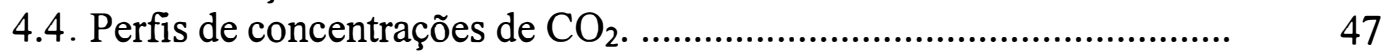

4.5 Radiação solar incidente $(S)$............................................................ $\quad 52$

4.6 Radiação solar refletida $(S r)$............................................................ $\quad 55$

4.7 Saldo de radiação $(R n)$................................................................... 57

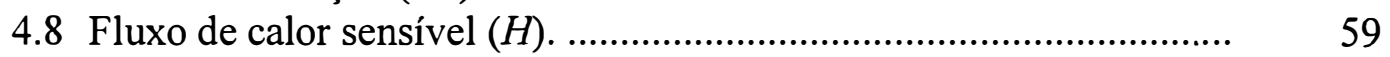

4.9 Fluxo de calor latente $(L E)$............................................................. 60

4.10 Velocidade de friç̧ão $\left(u^{*}\right)$.............................................................. 62

4.11 Temperatura do ar $(\mathrm{Ta})$.................................................................. 64

4.12 Temperatura do solo $(T s)$................................................................ 66

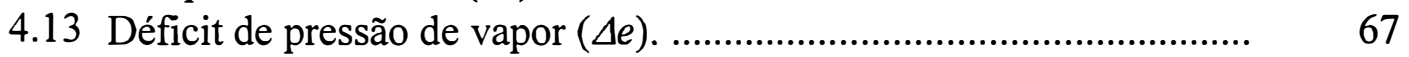

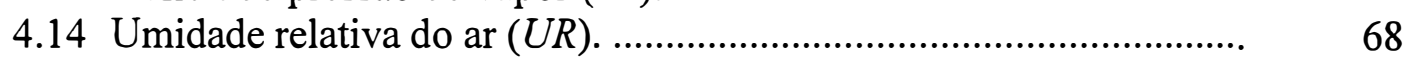

4.15 Velocidade do vento $(V v)$............................................................. $\quad 70$

4.16 Razão de Bowen $(\beta)$..................................................................... $\quad 71$

5. CONCLUSÕES...................................................................

REFERÊNCIAS BIBLIOGRÁFICAS ………………………………...... 


\section{LISTA DE FIGURAS}

Figuras

Página

1 Concentração de $\mathrm{CO}_{2}$ no último milênio ………………………...... 6

2 Concentração de $\mathrm{CO}_{2}$ em Mauna Loa, Hawaii, EUA......................... 6

3 Taxas de crescimento das Concentração de $\mathrm{CO}_{2}$ em Mauna Loa ... 7

$4 \quad$ Emissões globais de carbono de origem fóssil ............................... 10

$5 \quad$ Emissões brasileiras de carbono de origem fóssil ........................... 10

6 - Fixação de $\mathrm{CO}_{2}$ pelos estômatos .................................................. 14

$7 \quad$ Mapa de localização do sítio experimental ........................................ 23

$8 \quad$ Torre micrometeorológica …………………….............................. 25

9 Estação meteorológica automática ................................................. 26

10 Anemômetro sônico e Analisador infravermelho de gás ................. 28

11 e 12 Precipitação pluviométrica no período seco ................................... 35

13 e 14 Precipitação pluviométrica no período chuvoso .............................. 37

$15 \quad$ Fluxos de $\mathrm{CO}_{2}$................................................................. 40

16 Fluxos de $\mathrm{CO}_{2}$ e precipitação nos períodos seco e chuvoso ............ 41

17 Fluxo integrado e balanço de carbono ............................................ 45

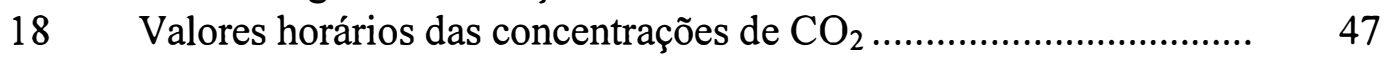

19 Perfis de concentrações de $\mathrm{CO}_{2}$ em 6 níveis no período seco ......... 49

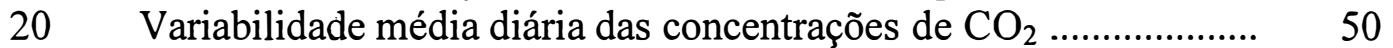

21 Valores médios diários das concentrações de $\mathrm{CO}_{2}$ :........................ 51

22 Concentrações médias de $\mathrm{CO}_{2}$ em 6 níveis no período seco ............ 51

23 Radiação solar incidente .............................................................. 54

24 • Radiação solar refletida .............................................................. 56

$25 \quad$ Saldo de radiação ....................................................................... 58

$26 \quad$ Fluxo de calor sensível ........................................................... 59-60

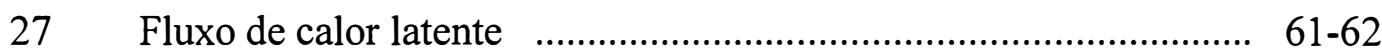

28 Velocidade de friç̧ão ............................................................... 63-64

29 Temperatura do ar .................................................................... 65

30 Temperatura do solo a $5 \mathrm{~cm}$ de profundidade ............................... 66-67

31 Déficit de pressão de vapor .......................................................... 68

32 Umidade relativa do ar ................................................................. $69-70$

33 Velocidade do vento ............................................................. 71

$34 \quad$ Razão de Bowen ........................................................................ 72 


\title{
FLUXOS DE DIÓXIDO DE CARBONO EM UMA ÁREA DE FLORESTA NA AMAZÔNIA CENTRAL.
}

\author{
Autor: RAFAEL FERREIRA DA COSTA \\ Orientador: Prof. ANTONIO ROBERTO PEREIRA
}

\section{RESUMO}

Medidas de fluxos e concentração de dióxido de carbono $\left(\mathrm{CO}_{2}\right)$ foram coletadas durante dois períodos distintos na Amazônia Central, em uma torre micrometeorológica com 41,5m de altura, montada na Reserva Biológica do Rio Cuieiras, 'na Bacia experimental do rio Tarumã-Açu (2 $\left.2^{\circ} 36^{\prime} \mathrm{S}, 60^{\circ} 7^{\prime} \mathrm{W}, 52 \mathrm{~m}\right)$ pertencente ao Instituto Nacional de Pesquisas da Amazônia (INPA), distante cerca de $57 \mathrm{~km}$ ao norte de Manaus (AM). A primeira fase de coleta, chamada de período seco, teve a duração de oito dias (21 a 28/10/1995) com o registro de apenas $12,6 \mathrm{~mm}$ de precipitação. A segunda fase, período chuvoso também com a duração de oito dias (15 a 22/02/1996) registrou 109,8mm de precipitação. Os fluxos de $\mathrm{CO}_{2}$ ocorreram da floresta para a atmosfera durante o período noturno até as primeiras horas da manhã (fluxos positivos), resultantes do predomínio do processo respiratório da vegetação. Durante o período diurno o fluxo de $\mathrm{CO}_{2}$ teve o sinal invertido, quando a absorção do $\mathrm{CO}_{2}$ atmosférico pela vegetação prevaleceu sobre a liberação (fluxos negativos), para utilização no processo de fotossíntese. Foram realizadas medidas em seis níveis distintos; $1 ; 9 ; 17,4 ; 25,3 ; 33,3$ e 46,5m durante o período seco. No período seco, em média, foi registrado um valor de $+12,9 \mu \mathrm{mol} \mathrm{m}^{-2} \mathrm{~s}^{-1}$ às $8 \mathrm{~h}$, enquanto que no período chuvoso, este valor foi de $+11,4 \mu \mathrm{mol} \mathrm{m}^{-2} \mathrm{~s}^{-1}$ às $7 \mathrm{~h}$. Para o período seco o valor registrado foi $-14,5 \mu \mathrm{mol} \mathrm{m} \mathrm{m}^{-2} \mathrm{~s}^{-1}$ às $12 \mathrm{~h}$, e para o período chuvoso $-16,4 \mu \mathrm{mol} \mathrm{m} \mathrm{m}^{-2} \mathrm{~s}^{-1}$ às 11 h. Os fluxos médios de $\mathrm{CO}_{2}$ mostraram que, no período seco, houve absorção de $-35,4 \mathrm{~kg} \mathrm{C} \mathrm{ha}^{-1} \mathrm{dia}^{-1}$, e um fluxo de liberação de $+21,8 \mathrm{~kg} \mathrm{C} \mathrm{ha}^{-1} \mathrm{dia}^{-1}$, resultando em 
um balanço médio diário de $-13,6 \mathrm{~kg} \mathrm{C}^{-1} \mathrm{dia}^{-1}$ (seqüestro). Durante o período chuvoso, a emissão média de carbono para a atmosfera foi de $+32,3 \mathrm{~kg} \mathrm{C}^{-1} \mathrm{dia}^{-1}$, sendo que no mesmo período o seqüestro médio foi de $-48,2 \mathrm{~kg} \mathrm{C} \mathrm{ha}^{-1} \mathrm{dia}^{-1}$. O balanço de carbono na época chuvosa foi de $-15,9 \mathrm{~kg} \mathrm{C} \mathrm{ha}^{-1} \mathrm{dia}^{-1}$, mostrando que a floresta foi sumidouro de carbono durante os períodios estudados. Extrapolando-se a floresta retiraria da atmosfera aproximadamente $-5 \mathrm{Mg} \mathrm{C} \mathrm{ha}^{-1} \mathrm{ano}^{-1} \mathrm{com}$ as taxas de seqüestro obtidas no período seco, e cerca de $-5,8 \mathrm{Mg} \mathrm{C} \mathrm{ha}^{-1} \mathrm{ano}^{-1}$ com os valores da época chuvosa, o que representa aproximadamente $16 \%$ mais carbono absorvido pela vegetação na época chuvosa do que na seca. A taxa média de seqüestro de carbono pela vegetação obtida neste trabalho, de aproximadamente $-5,4 \mathrm{Mg} \mathrm{C} \mathrm{ha}^{-1} \mathrm{ano}^{-1}$, se expandida para a área total da Amazônia (cerca de $5 \times 10^{8}$ ha), atingiria $-2,7 \mathrm{Pg} \mathrm{C}$ ano ${ }^{-1}$. Uma mitigação de carbono atmosférico desta proporção ajudaria a explicar, em parte, o chamado carbono desaparecido "missing carbon" apresentado nos balanços globais. As concentrações médias de $\mathrm{CO}_{2}$ acima da floresta foram de 387 ppmv no período seco e de 370 ppmv no chuvoso. A média geral da concentração de $\mathrm{CO}_{2}$ foi de aproximadamente 379 ppmv. As concentrações de $\mathrm{CO}_{2}$ acima do dossel foram aproximadamente $4,6 \%$ maiores no período seco do que no chuvoso. Na média, a concentração de $\mathrm{CO}_{2}$ atingiu valores máximos no nível de $1 \mathrm{~m}$ com aproximadamente 410 ppmv e de 409 ppmv em 9m, decrescendo progressivamente até atingir a mais baixa concentração em 46,5m com aproximadamente 387 ppmv. Esta diferença representou cerca de $+5,5 \%$ de $\mathrm{CO}_{2}$ no nível inferior. 
CARBON DIOXIDE FLUXES IN A FOREST SITE ON THE CENTRAL AMAZONIA.

\author{
Author: RAFAEL FERREIRA DA COSTA \\ Adviser: Prof. ANTONIO ROBERTO PEREIRA
}

\title{
SUMMARY
}

Carbon dioxide $\left(\mathrm{CO}_{2}\right)$ fluxes and concentrations were collected during two distinct periods in the Central Amazonia. In a micrometeorological tower with $41.5 \mathrm{~m}$, installed in Cuieiras reserve property of INPA (Amazonia National Research Institute) $2^{\circ} 36^{\prime} \mathrm{S}, 60^{\circ} 7^{\prime} \mathrm{W}, 52 \mathrm{~m}$ a.s.l., some $57 \mathrm{~km}$ northward of Manaus. The dry season (21-28 / $10 / 1995)$ recorded $12.6 \mathrm{~mm}$ of rainfall. In the wet season $(15-22 / 02 / 1996)$ th $\mathrm{e}$ rainfall was $109.8 \mathrm{~mm}$. The $\mathrm{CO}_{2}$ were released from the forest'to the atmosphere from sunset to sunrise. During sunlight the $\mathrm{CO}_{2}$ was absorved by vegetation by photossyntetic activity. $\mathrm{CO}_{2}$ concentrations samples were made in six levels: $1,9,17.4$, $25.3,33.3$ and $46.5 \mathrm{~m}$ above the ground during dry season. In the dry season, the mean release of $\mathrm{CO}_{2}$ was $+12.9 \mu \mathrm{mol} \mathrm{m}^{-2} \mathrm{~s}^{-1}$ at 8 A.M., while in the wet season, this value was $+11.4 \mu \mathrm{mol} \mathrm{m}^{-2} \mathrm{~s}^{-1}$ recorded at $7 \mathrm{~A} . \mathrm{M}$. The mean absorption of $\mathrm{CO}_{2}$ were, $-14.5 \mu$ mol m $\mathrm{m}^{-2} \mathrm{~s}^{-1}$ at 12 A.M. at the dry season, and $-16.4 \mu \mathrm{mol} \mathrm{m}^{-2} \mathrm{~s}^{-1}$ at 11 A.M. at the wet season. The tropical rainforest showed an average $\mathrm{CO}_{2}$ fluxes of $-35.4 \mathrm{~kg} \mathrm{C} \mathrm{ha}^{-1} \mathrm{day}^{-1}$ (absorption), and $+21.8 \mathrm{~kg} \mathrm{C} \mathrm{ha}^{-1}$ day $^{-1}$ (release) for the dry season, resulting a daily budget of $-13.6 \mathrm{~kg} \mathrm{C} \mathrm{ha}^{-1} \mathrm{day}^{-1}$ (carbon sequestration). In wet season the mean $\mathrm{CO}_{2}$ release to the atmosphere was $+32.3 \mathrm{~kg} \mathrm{C} \mathrm{ha}^{-1} \mathrm{day}^{-1}$, while average absorption was -48.2 $\mathrm{kg} \mathrm{C} \mathrm{ha}{ }^{-1}$ day $^{-1}$, giving a carbon budget of $-15.9 \mathrm{~kg} \mathrm{C}^{-1} \mathrm{day}^{-1}$, showing the tropical rainforest as a sink of atmospheric $\mathrm{CO}_{2}$ in the both seasons. The rainforest uptakes nearly $-5 \mathrm{Mg} \mathrm{C} \mathrm{ha}^{-1}$ year $^{-1}$ with the dry season sequestration values, and approximately $-5.8 \mathrm{Mg} \mathrm{C} \mathrm{ha}{ }^{-1}$ year $^{-1}$ in the wet season, representing around $16 \%$ more vegetation 
carbon absorption in the wet season than in the dry season. The average rate of carbon sequestration by vegetation on this work, near of $-5.4 \mathrm{Mg} \mathrm{C}^{-1} \mathrm{year}^{-1}$, if expanded overall Amazonia $\left(\sim 5 \times 10^{8} \mathrm{ha}\right)$ will reach $-2.7 \mathrm{Pg} \mathrm{C}$ year $^{-1}$. A atmospheric carbon mitigation ratio, help to explained in part, the called missing carbon showed on the globals budgets. The average $\mathrm{CO}_{2}$ concentrations above canopy were $387 \mathrm{ppmv}$ in the dry season, and $370 \mathrm{ppmv}$ in wet season, or approximately $4.6 \%$ more in the dry season. The general mean value of $\mathrm{CO}_{2}$ concentration was 379 ppmv. On average $\mathrm{CO}_{2}$ concentrations in different levels were 410 ppmv $(1 \mathrm{~m}), 409$ ppmv $(9 \mathrm{~m})$, progressively decreasing at lowest concentration of $387 \mathrm{ppmv}(46.5 \mathrm{~m})$, this difference represented $+5.5 \%$ in the inferior level. 


\section{INTRODUÇÃO}

O dióxido de carbono $\left(\mathrm{CO}_{2}\right)$ é amplamente conhecido como o mais importante dos gases que absorvem radiação infravermelha, os chamados gases de efeito estufa. As atividades antropogênicas contribuem como uma grande fonte de carbono para a atmosfera, pela queima de combustíveis fósseis e seus derivados. As mudanças no uso da terra, a substituição de vegetação nativa por culturas agrícolas ou atividades pecuárias são outros fatores da pressão antropogênica no aumento do carbono atmosférico.

A elevação das concentrações na atmosfera dos gases de efeito estufa, tais como o $\mathrm{CO}_{2}, \mathrm{~N}_{2} \mathrm{O}$ (óxido nitroso), $\mathrm{CH}_{4}$ (metano) e outros, afeta o balanço radiativo da atmosfera e da superfície terrestre. $\mathrm{O} \mathrm{CO}_{2}$ liberado permanecerá ativo durante vários anos, talvez séculos. O sistema terrestre, pelos processos biogeoquímicos, poderá levar milhares de anos para retornar aos níveis de $\mathrm{CO}_{2}$, similares aos da era pré-industrial (Tans et al., 1996).

Do início da era industrial, em meados do século XIX, até a atualidade, a concentração de $\mathrm{CO}_{2}$ na atmosfera cresceu em média, de 280 ppmv (partes por milhão de volume) para aproximadamente 367 ppmv (Keeling \& Whorf, 1999). Atualmente, cerca de metade do total de emissões antropogênicas ainda permanece na atmosfera (Tans et al., 1990; Conway et al., 1994). As emissões globais de carbono para a atmosfera alcançaram 6,32 $\mathrm{Pg} \mathrm{C}$ ano $^{-1}\left(\mathrm{Pg}=\right.$ Petagrama $=10^{15} \mathrm{~g}=$ bilhões de toneladas $)$ em 1998. Isto significou uma redução de $0,5 \%$ nas emissões, em relação ao ano anterior. Este foi o primeiro ano, desde 1993, que houve decréscimo nas emissões globais de carbono para a atmosfera, e mesmo assim, ainda foi cerca de 6,3\% maior que em 1990 (Flavin, 1999). 
Além da emissão de carbono para a atmosfera oriunda das atividades industriais, existe aquela cuja origem está vinculada à destruição de florestas, principalmente as tropicais. O carbono armazenado na biomassa da floresta pode ser liberado para a atmosfera na forma de $\mathrm{CO}_{2}$, pelos desmatamentos e queimadas (Wong, 1978; Seiler \& Crutzen, 1980; Andreae et al., 1988). Uma combustão eficiente libera até $35 \%$ do carbono contido na fitomassa florestal (Graça, 1997). A conversão de florestas tropicais em áreas de cultivo ou pastagens estaria funcionando como fonte de $\mathrm{CO}_{2}$ para a atmosfera (Scholes, 1999).

As florestas nativas ou plantadas têm enorme potencial de seqüestrar carbono da atmosfera, porém a estimativa dessa retirada ainda está sendo discutida (Valentini et al., 1996). As florestas tropicais são responsáveis por metade da absorção de $\mathrm{CO}_{2}$ realizada pela vegetação (Nobre \& Gash, 1997). Há necessidade de se aperfeiçoar o entendimento das funções que as florestas tropicais têm no ciclo de carbono. Neste sentido, nos últimos anos alguns trabalhos e estudos foram realizados (Wofsy et al., 1988; Fan et al., 1990; Delmas et al., 1992; Grace et al., 1995a,b, 1996a; Malhi et al., 1998; Culf et al., 1999). As pesquisas mais recentes utilizam a técnica da correlação dos vórtices turbulentos (eddy correlation), que tem se mostrado extremamente confiável na determinação das interações solo-planta-atmosfera. É uma técnica não destrutiva, e opera em escala de tempo de alguns segundos até vários anos, sendo possível relacionar as trocas de carbono na atmosfera aos fatores biofísicos do ambiente (Baldocchi et al., 1988, 1996; Lenschow, 1995; Moncrieff et al., 1996).

A Amazônia, devido sua localização e dimensão, tem função importante no ciclo biogeoquímico do carbono. É a maior tributária de calor e umidade para a atmosfera global, e alterações na sua vegetação e propriedades do solo, podem resultar em aumento da temperatura à superfície, reduções na evapotranspiração e precipitação na região (Peagle, 1987; Nobre et al., 1991; Henderson-Sellers et al., 1993).

Medidas de fluxos e concentrações de $\mathrm{CO}_{2}$ realizadas na região, têm classificado a Amazônia como um importante sumidouro de carbono da atmosfera, utilizado pela vegetação no processo de fotossíntese (Grace et al., 1995b, 1996a,b; Malhi et al., 1998). O padrão de variação dos fluxos de $\mathrm{CO}_{2}$ é caracterizado por um predomínio 
da absorção de $\mathrm{CO}_{2}$ pela vegetação desde o meio da manhã, até quase o final da tarde, quando o processo de respiração suplanta a assimilação do sistema solo-planta atuando durante toda a noite até as primeiras horas após o amanhecer (Fan et al., 1990; Grace et al., 1995b, 1996a,b; Malhi et al., 1998).

Este trabalho tem como objetivo analisar as variações sazonais dos fluxos e concentrações médias de $\mathrm{CO}_{2}$, em uma área de floresta tropical na região central da Amazônia, caracterizadas por dois períodos distintos durante as estações seca e chuvosa. As variações interdiurnas de $\mathrm{CO}_{2}$ para cada período serão associadas às séries temporais de diversos elementos climáticos, tais como: radiação solar incidente e refletida, saldo de radiação, temperatura do ar e do solo, precipitação, déficit de pressão de vapor, etc. Serão analisadas e quantificadas as concentrações de $\mathrm{CO}_{2}$, em diferentes alturas dentro do dossel vegetativo. Os dados utilizados neste trabalho, fazem parte de um conjunto maior obtido durante o projeto JACAREX - Joint Amazonian Carbon Dioxide Experiment (Malhi et al. 1998). 


\section{REVISÃO DE LITERATURA}

\subsection{O passado e o presente do $\mathrm{CO}_{2}$ atmosférico}

Para a determinação da provável composição da atmosfera de épocas passadas, analisam-se minúsculas bolhas de ar, que foram aprisionadas por camadas sucessivas de gelo nas regiões polares do planeta. Por meio de sondagens profundas, realizadas nas camadas de gelo, é possível ter acesso aos núcleos de ar que contêm as informações do passado atmosférico.

Michel (1999) observou que as amostras de ar relacionadas aos períodos entre os séculos X e XV são de baixa resolução, dificultando a avaliação das oscilações do $\mathrm{CO}_{2}$ atmosférico. Barnola et al. (1995) analisaram a evolução do $\mathrm{CO}_{2}$ durante os últimos mil anos utilizando amostras obtidas na Groenlândia e na Antártica. Etheridge et al. (1996) fizeram suas avaliações a partir de informações coletadas na Antártica. Estes núcleos de gelo, que funcionaram como verdadeiros arquivos da atmosfera antiga, revelaram que existia um estado de quase equilíbrio nas concentrações de $\mathrm{CO}_{2}$, que variavam em torno de $280 \pm 10$ ppmv. Esta situação foi mantida desta maneira até aproximadamente o século XVII. Grove (1988) reportou que as concentrações de $\mathrm{CO}_{2}$ sofreram um suave decréscimo naquela época, período que coincidiu com a ocorrência da chamada 'pequena era do gelo' que afetou principalmente o Hemisfério Norte. Bradley \& Jones (1993) e Keigwin (1996) também relataram a influência deste período na Europa. As temperaturas sofreram uma redução acentuada, o que possivelmente causou redução na respiração do solo, afetando o nível de concentração de $\mathrm{CO}_{2}$ na atmosfera. Em meados do século XVIII, a quantidade de $\mathrm{CO}_{2}$ começou a aumentar com o término da 'pequena era do gelo'. Indermühle (1999) ressaltou que, até aquela época, 
a biosfera terrestre e aquática, assim como as interações com os sedimentos oceânicos, eram as principais responsáveis pela liberação ou seqüestro de $\mathrm{CO}_{2}$ da atmosfera. Após aquele período as concentrações de $\mathrm{CO}_{2}$ atmosférico se mantiveram praticamente inalteradas, até a segunda metade do século XIX, quando teve início o período conhecido como Revolução Industrial.

Neftel et al. (1985) evidenciaram o aumento nas concentrações de $\mathrm{CO}_{2}$ na atmosfera após o início da industrialização. Em 1850, as concentrações eram de aproximadamente 286 ppmv, sofrendo, a partir de então, uma elevação contínua, porém, ainda lenta até as primeiras décadas do século XX. Em 1930, as concentrações oscilavam em torno de 310 ppmv. Estes valores das concentrações de $\mathrm{CO}_{2}$ na atmosfera até a década de 30, ainda foram obtidos por meio da análise de núcleos de gelo polar (Figura 1).

Kelling \& Whorf (1999) apresentam medições realizadas na estação de Mauna Loa, no Estado norte americano do Hawaii, a partir do final da década de 1950. Os valores são obtidos por meio de análise de amostras de ar coletadas no local. As informações conseguidas no Hawaii formam a mais longa série existente de dados de $\mathrm{CO}_{2}$ atmosférico. Apesar de ser uma medida pontual, e em uma pequena ilha distante de qualquer continente, serve de referência mundial para os estudos sobre a evolução do conteúdo de $\mathrm{CO}_{2}$ atmosférico. Os primeiros registros, no ano de 1958, indicaram uma concentração de aproximadamente 315 ppmv (Figura 2). A taxa média de crescimento das concentrações de $\mathrm{CO}_{2}$ tem sido de aproximadamente 1,5 ppmv ano ${ }^{-1}$ valor obtido pela aplicação das médias móveis dos dados (Figura 3a). Há um ciclo sazonal bem caracterizado, sendo que freqüentemente em maio ocorre o valor mais elevado do ano, enquanto que setembro registra os valores mais baixos (Figura $3 \mathrm{~b}$ ). As medidas mais recentes, registraram uma concentração média anual, para 1998, de aproximadamente 367 ppmv (Figura 3c), um aumento de aproximadamente 14\% nos últimos 40 anos, refletindo a elevação das emissões globais de carbono com origem nas atividades antropogênicas. 


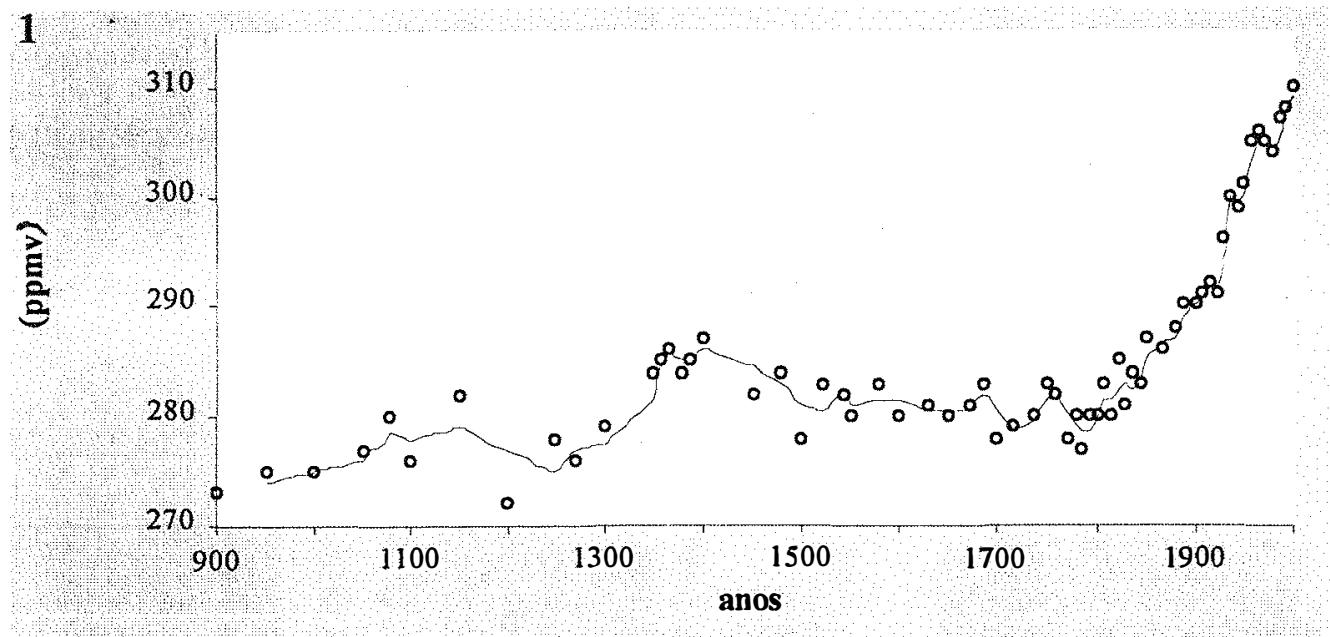

Figura 1 Concentração de $\mathrm{CO}_{2}$ nos últimos mil anos, obtida por meio de análises de núcleos de gelo na Antártica. A linha representa a média móvel das medidas. Fonte: IPCC 1996, Technical summary.

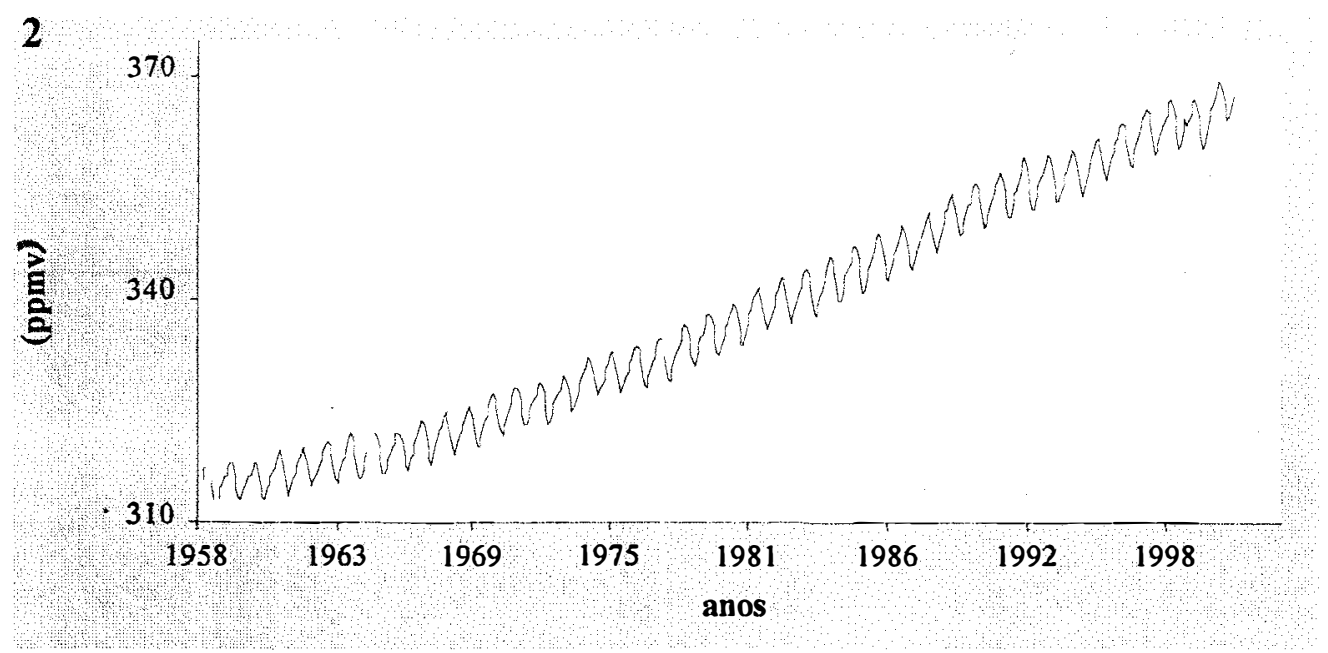

Figura 2 Medidas mensais de concentração de $\mathrm{CO}_{2}$ na estação de Mauna Loa, Hawaii, EUA, desde 1958. Fonte: Kelling \& Whorf, 1999. 

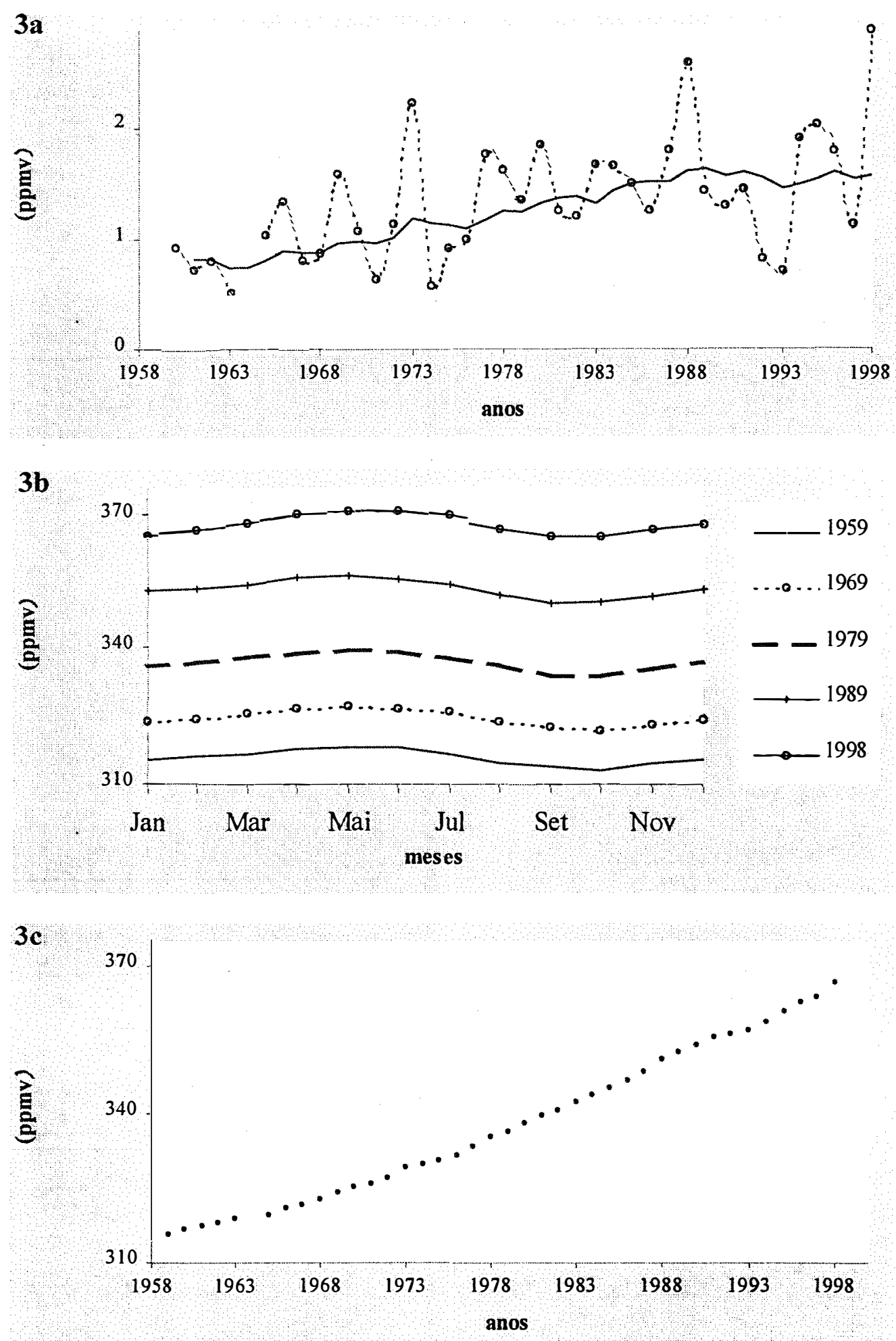

Figuras 3 Concentração de $\mathrm{CO}_{2}$, desde 1958, na estação de Mauna Loa, Hawaii, EUA: a) taxa de crescimento anual. b) médias mensais. c) crescimento médio anual. Fonte: Kelling \& Whorf, 1999. 


\subsection{Emissões globais e regionais de $\mathrm{CO}_{2}$}

Estimativas das emissões globais de carbono para a atmosfera foram apresentadas por Marland et al. (1999). A utilização de combustíveis fósseis e a produção de cimento teriam sido responsáveis pela liberação na atmosfera de aproximadamente $265 \mathrm{Pg} \mathrm{C}$ desde 1751. Metade destas emissões teria ocorrido durante as últimas três décadas. Globalmente, a utilização de material fóssil está dividida de seguinte maneira: cerca de $77,5 \%$ das emissões são representadas por combustíveis líquidos e sólidos, os combustíveis gasosos seriam aproximadamente 18,3\%, enquanto que a produção de cimento contribuiu com menos de $5 \%$ das emissões totais.

A Administração Nacional para Oceano e Atmosfera (NOAA) e o Laboratório de Diagnóstico e Monitoramento Climático (CDML) ambos dos Estados Unidos da América, medem o $\mathrm{CO}_{2}$ atmosférico em amostras de ar coletadas semanalmente em duas estações desde a década de 1960 e em uma rede global de estações desde o início dos anos de 1970 (Conway \& Tans, 1996). As análises mostraram que a longo prazo está ocorrendo aumento nas concentrações de $\mathrm{CO}_{2}$ atmosférico.

Análise de dados recentes realizadas no Worldwatch Institute (Washington, D.C., EUA. http://www.worldwatch.org), sobre o consumo mundial de energia, detectaram uma redução de 0,5\% em 1998, em relação a 1997, nas emissões globais de carbono para a atmosfera, oriundas da utilização de combustíveis fósseis (Flavin, 1999). A quantidade de carbono liberada no ar durante 1998 foi de aproximadamente 6,3 Pg C, sendo este o primeiro ano, desde 1993, em que se registrou redução nas emissões de carbono, quaando comparadas ao ano imediatamente anterior (Figura 4). Se comparadas às emissões do início da década (1990), houve um acréscimo de cerca de 6,3\% nas liberações. A redução nas emissões anuais de carbono para a atmosfera foi em parte, devido a uma utilização mais eficiente da energia e da diminuição do uso do carvão. Isto está relacionado com o crescimento de setores da economia mundial, que não são grandes consumidores de energia tais como, as áreas de serviço e de tecnologia. 
Em escala regional, individualmente os Estados Unidos da América são o país que mais emite $\mathrm{CO}_{2}$ para a atmosfera, com aproximadamente $1,46 \mathrm{Pg} \mathrm{C}_{\text {ano }}{ }^{-1} \mathrm{em}$ 1998 , cerca de $0,4 \%$ a mais que em 1997 , e aproximadamente $23 \%$ do total das emissões globais. Depois vem a China com $803 \mathrm{Tg} \mathrm{C} \mathrm{ano}^{-1}\left(\mathrm{Tg}=\right.$ Teragrama $=10^{12} \mathrm{~g}=$ milhões de toneladas), com redução de 3,7\% em relação a 1997 , e cerca de $12,7 \%$ das emissões totais. A Comunidade Européia emitiu $548 \mathrm{Tg} \mathrm{C}$ ano $^{-1}$, menos 0,9\% em relação a $1997 \mathrm{e}$ $9 \%$ do global. Em seguida vem a Russia com $400 \mathrm{Tg} \mathrm{C}$ ano $^{-1}$, reduzindo $1,3 \% \mathrm{em}$ relação ao ano anterior e cerca de 6\% do total das emissões globais. O Japão com 297 $\mathrm{Tg} \mathrm{C}$ ano $^{-1}$ e a Índia com $276 \mathrm{Tg} \mathrm{C}$ ano $^{-1}$ completam a lista dos maiores emissores de carbono para a atmosfera (Tabela 1).

A América Latina como um todo emitiu, em 1996, cerca de $337 \mathrm{Tg} \mathrm{C}^{\mathrm{ano}}{ }^{-1}$ para a atmosfera. Somente dois países da região estão entre os vinte maiores emissores de carbono, México e Brasil, que juntos representam aproximadamente $50 \%$ do total das emissões regionais. O México emitiu cerca de $95 \mathrm{Tg} \mathrm{C}$ ano $^{-1}$, em 1996, sendo o décimo quarto do mundo, com uma taxa per capita em torno de $1,02 \mathrm{Mg} \mathrm{C}^{-1} \mathrm{hab}^{-1} \mathrm{ang}^{-1}(\mathrm{Mg}=$ Megagrama $=10^{6} \mathrm{~g}=$ toneladas), representando cerca de $28 \%$ das emissões regionais. $\mathrm{O}$ Brasil, segundo maior emissor do bloco latino-americano, liberou aproximadamente 75 Tg C ano ${ }^{-1}$, em 1996, com cerca de de $22 \%$ do total regional, com um aumento de $+9 \%$ em relação ao ano anterior, e uma taxa per capita de $0,46 \mathrm{Mg} \mathrm{C} \mathrm{hab}^{-1} \mathrm{ano}^{-1}$. O país ocupou a décima sétima posição no ranking dos maiores emissores mundiais (Marland et al., 1999). 77\% das emissões totais do Brasil, foram por uso de combustíveis líquidos e gasosos, enquanto que aproximadamente $23 \%$ foram oriundos de combustíveis sólidos e produção de cimento (Figura 5). 


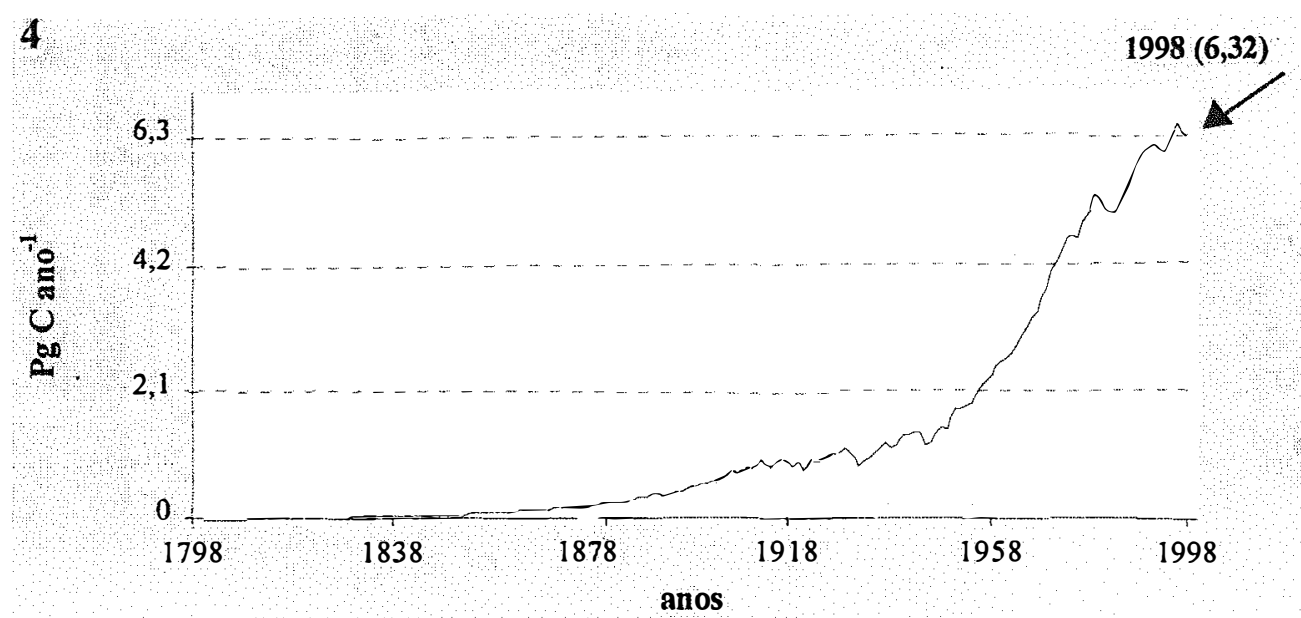

Figura 4 Emissões de carbono de origem fóssil para a atmosfera nos últimos duzentos anos. A elevação dos valores a partir do final do século XIX é bem definida. A emissão nas últimas quatro décadas sofreu grande intensificação, em 1998 atingiu cerca de 6,3 bilhões de toneladas de carbono. Fonte: Worldwatch Institute. http://www.worldwatch.org

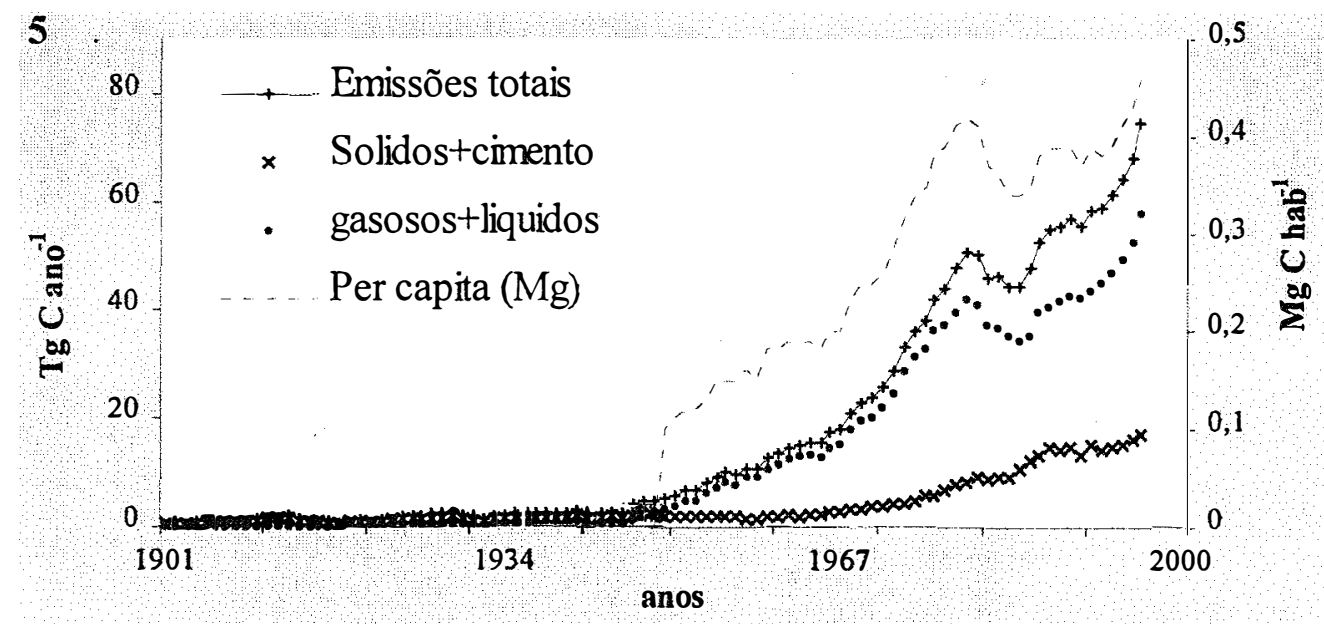

Figura 5 Taxas de emissão de carbono para a atmosfera no Brasil, desde o início do século XX. A emissão per capita (----) foi de aproximadamente meia tonelada em 1996. As emissões totais do país atingiram cerca de 75 milhões de toneladas de carbono em 1996. Fonte: Marland, G. 1999. http://cdiac.esd.ornl.gov 
TABELA 1 Principais países ou blocos econômicos na emissão global de carbono de origem fóssil, em 1998.

\begin{tabular}{|c|c|c|}
\hline \multirow[t]{2}{*}{ País / Bloco } & \multicolumn{2}{|c|}{ Produção } \\
\hline & $\left(\mathrm{Pg} C \mathrm{ano}^{-1}\right)$ & (\%) \\
\hline Estados Unidos da América & 1,46 & 23,1 \\
\hline China & 0,8 & 12,7 \\
\hline União Européia & 0,55 & 8,7 \\
\hline Russia & 0,4 & 6,3 \\
\hline América Latina* & 0,34 & 5,3 \\
\hline Japão & 0,3 & 4,7 \\
\hline Índia & 0,28 & 4,4 \\
\hline Outros & 2,19 & 34,8 \\
\hline Total & 6,32 & 100 \\
\hline Brasil* & 0,08 & 1,2 \\
\hline
\end{tabular}

${ }^{*}$ Dados referentes ao ano de 1996. Fonte: Worldwatch Institute. http://www.worldwatch.org

\subsection{Mudanças no uso da terra}

As conseqüências provenientes das mudanças no uso da terra sobre o balanço global de carbono têm sido objeto de freqüentes debates. Alguns estudos têm demonstrado a diminuição dos sorvedouros biosféricos de carbono devido ao aumento da destruição de áreas de florestas em escala global, nas últimas três décadas (Auclair \& Bedford, 1993).

Nos trópicos, a conversão de áreas com florestas, em campos de cultivo ou pastagens, estaria funcionando como uma fonte de $\mathrm{CO}_{2}$ para a atmosfera (Scholes, 1999). As emissões de $\mathrm{CO}_{2}$ provocadas pelos desmatamentos das florestas tropicais têm aumentado nas últimas décadas (Leemans, 1999). A crescente necessidade de áreas maiores disponíveis às atividades agrícolas e pecuárias, forçada pelo aumento da demanda no consumo mundial de alimentos, tem incentivado a destruição das florestas.

Houghton et al. (1987) e Houghton (1993) afirmaram que os desmatamentos e as queimadas nas regiões tropicais do planeta, contribuem com a maior parte do carbono liberado para a atmosfera, pois, a destruição da biomassa vegetal e outras trocas no uso da terra, poderiam emitir entre 0,6 e $2 \mathrm{Pg} \mathrm{C}$ ano $^{-1}$. 
Os aerossóis e as mudanças nas atividades fotossintéticas da vegetação, produzidos pela queima da biomassa, também podem afetar o balanço de radiação (Tans et al., 1990; Penner et al., 1992).

Graça (1997) estimou que cerca de $25 \%$ das emissões globais de $\mathrm{CO}_{2}$ para a atmosfera foram resultantes das mudanças no uso da terra, causadas principalmente pelo desmatamento.

As pastagens, criadas em áreas originalmente cobertas por florestas, reduzem o potencial da região em absorver carbono do ar. Entretanto, estas têm uma perda efetiva de carbono menor do que as culturas anuais, pois as pastagens perenes fixam o carbono no solo durante um período mais prolongado (Houghton, 1990). As pastagens têm grande potencial de produção de raízes, o que possibilitaria um maior acúmulo de carbono (Cerri et al., 1991). Mortatti et al. (1994) ressaltaram que o $\mathrm{CO}_{2}$ emitido pela prática da agricultura, dentre outras atividades antrópicas, tem contribuido sobremaneira para com as mudanças climáticas globais.

Em uma cultura de cana-de-açúcar, Rocha (1998) observou que durante nove meses do ano, a vegetação absorveu mais do que liberou carbono para atmosfera. Entretanto, nos outros três meses do ano, após a colheita, houve um predomínio da respiração do solo, provocando maior liberação de carbono no ar.

Na Amazônia, as mudanças no uso da terra ganharam evidência a partir de meados do século XX, quando a exploração econômica regional foi possível, após a implantação de rodovias. Com as estradas, os projetos agropecuários e o extrativismo vegetal e mineral se tornaram as atividades antropogênicas responsáveis pela retirada e/ou substituição da floresta primária (Ferreira da Costa et al., 1998).

Para tentar entender melhor como que as mudanças no uso da terra e no clima da Amazônia influenciam nas características biogeoquímicas da região, foram realizados diversos experimentos científicos. Para estudar o balanço de energia e a evapotranspiração houve o ARME (Amazonian Research Micrometeorological Experiment), entre os anos de 1983-86, com detalhes em Suttleworth et al., (1984) e Shuttleworth (1988). Para compreender os ciclos dos gases e aerossóis liberados na atmosfera da Amazônia, realizou-se o ABLE (Amazon Boundary Layer Experiment), 
em duas etapas: 2a em 1985 e 2b em 1987 (Harriss et al., 1988, 1990). O balanço de umidade na região, foi objeto de pesquisa durante o FLUAMAZON (Fluxo de Umidade na região Amazônica) no final de 1989 (Rocha, 1991). Durante os anos de 1990 a 1994 foi realizado o maior projeto de pesquisa na Amazônia, até então, o ABRACOS (AngloBrazilian Amazonian Climate Observation Study), com objetivo de analisar as modificações microclimáticas nas áreas de florestas e pastagens na região (Nobre et al., 1996). Para determinar qual a influência dos desmatamentos na Amazônia no clima e na estrutura da camada limite planetária, foi realizado, entre os anos de 1992-94 o RBLE (Rondonia Boundary Layer Experiment), detalhado em Fisch (1996). No final de 1995, com o objetivo de analisar o conteúdo de $\mathrm{CO}_{2}$ dentro da camada limite noturna, na Amazônia central, foi realizado o MACOE (Manaus Atmospheric $\mathrm{CO}_{2}$ Experiment), obtendo-se medidas de $\mathrm{CO}_{2}$ em diversas alturas, com o uso de balão cativo (Culf et al.1999). Análise de $\mathrm{CO}_{2}$ acima e dentro da floresta, foram realizadas nos anos de 199596 durante o JACAREX (Joint Amazonian Carbon Dioxide Experiment), em uma área de floresta, na região central da Amazônia. Parte dos resultados estão em Malhi et al. (1998) e serão objeto deste trabalho. Atualmente, está sendo realizado o LBA (Large

Scale Biosphere-Atmosphere Experiment in Amazonia), um ambicioso projeto científico, que visa compreender o funcionamento climatológico, ecológico, biogeoquímico e hidrológico da Amazônia, do impacto das mudanças do uso da terra e as interações da Amazônia com o sistema biofísico global do planeta (LBA, 1996).

\subsection{As interações do carbono atmosférico}

Sem o ciclo biogeoquímico do $\mathrm{CO}_{2}$ e da água entre a superfície terrestre os oceanos e a atmosfera, a vida, como nós conhecemos seria insustentável. $\mathrm{O} \mathrm{CO}_{2}$ e a água têm um importante papel nas atividades biológicas e climáticas do planeta, pois são grandes absorvedores de radiação infravermelha, influenciando no aquecimento atmosférico global. O nível da concentração de $\mathrm{CO}_{2}$ atmosférico tem aumentado, com maior ênfase neste século, e a origem desta elevação está no desequilíbrio entre as fontes emissoras (uso de combustíveis fósseis, queima de biomassa, respiração microbiana e 
vegetal) e os sumidouros biosféricos (oceanos, mares e a vegetação terrestre). A fixação de $\mathrm{CO}_{2}$ por fotossíntese converte a energia solar em energia química (Figura 6) que é utilizada para a manutenção e crescimento da vegetação terrestre e aquática, e sustenta a cadeia trófica (Baldocchi et al., 1996). A variação da abertura estomática na superfície foliar controla a liberação da umidade contida na vegetação, assim como a entrada do $\mathrm{CO}_{2}$ presente na atmosfera

6

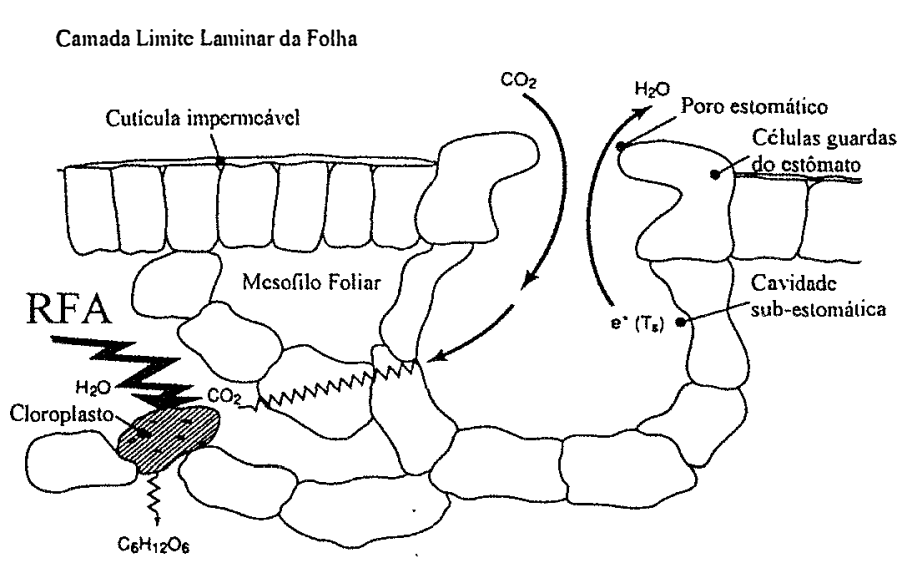

Figura 6 Fixação de $\mathrm{CO}_{2}$ pelas folhas.

Manabe \& Stouffer (1994) destacaram que nos diversos efeitos do aumento das concentrações de $\mathrm{CO}_{2}$ na atmosfera, além do aquecimento global, estão as perturbações no padrão de umidade do solo e na precipitação regional. Por outro lado, alguns autores como Eamus \& Jarvis (1989) e Mussleman \& Fox (1991) comentaram que potenciais benefícios de um aumento nas concentrações de $\mathrm{CO}_{2}$ atmosférico, seriam uma fotossíntese mais estimulada, um aumento na produção agrícola e uma eficiência maior no uso da água. Em contrapartida McMurtrie et al. (1992) e Melillo et al. (1993) enfatizaram que o aumento na produção de biomassa, talvez não fosse experimentado por todo o ecossistema natural. E que a limitação do nitrogênio do solo e o aumento na respiração, talvez restringisse o ganho de biomassa estimulado pelo $\mathrm{CO}_{2}$ adicional. 
Outros estudos de fisiologia vegetal como, Epron \& Dreyer (1993) e Kubiske \& Abrams (1994) mostraram que a redução nas taxas de assimilação de $\mathrm{CO}_{2} \mathrm{e}$ da condutância estomática estão associadas ao baixo potencial de água nas folhas ou o reduzido conteúdo de água no solo. Tardieu \&Davies (1992) relataram que evidências experimentais indicaram, que o déficit de umidade no solo inicia uma ação hormonal induzindo o fechamento estomático, limitando a absorção de carbono.

Pielke et al. (1998) destacaram que a resposta da condutância das folhas às condições atmosféricas representa uma troca rápida entre a biosfera e a atmosfera. A variação na abertura estomática é uma rápida resposta à redução da radiação de ondas curtas produzida pela passagem de uma nuvem em dia claro. Uma troca um pouco mais lenta entre a biosfera e a atmosfera, seria a diminuição da quantidade de umidade do solo e a secagem da superfície provocadas pela evapotranspiração. Quando a vegetação inicia o processo de estresse hídrico, por alguns instantes os estômatos se fecharão, objetivando manter a água restante. Desta maneira a maior parte da radiação líquida é transformada em fluxo de calor sensível. O índice de área foliar (IAF), que é a razão entre o metro quadrado de área total de folha pelo metro quadrado de solo, sofre variações entre as estações do ano (modificações sazonais), que alterarão a partição de energia nos fluxos de calor sensível e latente. Segundo Williams et al. (1998) as variações no IAF têm certo impacto, porém, isoladamente, não explicam as mudanças na fotossintese Alterações no IAF afetarão o albedo, que é a razão entre a radiação solar refletida e a radiação solar incidente em uma superfície. Culf et al. $(1995,1996)$ apresentaram valores de albedo para a Amazônia que determinaram uma variação sazonal. Em média, oscilaram em torno de $12 \%$ na época chuvosa e $14 \%$ na época seca. A precipitação foi destacada por Pielke, (op cit., p.463) podendo representar uma troca de curta duração entre a biosfera e a atmosfera, que rapidamente poderá repor a umidade do solo, assim como criar uma camada de água na superfície da vegetação, por intermédio da interceptação. Ubarana (1996), realizando experimentos de perda por interceptação da precipitação em áreas de floresta na Amazônia, determinou que, em média, cerca de $12 \%$ da precipitação ocorrida, são interceptados pelo dossel vegetativo. 
Schimel et al. (1996) observaram que o estoque de carbono orgânico nos ecossistemas terrestres é mais que o dobro do carbono contido na atmosfera, na forma de $\mathrm{CO}_{2}$, cerca de 1600 e $765 \mathrm{Pg} \mathrm{C}$, respectivamente. Mesmo com os continentes e ilhas representando menos de um terço da superfície do planeta, e não sendo totalmente vegetados, as trocas de carbono entre os ecossistemas terrestre e a atmosfera representariam cerca de $120 \mathrm{Pg} \mathrm{C}$ ano ${ }^{-1}$, com a matéria orgânica sendo criada pela fotossíntese, aproximadamente balanceada pela liberação de $\mathrm{CO}_{2}$ na respiração e decomposição.

Andres et al. (1996) atentaram para o fato de que, uma pequena variação de apenas $5 \%$ nas trocas naturais de carbono entre os ecossistemas terrestres e a atmosfera, seria da mesma magnitude do total das emissões globais de carbono de origem industrial para a atmosfera, cerca de 6,3 Pg C ano-1 em 1998. Apesar de tudo, Schimel et al. op. cit., evidenciaram que a função da biosfera terrestre no balanço global de carbono, parece ser de agir como um sorvedouro de 1 a $2 \mathrm{Pg} \mathrm{C}$ ano $^{-1}$ da atmosfera. Vários autores atribuiram que esta função poderia ser operada por uma combinação de fatores. Para Schindler \& Bayley (1993), seria por deposição de nitrogênio. Dai \& Fung (1993) vincularam às flutuações climáticas. Dixon et al. (1994) responsabilizaram os resflorestamentos, principalmente no Hemisfério Norte. Gifford (1994) e Friedlingstein et al. (1995) atribuiram à contribuição da autofertilização por $\mathrm{CO}_{2}$.

\subsection{Técnicas de medidas de $\mathrm{CO}_{2}$}

A quantificação dos fluxos e concentrações de $\mathrm{CO}_{2}$ em ecossistemas vem sendo determinada pela utilização de variadas técnicas e equipamentos.

Lieth \& Whittaker (1975), citados por Valentini et al. (1996) realizaram medidas de carbono por meio de amostragens destrutivas, o que não era muito vantajoso. Fung et al. (1987) utilizaram o sensoriamento remoto para estimar o conteúdo de carbono. Delmas et al. (1992) tiveram seus resultados obtidos pela análise das concentrações de $\mathrm{CO}_{2}$ por cromatografia gasosa. Wofsy et al. (1988), também utilizaram esta técnica, porém, além de medirem os perfis de concentração de $\mathrm{CO}_{2}$ dentro e acima 
da floresta, as determinaram dentro da camada limite atmosférica. Estas últimas foram realizadas a partir de uma aeronave.

Nos últimos anos, com o desenvolvimento de novas tecnologias, tornou-se possível realizar medidas de fluxo e concentração de gases, de uma forma mais prolongada e confiável. Com o aperfeiçoamento do anemômetro sônico e dos analisadores infravervelhos de gases, a aplicação da técnica da correlação dos vórtices turbulentọs (eddy correlation) permitiu a medição das trocas totais de carbono, em nível de ecossistemas, com a vantagem de não ser destrutiva, e trabalhar em uma escala de tempo de poucas horas até vários anos. Permite também, ainda relacionar estas trocas aos fatores ambientais (Valentini et al., 1996). Longos períodos de medidas de fluxos podem ser conseguidos, com um planejamento adequado e uma boa manutenção dos equipamentos (Leuning \& Judd, 1996).

Em uma escala local, a covariância dos turbilhões, como também é conhecida esta técnica, é um método testado e aprovado para as medidas de densidade e fluxos de gases traços entre a biosfera e a atmosfera (Baldocci et al., 1988; Grelle \& Lindroth, 1996; Lenschow, 1995; Moncrieff et al., 1996). É um método direto e confiável de medidas de fluxos de gases, porém, tem suas limitações, como os erros sistemáticos, seletivos e aleatórios, descritos por Goulden et al. (1996), Baldocci et al. (1996) e Moncrieff op.cit.

Ruimy et al. (1996) destacaram que as medidas por correlação dos fluxos turbulentos poderão ser usadas no estudo da fisiologia dos ecossistemas, como resposta do fluxo de $\mathrm{CO}_{2}$ às variáveis ambientais, permitindo ainda ser aplicadas como testes para modelos teóricos de ecossistemas. Os fluxos de $\mathrm{CO}_{2}$ obtidos por este método micrometeorológico têm características espacial e temporal, que os tornam potencialmente úteis na modelagem do balanço global de carbono.

\subsection{Alguns estudos de $\mathrm{CO}_{2}$ em florestas}

Os estudos de $\mathrm{CO}_{2}$ em florestas, têm sido realizados freqüentemente no Hemisfério Norte, nas florestas temperadas. Estas regiões, de modo geral, passam uma 
parte do ano sob condições climáticas que se caracterizam pela presença de neve. Deste modo, há um evidente ciclo sazonal nas funções fisiológicas da vegetação.

Goulden et al. (1996) caracterizaram claramente a sazonalidade ocorrida nas trocas líquidas de $\mathrm{CO}_{2}$ entre a atmosfera e uma floresta temperada no nordeste dos Estado Unidos da América (Harvard Forest, Massachusetts), entre os anos de 1991 e 1994. Nos meses de verão da região, principalmente julho, o ecossistema florestal absorveu $\mathrm{CO}_{2}$ da atmosfera com grande intensidade. Enquanto que, nos meses mais frios, dezembro e janeiro principalmente, praticamente não ocorreu absorção de $\mathrm{CO}_{2}$ pela floresta. $\mathrm{Na}$ média do período, a floresta atuou como um sorvedouro de $\mathrm{CO}_{2}$ da atmosfera, em uma taxa de $-2,1 \mathrm{Mg} \mathrm{C}$ ha $^{-1} \mathrm{ano}^{-1}$.

Valentini et al. (1996) realizaram estudos de $\mathrm{CO}_{2}$ em uma floresta localizada na região de Collelongo na Itália central, entre os meses de maio a novembro de 1993. Durante o período analisado, a floresta absorveu $\mathrm{CO}_{2}$ na média de $-4,7 \mathrm{MgC} \mathrm{ha}^{-1} \mathrm{ano}^{-1}$.

Greco \& Baldocci (1996) estudaram o fluxo líquido de carbono entre a atmosfera e uma floresta temperada, localizada em Oak Ridge, Tennessee, E.U.A. As medidas foram realizadas entre abril de 1993 e abril de 1994. A sazonalidade nos fluxos ficou evidenciada . Na primavera, a floresta absorveu carbono da atmosfera, enquanto que no inverno, predominou a liberação de carbono para a atmosfera. A taxa média líquida do fluxo de $\mathrm{CO}_{2}$ foi de $-5,25 \mathrm{Mg} \mathrm{C}^{-1} \mathrm{ano}^{-1}$, representando um considerável sorvedouro de carbono da atmosfera.

Poucos trabalhos têm sido feitos abordando as trocas de $\mathrm{CO}_{2}$ entre a atmosfera e as florestas tropicais. Delmas et al. (1992) fizeram medidas sobre uma região de floresta tropical na bacia do rio Congo, na África equatorial. As análises foram realizadas sobre as informações obtidas com a utilização de cromatografia gasosa.

\subsection{Estudos de $\mathrm{CO}_{2}$ na Amazônia}

A Amazônia que é a maior área de floresta contínua na região equatorial, só recentemente tem recebido a atenção dos pesquisadores, para tentar entender sua função 
nas interações de $\mathrm{CO}_{2}$ entre a floresta e a atmosfera, e dimensionar sua importância no balanço global de carbono.

Wofsy et al. (1988) realizaram medidas a partir de uma aeronave-laboratório que ajudaram na compreensão do ciclo diurno da concentração de $\mathrm{CO}_{2}$ e as interações com os diferentes tipos de superfície, tais como, floresta de terra firme, regiões alagadas e oceanos. Mostraram que, durante o período noturno, o perfil integrado da concentração de $\mathrm{CO}_{2}$ sobre a floresta foi superior ao de áreas alagadas, que por sua vez, tinha sido maior que o perfil medido sobre o oceano. Informações como estas, mostraram nitidamente a função da floresta de liberar $\mathrm{CO}_{2}$ para a atmosfera durante a noite, por intermédio da respiração combinada do sistema solo-planta.

Fan et al. (1990) realizaram um trabalho na Reserva Florestal Ducke, próxima à Manaus (AM), entre os dias 22 de abril a 8 de maio de 1987, durante o ABLE 2b. O ciclo diurno da variação dos fluxos de $\mathrm{CO}_{2}$ foi bem definido, mostrando a influência da radiação solar incidente. A absorção de carbono pela vegetação, durante o dia, foi em média balanceada pela respiração à noite. A respiração do solo foi responsável por cerca de $90 \%$ do total da liberação de carbono para a atmosfera. Durante o período estudado, a floresta foi um sumidouro de carbono da atmosfera. A taxa de assimilação foi de $-2,2 \mathrm{Mg} \mathrm{C} \mathrm{ha-1} \mathrm{ano-1,} \mathrm{quando} \mathrm{estendida} \mathrm{para} \mathrm{o} \mathrm{período} \mathrm{de} \mathrm{um} \mathrm{ano.} \mathrm{As}$ concentrações de $\mathrm{CO}_{2}$ medidas acima do dossel, em média, variaram entre o mínimo de aproximadamente 340 ppmv ao meio-dia e o máximo de cerca de 370 ppmv antes do nascer do sol.

Grace et al. (1995a,b; 1996a,b) realizaram medidas de $\mathrm{CO}_{2}$ em uma área de floresta em Rondônia, no sudoeste da Amazônia. Na Reserva Biológica do Jarú foram coletadas informações durante 44 dias, entre maio e junho de 1993. A concentração de $\mathrm{CO}_{2}$ medida acima do dossel variou de menos de 350 ppmv no meio do dia, até mais de 500 ppmv no final da noite e início da manhã. A média do período foi de $405 \pm 48$ ppmv. O fluxo de $\mathrm{CO}_{2}$ entre a floresta e a atmosfera apresentou um padrão diumo bem definido. A respiração atingiu picos de até $+20 \mu \mathrm{mol} \mathrm{m}^{-2} \mathrm{~s}^{-1}$, ficando em média, entre +6 $\mathrm{e}+7 \mu \mathrm{mol} \mathrm{m}^{-2} \mathrm{~s}^{-1}$. A absorção de $\mathrm{CO}_{2}$ foi acentuada nos horários de maior incidência de radiação solar, entre 12 e 14 horas, alcançando cerca de $-17 \mu \mathrm{mol} \mathrm{m}^{-2} \mathrm{~s}^{-1}$. Durante 33 
dos 44 dias analisados, o balanço líquido de carbono indicou uma absorção pela floresta do carbono atmosférico. Os onze dias restantes, quando o sistema solo-planta perdeu carbono para a atmosfera, coincidiram com a ocorrência das friagens, que são períodos influenciados pela passagem de sistemas climáticos que reduzem drasticamente a temperatura do ar na região. Mais detalhes destes fenômenos estão em Marengo et al. (1997). As medidas de $\mathrm{CO}_{2}$ mostraram um seqüestro líquido de carbono da atmosfera pela floresta. A aplicação de um modelo combinado de condutância estomática e bioquímico, utilizando dados climáticos de um ano, de 1 de julho de 1992 a 30 de junho de 1993, estimou para este período um seqüestro de aproximadamente $1 \mathrm{Mg} \mathrm{C} \mathrm{ha}^{-1}$ ano ${ }^{-1}$. $\mathrm{O}$ modelo foi sensível à temperatura, pois quando acrescentaram $+0,5^{\circ} \mathrm{C}$ ( o que teria sido reduzido da temperatura média devido à erupção do vulcão Pinatubo, nas Filipinas) o resultado foi que, a floresta acumularia menos carbono, cerca de $0,84 \mathrm{Mg} \mathrm{C} \mathrm{ha}^{-1} \mathrm{ano}^{-1}$. Quando acrescentaram $+4 \%$ nos valores de radiação solar (pelo mesmo motivo anterior) o modelo estimou uma assimilação de aproxiamdamente $1,2 \mathrm{Mg} \mathrm{C}^{-1} \mathrm{ano}^{-1}$ pela floresta. Sarmiento (1993) enfatizou que anomalias climáticas podem resultar em flutuações no balanço de carbono de um ano para outro.

Malhi et al. (1998) apresentaram os resultados das medidas de $\mathrm{CO}_{2}$ obtidos na Reserva Biológica do Rio Cuieiras no Amazonas, no período de setembro de 1995 a agosto de 1996. Os resultados sugerem que a floresta tropical de terra firme na Amazônia tem uma estabilidade nas funções fisiológicas, apesar de sua altíssima biodiversidade, pois, os padrões dos ciclos diurnos de $\mathrm{CO}_{2}$ obtidos na Reserva Jarú em Rondônia (distante cerca de $850 \mathrm{~km}$ de Cuieiras), e na Reserva Ducke no Amazonas (distante cerca de $50 \mathrm{~km}$ de Cuieiras) foram bastante similares nos valores de respiração noturna. A variação espacial na Amazônia parece ser da mesma magnitude da variação sazonal. O ciclo diário de $\mathrm{CO}_{2}$ registrou valores entre $-28 \mathrm{a}-24 \mu \mathrm{mol} \mathrm{m}^{-2} \mathrm{~s}^{-1}$ nos horários de maior fotossíntese, enquanto que a taxa de respiração ficou entre $+6 a+8 \mu$ mol m $\mathrm{m}^{-2} \mathrm{~s}^{-1}$. A sazonalidade observada nos fluxos de carbono entre a floresta e a atmosfera foi relacionada ao conteúdo de água no solo, que por sua vez, está vinculado à grande variação sazonal apresentada pelas chuvas na região. A sazonalidade pluviométrica tem um impacto na fisiologia do dossel, alterando o albedo, pois o dossel 
fica com o verde mais escuro na época das chuvas pela renovação de parte da folhagem. $\mathrm{Na}$ época seca, a redução da evapotranspiração, induziu a um maior fluxo de calor sensível e, consequentemente, temperaturas mais elevadas e maiores déficits de pressão de vapor. A limitação da umidade (estresse hídrico) pode ser o fator sazonal mais importante para a atividade microbiana, reduzindo a respiração na época seca, implicando que a variação sazonal na fotossíntese seja responsável pelas alterações no fluxo líquido de carbono durante o ano.

Culf et al. (1999) estudaram as variações nas concentrações de carbono na camada limite noturna, sobre uma área de floresta na região central da Amazônia. Com o auxílio de um balão cativo, obtiveram medidas de carbono até cerca de $300 \mathrm{~m}$ de altura, durante dez noites em novembro de 1995 . Em uma pequena clareira de $50 \mathrm{~m}$ X 50m foram realizadas medidas das concentrações de carbono, desde $5 \mathrm{~m}$ até cerca $300 \mathrm{~m}$, em intervalos aproximadamente regulares de $50 \mathrm{~m}$. Em uma comparação entre as medidas obtidas na borda da clareira ( $5 \mathrm{~m}$ de altura) e outras coletadas dentro da floresta $(5,3 \mathrm{~m}$ de altura) distantes cerca de $750 \mathrm{~m}$ entre si, houve uma excelente concordância, isto sugere que as concentrações de carbono, próximas ao solo, são notavelmente uniformes na floresta. As medidas realizadas no primeiro perfil (aproximadamente $50 \mathrm{~m}$ de altura) na clareira e as obtidas no topo de uma torre dentro da floresta (46,5m de altura), também apresentaram uma boa concordância. Durante a noite, as variações nas concentrações de gases próximos à superfície, podem ser fortemente influenciadas pela estrutura da camada atmosférica acima. Culf et al. (1997) consideraram importante a altura da camada de mistura na determinação da concentração de $\mathrm{CO}_{2}$ na atmosfera. As concentrações seriam freqüentemente dominadas pelo entranhamento do fluxo originário da variação de altura da camada de mistura. As concentrações noturnas de $\mathrm{CO}_{2}$ foram mais sensíveis às diferenças, tanto na altura da camada limite como nos valores dos fluxos de superfïcie. 


\section{MATERIAL E MÉTODOS}

\subsection{Localização}

Este trabalho foi realizado com dados coletados na Reserva Biológica do Rio Cuieiras, na bacia do rio Tarumã-açu, localizado na região central do Amazonas, $2^{\circ} 36^{\prime}$ $\mathrm{S}, 60^{\circ} 7^{\prime} \mathrm{W}, 52 \mathrm{~m}$, distante aproximadamente $57 \mathrm{~km}$ ao norte de Manaus (Figura 7).

A reserva que pertence ao Instituto Nacional de Pesquisas da Amazônia (INPA), faz parte de uma grande área de terra firme, que no início dos anos 80 começou a ser estudada como uma amostra representativa da floresta tropical. O acesso é feito pela rodovia BR174 que liga Manaus (AM) a Boa Vista (RR). Após cerca de $50 \mathrm{~km}$ na estrada principal o acesso à torre passa a ser feito por uma estrada vicinal (ZF-2), por aproximadamente $10 \mathrm{~km}$ sem pavimentação asfáltica, e por isso de difícil utilização durante o período mais chuvoso do ano. Na parte final do percurso, uma trilha na floresta com aproximadamente $1 \mathrm{~km}$ de extensão liga a estrada à torre. 


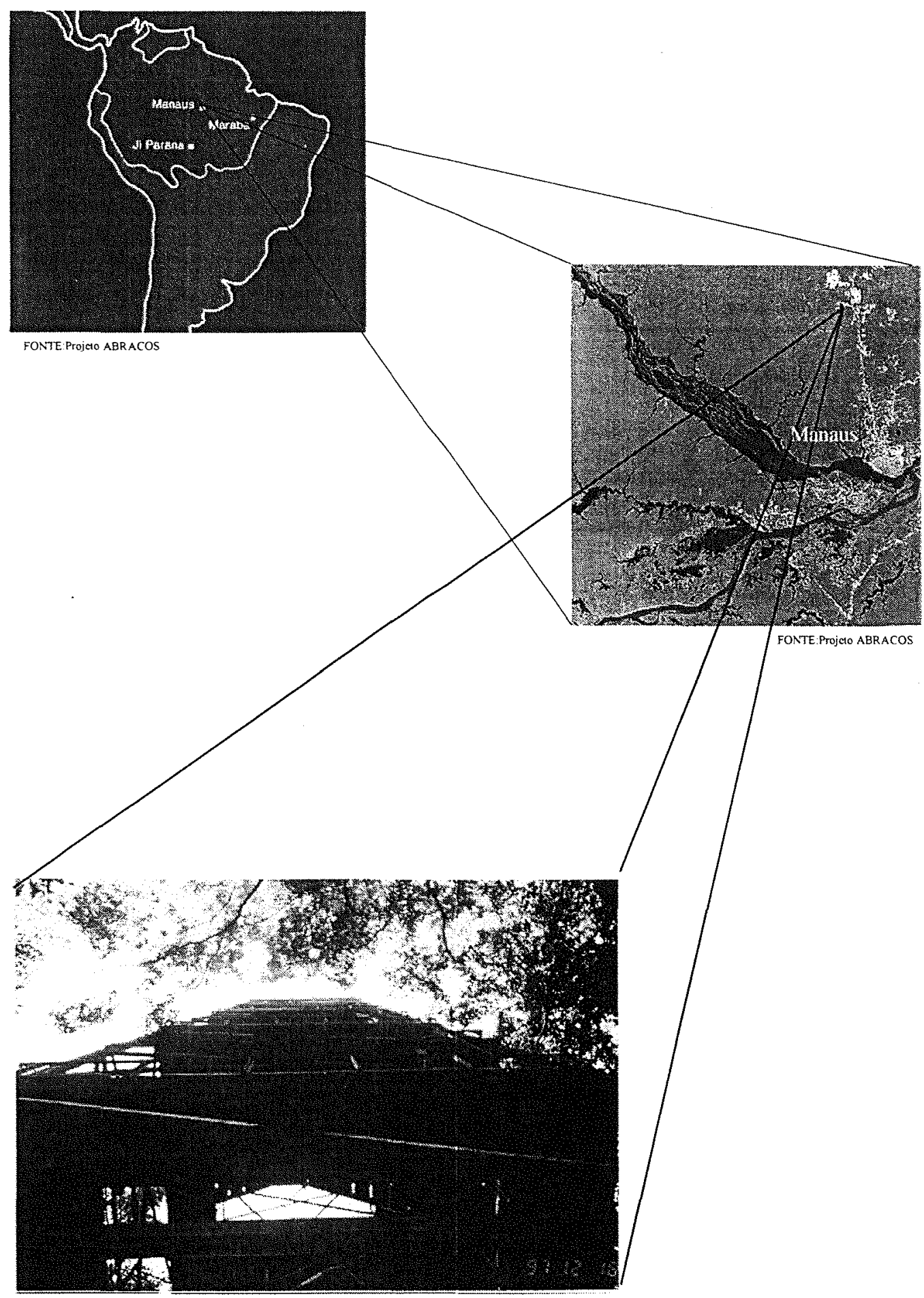

FOTOS Arquii o pessoal

Figura 7 Localização da Reserva Biológica do Rio Cuieiras, distante cerca de $57 \mathrm{~km}$ de Manaus, AM (área clara no centro à direita da imagem de satélite). No detalhe abaixo a torre micrometeorológica, com $41,5 \mathrm{~m}$ de altura. 


\subsection{Características do solo}

A Reserva de Cuieiras, é caracterizada como uma floresta de terra firme e possui um solo bastante comum na região amazônica. O latossolo amarelo-argiloso, contendo cerca de $80 \%$ de argila e $10 \%$ de areia, e uma profundidade variando de 3 a $8 \mathrm{~m}$. É um solo pobre em nutrientes, ácido com pH entre 4,3 e 5, uma porosidade alta oscilando entre 50 e $80 \%$. Possui elevada condutividade hidráulica com os macroporos e mesoporos drenando com eficiência no primeiro metro de profundidade, somente os microporos retem a água, que será pouco disponível às plantas (Chauvel et al., 1991). A capacidade de água disponível é baixa, cerca de $70 \mathrm{~mm} \mathrm{~m}^{-1}$ no primeiro metro, e de aproximadamente $30 \mathrm{~mm} \mathrm{~m}^{-1}$ abaixo de $2 \mathrm{~m}$ de profundidade com uma retirada máxima de água próxima de $250 \mathrm{~mm} \mathrm{ano}^{-1}$ abaixo da camada de $2 \mathrm{~m}$ (Correia, 1984; Hodnett et al., 1996). A baixa disponibilidade de água nos perfis superiores do solo, provocada por períodos de menor precipitação, forçará as plantas a retirarem água em grandes profundidades, entre 8 e 9m, para atender às suas necessidades hídricas (Nepstad et al., 1994; Hodnett et al., 1996; Tomasella \& Hodnett, 1996).

\subsection{Vegetação}

A região apresenta uma vegetação de grande porte, com uma altura média do dossel de $\sim 30 \mathrm{~m}$, e a presença de algumas árvores emergentes que alcançam entre 40 e $45 \mathrm{~m}$. Possui uma composição com grande variedade, com cerca de 180 espécies por hectare, com DAP superior a 0,15m (McWilliams et al., 1993). O índice de área foliar (IAF) variou entre 5,5 e 6,7. Em uma estratificação vertical o IAF foi maior na altura entre 15 e $20 \mathrm{~m}$, com os menores valores registrados abaixo de $10 \mathrm{~m}$ (Roberts et al., 1996). A densidade de biomassa acima do solo foi aproximadamente estimada em 350

$\mathrm{Mg} \mathrm{ha}{ }^{-1}$. Lucas et al. (1996) apresentaram uma ampla variação da estimativa de biomassa para a floresta da região, podendo oscilar de $225 \mathrm{Mg} \mathrm{ha}^{-1}$ até $563 \mathrm{Mg} \mathrm{ha}^{-1}$. 


\subsection{Torre micrometeorológica}

A estrutura utilizada para a instalação dos equipamentos de medida na floresta foi uma torre metálica com $41,5 \mathrm{~m}$ de altura e $6 \mathrm{~m}$ de comprimento lateral (Figura 8). É uma torre cuja a estrutura tem dimensões maiores que as utilizadas freqüentemente em estudos micrometeorológicos de fluxos. Para minimizar possíveis distorções nas medidas dos fluxos, causadas pela própria torre, o coletor de amostra de ar e o anemômetro sônico foram instalados na extremidade de um mastro com $5 \mathrm{~m}$ de comprimento (completando a altura total de $46,5 \mathrm{~m}$ ), posicionado na direção nordeste e afastado cerca de $3 \mathrm{~m}$ da estrutura principal (Figura 9).

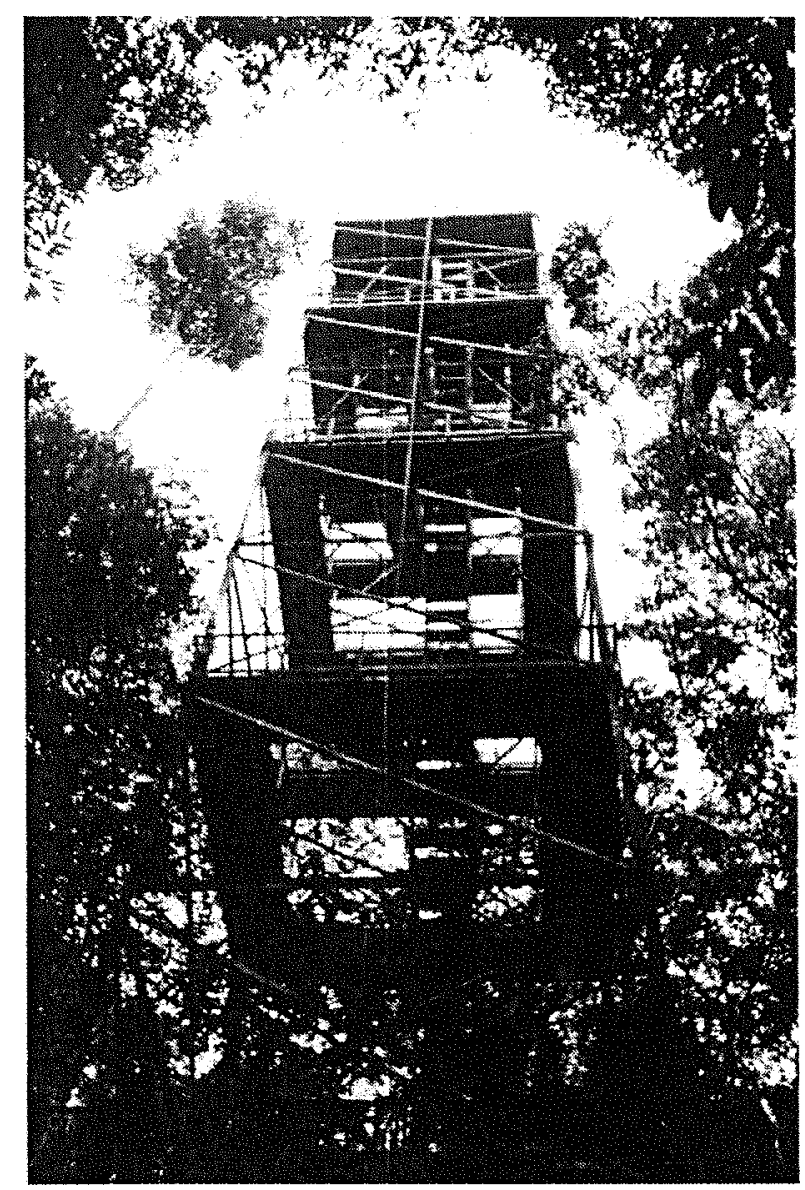

Figura 8 Torre micrometeorológica com $41,5 \mathrm{~m}$ de altura e $6 \mathrm{~m}$ de seção lateral instalada na Reserva Biológica do Rio Cuieiras (AM). 


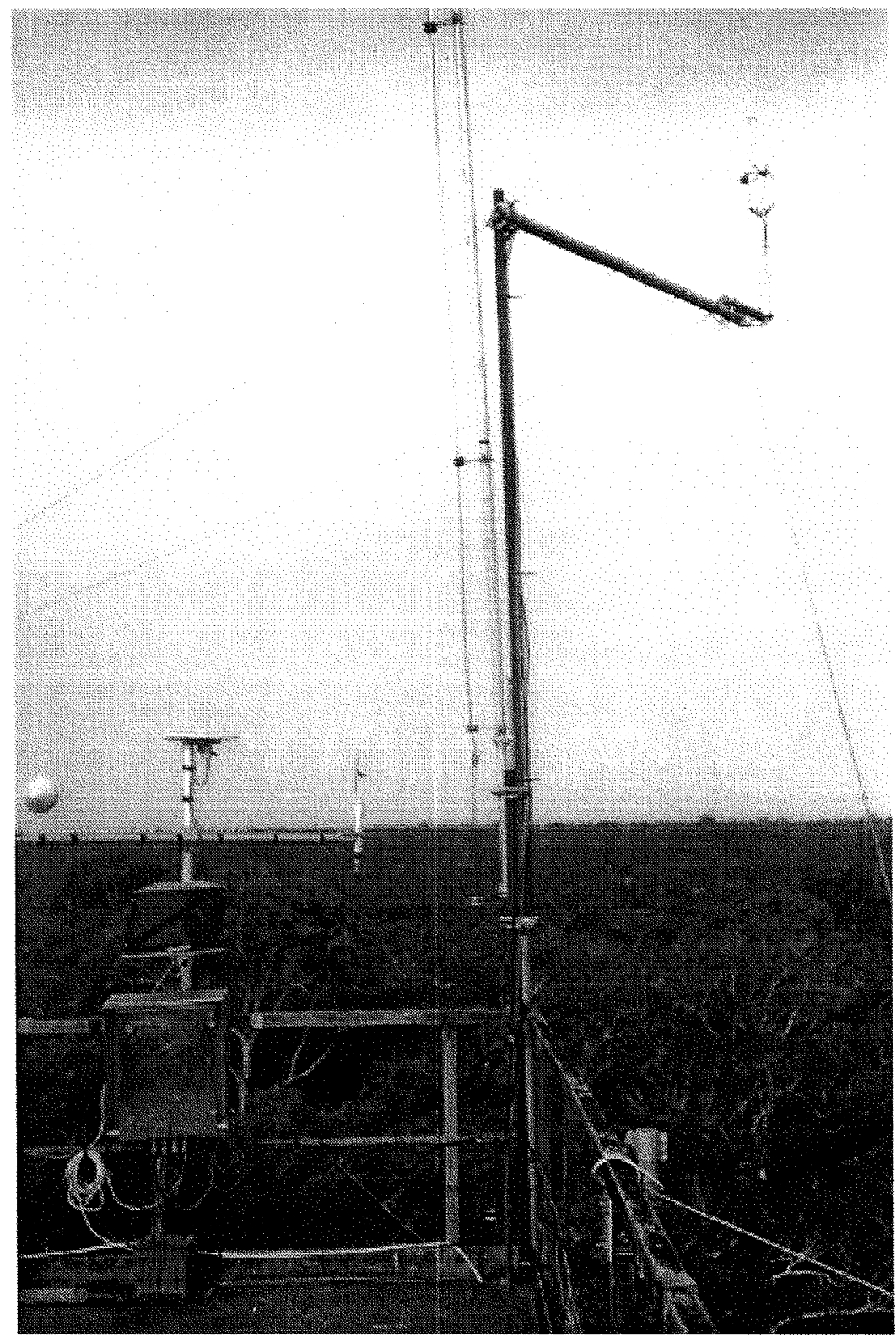

Figura 9 Estação meteorológica automática, abaixo à esquerda. Haste metálica com $5 \mathrm{~m}$ de comprimento (altura total $46,5 \mathrm{~m}$ ) para sustentação do anemômetro sônico reduzindo a influência da estrutura principal sobre as medidas de fluxos. 


\subsection{Covariância dos fluxos turbulentos}

A técnica da covariância dos fluxos turbulentos (eddy covariance) foi utilizada para medir as interações de $\mathrm{CO}_{2}$ entre a atmosfera e a floresta. Isto permite determinar o fluxo vertical de $\mathrm{CO}_{2}$, usando o cálculo da covariância entre as flutuações da velocidade vertical do vento (w') e das concentrações de $\mathrm{CO}_{2}\left(\mathrm{co}_{2}{ }^{\prime}\right)$ em todas as freqüências.

A velocidade vertical instantânea do vento, foi determinada pelo anemômetro sônico tridimensional Solent (Gill instruments, Lymington, Reino Unido) (Figura 10a). As concentrações de $\mathrm{CO}_{2}$ foram determinadas a partir de amostras de ar coletadas próximo ao anemômetro e conduzidas através de um tubo de teflon Dekabon com $10 \mathrm{~m}$ de comprimento e $6 \mathrm{~mm}$ de diâmetro, a um fluxo de $6 \mathrm{dm}^{3} \mathrm{~min}^{-1}$, para dentro de um analisador infravermelho de gás de resposta rápida LI6262 (LICOR, Lincoln, Nebraska, EUA), que trabalhou a uma freqüência efetiva de $5 \mathrm{~Hz}$. O sinal analógico de saída produzido pelo analisador foi enviado ao anemômetro sônico, onde foi digitalizado e combinado com os dados de vento. A saída digital combinada foi coletada em computador portátil à uma freqüência de $20,8 \mathrm{~Hz}$ (Figura 10b). Os fluxos foram calculados em tempo real com a utilização do programa EDISOL (University of Edinburgh, Reino Unido), maiores detalhes foram apresentados por Moncrieff et al. (1997). Um outro analisador infravermelho de gás (PP systems, Hitchin, Reino Unido) foi usado para medir as concentrações de $\mathrm{CO}_{2}$ em 6 alturas diferentes: 1; 9; 17,4;25,3; 33,3 e 46,5m, sendo que a amostragem mais alta foi o fluxo de saída do sistema de covariância dos turbilhões, para permitir a consistência entre os dois instrumentos. Para cada altura, foi realizado uma amostragem durante 5 minutos. Fan et al. (1990) usaram 4 minutos por amostragem. Este tempo foi suficiente para possibilitar a eliminação de resíduos de ar no interior do tubo. Um ciclo completo nos perfis foi realizado a cada meia hora, enquanto que em tempo real os dados foram armazenados em médias de dez minutos. A energia para a manutenção de todos os instrumentos foi fornecida por baterias de $12 \mathrm{~V}$, que eram permanentemente alimentadas por dez painéis solares 
SOLAREX (MSX60). Os analisadores de gás foram semanalmente calibrados com amostras de $\mathrm{CO}_{2}$ com concentração conhecida.
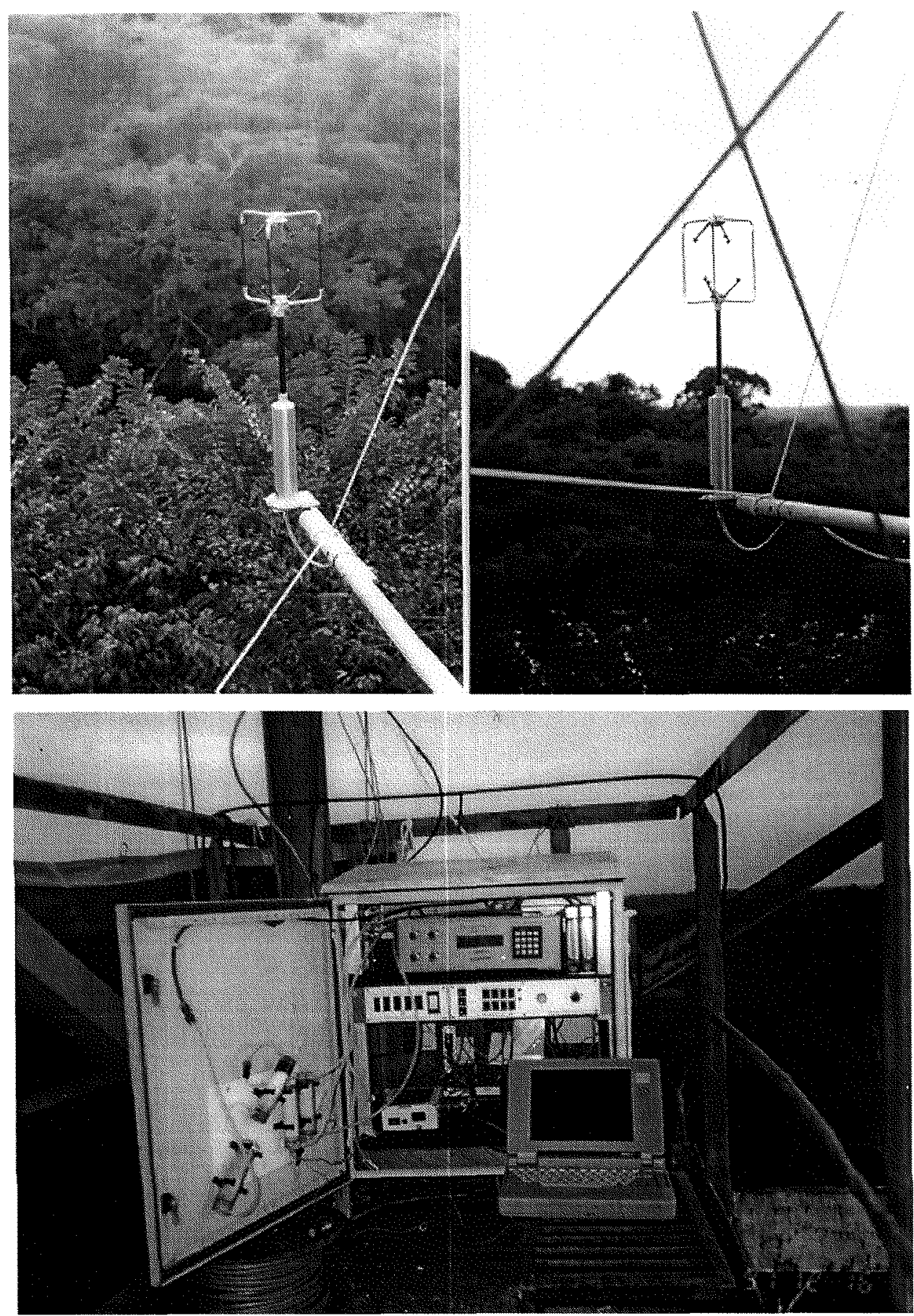

Figuras 10 a) Anemômetro sônico tridimensional Solent (Gill instruments, Reino Unido). b) Analisador infravermelho de gás LI-6262 (LICOR, EUA), com microcomputador contendo o programa EDISOL (UoE, Reino Unido). 
As variáveis meteorológicas foram determinadas pelos instrumentos de uma estação automática instalada no topo da torre (Figura 9). As temperaturas do bulbo seco e úmido foram determinadas por um psicrômetro aspirado com sensores de platina e resolução de $0,1{ }^{\circ} \mathrm{C}$ ( $\mathrm{IH}$, Wallingford, Reino Unido). Foram utilizados ainda, um pluviômetro de báscula com resolução de 0,2mm, e um anemômetro (Didcot Instruments Company, Abingdon, Reino Unido), termômetros de solo instalados a $5 \mathrm{~cm}$ de profundidade (Elmer, New Jersey, EUA), piranômetros registrando no espectro de 0,3 a 3,0 $\mu \mathrm{m}$ (Kipp \& Zonen, Delft, Holanda), saldo radiômetro Q*6 (REBS, Seattle, EUA). As informações foram armazenadas em um módulo solid state (Campbell Scientific, Shepshed, Reino Unido). Algumas variáveis utilizadas, foram obtidas pela aplicação de algumas equações que estão detalhadas a seguir (Pereira et al. 1997):

O déficit de pressão do vapor $(\Delta e)$ é a diferença entre a pressão de saturação de vapor $\left(e_{s}\right)$ e a pressão parcial ou atual do vapor $\left(e_{a}\right)$, todos expressos em $\mathrm{kPa}$ (Equação 1).

$$
\Delta e=e_{s}-e_{a}
$$

sendo que $e_{s}$ foi determinada pela aplicação da equação de Tetens (Equação 2) e $e_{a}$ pela equação psicrométrica (Equação 3).

$$
\begin{aligned}
& e_{s}=0,61.10^{\left(\frac{7.5 . t a}{237,3+1 a}\right)} \\
& e_{a}=e_{s u}-\gamma \cdot \Delta t
\end{aligned}
$$

em que $\Delta t$ é a depressão psicrométrica, $\gamma$ o coeficiente psicrométrico e $e_{s u}$ é a pressão de saturação do vapor à temperatura úmida. 
A umidade relativa do $\operatorname{ar}(U R)$ foi obtida pela equação (4):

$$
U R=\frac{e a}{e s} 100
$$

A razão de Bowen ( $\beta$ ) foi calculada pela Equação 5:

$$
\beta=\frac{H}{L E} \quad \text { (admensional) }
$$

sendo o $H$ o fluxo de calor sensível e o $L E$ o fluxo de calor latente ambos expressos em $\mathrm{W} \mathrm{m} \mathrm{m}^{-2}$ e obtidos pela covariância dos turbilhões.

O albedo $(\alpha)$ ou refletividade foi determinado pela razão entre radiação solar refletida $(S r)$ e a radiação solar incidente $(S)$, (Equação 6):

$$
\alpha=\frac{S r}{S} 100
$$

A energia armazenada na biomassa $(B)$ foi obtida com a equação proposta por Moore \& Fisch (1986), (Equação 7).

$$
B=B_{1}+B_{4}+B_{b}=16,7 \delta t+28 \delta q+12,6 \delta t *
$$

sendo $B_{t}$ e $B_{q}$ as energias armazenadas no ar pelas variaçõe horárias da temperatura $(\delta t)$ e umidade específica $(\delta q)$. A energia armazenada pelos troncos das árvores é representada por $B_{b}$ e estimada em função da variação horária da temperatura adiantada em uma hora $\left(\delta t^{*}\right)$.

Os valores de fluxos turbulentos foram calculados pela aplicação da técnica de correlações de vórtices, com medidas simultâneas de desvios de velocidade vertical (w') e de concentração $\left(\mathrm{CO}_{2}{ }^{\prime}\right)$. O fluxo vertical de um escalar, tal como o $\mathrm{CO}_{2}$, pode ser considerado como o balanço entre a quantidade do escalar transportado através de um 
plano horizontal por uma parcela de ar que se move para cima e para baixo. O valor médio de um fluxo $F$ pode ser representado por:

$$
F=\left(\frac{1}{T}\right)_{0}^{T} \int_{0}^{\prime}(t) C O_{2}{ }^{\prime}(t+\Delta t) d t
$$

sendo $T$ o intervalo médio, e $\Delta t$ o retardamento no tempo entre o sinal da medida da velocidade vertical $w$, e a concentração $\mathrm{CO}_{2}$. O primeiro termo em (8) denota o produto dos desvios w' e $\mathrm{CO}_{2}$ ' de suas respectivas médias, computadas no intervalo $T$. Os sensores de w e $\mathrm{CO}_{2}$ devem ser sensíveis o suficiente e responder às resoluções de pequenos desvios em freqüências importantes para o transporte turbulento. $\mathrm{O}$ intervalo médio $(T)$ deve ser suficientemente pequeno para resolver as variações atmosféricas no fluxo e grande o bastante para ter significância estatística.

O balanço de carbono $B c$ na floresta foi obtido pela aplicação da Equação 9.

$$
B c=\int_{r}^{f r} R+\int_{f}^{f f} F \quad\left(\mu \mathrm{mol} \mathrm{CO}_{2} \mathrm{~m}^{-2} \mathrm{~s}^{-1}\right)
$$

em que $R$ é a "respiração" (emissão maior que assimilação), ir é a hora inicial da "respiração" (18 h no período seco e 19 h no período chuvoso) e fr é a hora final da "respiração" ( $8 \mathrm{~h}$ em ambos os períodos). Convencionalmente, a emissão de fluxo de $\mathrm{CO}_{2}$ do sistema para a atmosfera tem sinal positivo. O segundo termo da equação é relativo ao seqüestro de carbono usado na fotossintese $(F)$ pela floresta, sendo if a hora inicial da fotossíntese ( $9 \mathrm{~h} \mathrm{em}$ ambos os períodos) e ff a hora final da fotossíntese ( $17 \mathrm{~h}$ na época seca e $18 \mathrm{~h}$ na época chuvosa). Este termo por convenção tem sinal negativo.

As medidas de fluxo foram determinadas em $\mu \mathrm{mol} \mathrm{CO}_{2} \mathrm{~m}^{-2} \mathrm{~s}^{-1}$, e para definir o balanço total de carbono na floresta foram usadas algumas transformações:

$\mathrm{ha}=10^{4} \mathrm{~m}^{2}$

$\mu \mathrm{mol} \mathrm{CO} 2=$ micromol de dióxido de carbono $=10^{-6} \mathrm{~mol} \mathrm{CO}_{2}$

mol $\mathrm{CO}_{2}=$ mol de dióxido de carbono $=44 \mathrm{~g}$ 
mol $\mathrm{O}=$ mol de oxigênio $=16 \mathrm{~g} \rightarrow \mathrm{O}_{2}=32 \mathrm{~g}$

mol $\mathrm{C}=$ mol de carbono $=12 \mathrm{~g}$

$\mathrm{kg} \mathrm{C}=10^{3} \mathrm{~g} \mathrm{C}=$ Kilograma de carbono

$\mathrm{MgC}=10^{6} \mathrm{~g} \mathrm{C}=$ Megagrama = tonelada de carbono

$\mathrm{Gg}=10^{9} \mathrm{~g} \mathrm{C}=$ Gigagrama $=$ mil toneladas de carbono

$\mathrm{Tg}=10^{12} \mathrm{~g} \mathrm{C}=$ Teragrama $=$ milhão de toneladas de carbono

$\mathrm{Pg}=10^{15} \mathrm{~g} \mathrm{C}=$ Petagrama = bilhão de toneladas de carbono

\subsection{Análise dos dados}

Todas as variáveis utilizadas neste trabalho foram organizadas em médias horárias, durante dois períodos distintos com 8 dias cada. O período seco compreendeu os dias 21 a 28 de outubro de 1995, enquanto que o período chuvoso foi de 15 a 22 de fevereiro de 1996. No período seco, além das variáveis medidas no alto da torre, foram obtidas as concentrações de $\mathrm{CO}_{2}$ em diferentes alturas dentro da floresta.

Para todas as variáveis foram realizadas análises nas mudanças ocorridas durante os períodos estudados. Os ciclos diários médios também foram objeto de análise e serão detalhadamente descritos no decorrer deste trabalho.

Os fluxos de $\mathrm{CO}_{2}$ emitidos pelo sistema solo-planta para a atmosfera (por convenção positivos) foram determinados, no ciclo médio diário, como sendo os ocorridos entre as $18 \mathrm{~h}$ e $8 \mathrm{~h}$ durante o período seco, e entre as $19 \mathrm{~h}$ e $8 \mathrm{~h}$ no período chuvoso. Para a época seca, das cento e vinte médias horárias possíveis foram utilizadas nos cálculos cento e quatro, representando $87 \%$ do total enquanto que na etapa chuvosa, dos cento e doze dados possíveis, cento e cinco foram aproveitados, cerca de $94 \%$ do total.

Para os dados de fluxo de $\mathrm{CO}_{2}$ da atmosfera para a floresta (sinal negativo), durante a época seca foram utilizados sessenta e um dados horários dos setenta e dois possíveis ( $85 \%$ ), enquanto que no período chuvoso sessenta e sete dos 80 dados foram úteis $(84 \%)$. 
Durante o período seco foram utilizados 165 dados horários, entre emissão e seqüestro de $\mathrm{CO}_{2}$ representando cerca de $86 \%$ das informaçõ̀es do período. Para a etapa chuvosa foram considerados 172 dados horários, significando aproximadamente $90 \%$ do total das informações do período. Alguns dados eliminados por apresentarem problemas nas medidas, principalmente nos horários de manutenção dos equipamentos.

Estes valores, em média $88 \%$ dos dados, garantem a representatividade das medidas obtidas para os fluxos de liberação e retirada de $\mathrm{CO}_{2}$ no sistema solo-plantaatmosfera.

Para as análises das variáveis meteorológicas e fisiológicas medidas no alto da torre ou determinadas por equações, foram aplicados todos os dados horários nos respectivos períodos. Entretanto, quando estas variáveis foram correlacionadas com as informações de fluxo de $\mathrm{CO}_{2}$, somente foram utilizadas as medidas obtidas nos horários com dados nos dois grupos.

As correlações entre as variáveis e os fluxos de $\mathrm{CO}_{2}$ foram feitas separando as emissões para a atmosfera (fluxo positivo) e as absorções pela floresta (fluxo negativo) para cada período analisado.

Desta forma foi possível visualizar a influência que cada variável teve nos processos de liberação e assimilação de carbono pela vegetação. 


\section{RESULTADOS E DISCUSSÃO}

Este estudo teve um enfoque nas variações sazonais apresentadas pelas diferentes medidas realizadas na Amazônia Central. Os dados utilizados foram separados em dois grupos distintos. A seleção dos dados foi feita a partir da caracterização do regime pluviométrico de cada grupo. Assim foram definidos os períodos: seco (outubro de 1995) e chuvoso (fevereiro de 1996) que foram analisados detalhadamente. Os resultados obtidos serão apresentados à seguir.

\subsection{Precipitação pluviométrica}

A chuva é um elemento fundamental na classificação climática de uma região, e os amazônidas freqüentemente distinguem as estações do ano pelas épocas chuvosa e seca (Ferreira da Costa et al., 1998). Os dois períodos selecionados para esta análise apresentaram características bastante diferenciadas quanto à precipitação. $\mathrm{O}$ período de 22 a 28 de outubro de 1995 (seco), registrou um total de $12,6 \mathrm{~mm}$ de chuva. Dos oito dias estudados nesta etapa, quatro registraram a ocorrência de chuva $(23,24,25$ e 27). Foram precipitações de pequena intensidade, concentradas nos dias 24 e $27 \mathrm{com}$ 6,4 e $4,6 \mathrm{~mm}$, respectivamente, acumulando mais de $87 \%$ do total de chuva do período (Figura 11). As precipitações são primordialmente de características convectivas ocorrendo com mais freqüência nos horários de maior aquecimento. Cerca de $81 \%$ do total de chuva do período $(10,2 \mathrm{~mm})$ ocorreu às $13 \mathrm{~h}(38 \%)$ e às $14 \mathrm{~h}(43 \%)$, enquanto que durante a noite foi registrado apenas $1,6 \%$ do total de chuva (Figura 12). A média diária da precipitação no período seco foi de $1,6 \mathrm{~mm} \mathrm{dia}^{-1}$. As chuvas mais intensas 
ocorridas na época seca foram de $4,2 \mathrm{~mm} \mathrm{~h}^{-1}$ às $14 \mathrm{~h}$ do dia $27 \mathrm{e} 4 \mathrm{~mm} \mathrm{~h}^{-1}$ às $13 \mathrm{~h}$ do dia 24.

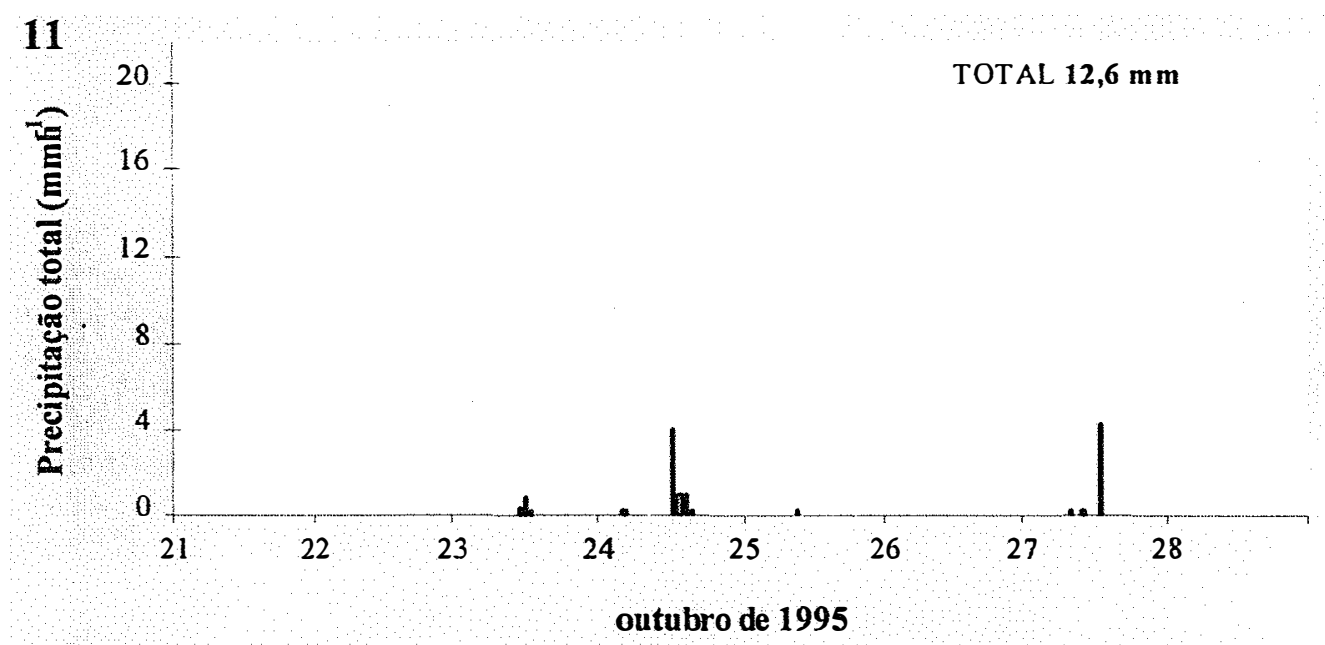

Figura 11 Precipitação pluviométrica durante o período seco, de 21 a 28 de outubro de 1995.

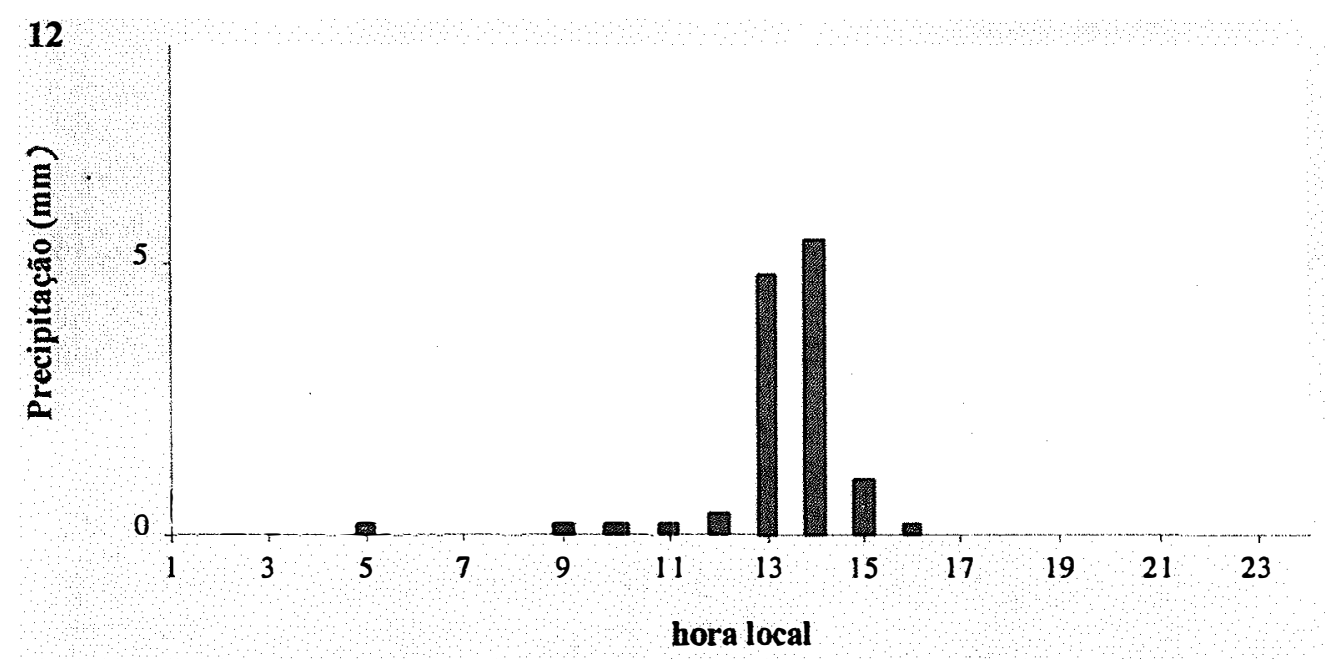

Figura 12 Ciclo diário da Precipitação horária $\left(\mathrm{mm} \mathrm{dia}^{-1}\right)$ do período seco. 
O período chuvoso analisado foi de 15 a 22 de fevereiro de 1996. O total de chuva foi de 109,8 mm distribuído em seis dos oito dias pesquisados (Figura 13). Na Amazônia Central, o mês de fevereiro está inserido na época de maiores precipitações. Há uma grande variação na intensidade das chuvas nesta época do ano. Durante os dias estudados, $75 \%$ das chuvas foram entre 7 e $18 \mathrm{~h}(83 \mathrm{~mm})$. Entretanto, a chuva mais intensa do período todo ocorreu às $6 \mathrm{~h}$ do dia 17 , com $19,8 \mathrm{~mm}$ ou $18 \%$ do total (ver item 4.2 Figura 16b) influenciando fortemente no fluxo (positivo) de $\mathrm{CO}_{2}$ para a atmosfera, fato que se repetiu claramente nos dias $15,18,19$ e 20 . Cerca de $29 \%$ das chuvas ocorreram às $15 \mathrm{~h}(31,6 \mathrm{~mm})$, mas observou-se uma distribuição das chuvas durante todo o dia (Figura 14). A média diária da precipitação no período chuvoso analisado foi de $13,7 \mathrm{~mm} \mathrm{dia}^{-1}$, ou cerca de $0,6 \mathrm{~mm} \mathrm{~h}^{-1}$.

As precipitações maiores que $5 \mathrm{~mm} \mathrm{~h}^{-1}$ ocorreram em cinco dos seis dias com chuva no período, com uma média de um evento para cada 27 horas. Lloyd \& Marques (1988), em um estudo para Reserva Ducke (distante cerca de $57 \mathrm{~km}$ de Cuieiras) determinaram que seria aceitável assumir uma chuva com $5,2 \mathrm{~mm} \mathrm{~h}^{-1}$ durante 2 $\mathrm{h}$, que ocorreria entre 13 e $15 \mathrm{~h}$ em três de cada cinco dias. As chuvas com intensidade maior que $10 \mathrm{~mm} \mathrm{~h}^{-1}$ ocorreram quatro vezes em três dias, representando cerca de $22 \%$ do total de eventos período. Ferreira da Costa et al. (1998), com dados do período chuvoso (jan/fev/mar) em uma área de floresta em Rondônia no sudoeste da Amazônia, determinaram que as precipitações acima de $10 \mathrm{~mm} \mathrm{~h}^{-1}$ representaram $14 \%$ do total de chuva no local. Esta diferença seria explicada pela variabilidade espacial das precipitações na Amazônia, pois estes sítios experimentais estão separados por uma distância de aproximadamente $850 \mathrm{~km}$, além do que os dados não foram coletados na mesma época. As diferenças quanto às precipitações entre os dois períodos estudados foram consideráveis. Outubro é o mês em que se inicia a época das chuvas na região central da Amazônia, que se estenderá até maio. Porém, ainda apresenta períodos com precipitação reduzida como foi o caso do ano de 1995. Por outro lado o mês de fevereiro está no meio da época chuvosa, quando a ocorrência de chuvas freqüentes é comum na região. 


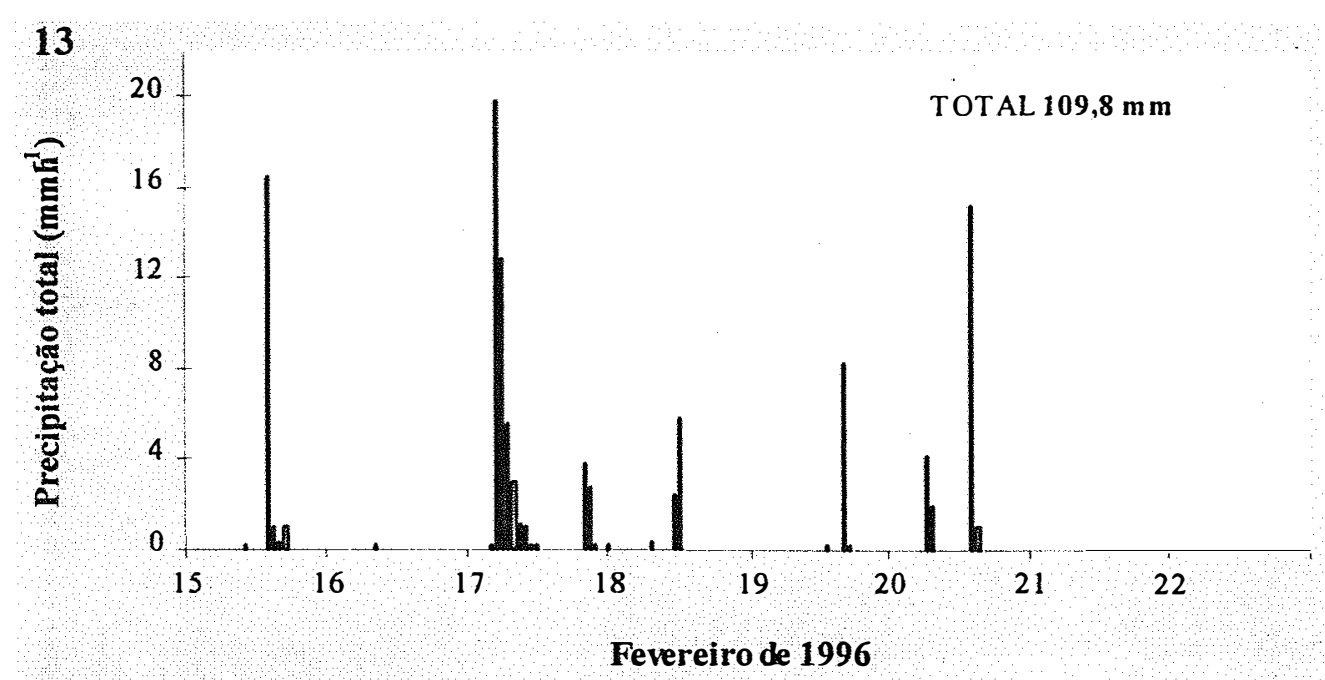

Figura 13 Precipitação pluviométrica durante o período chuvoso, de 15 a 22 de fevereiro de 1996.

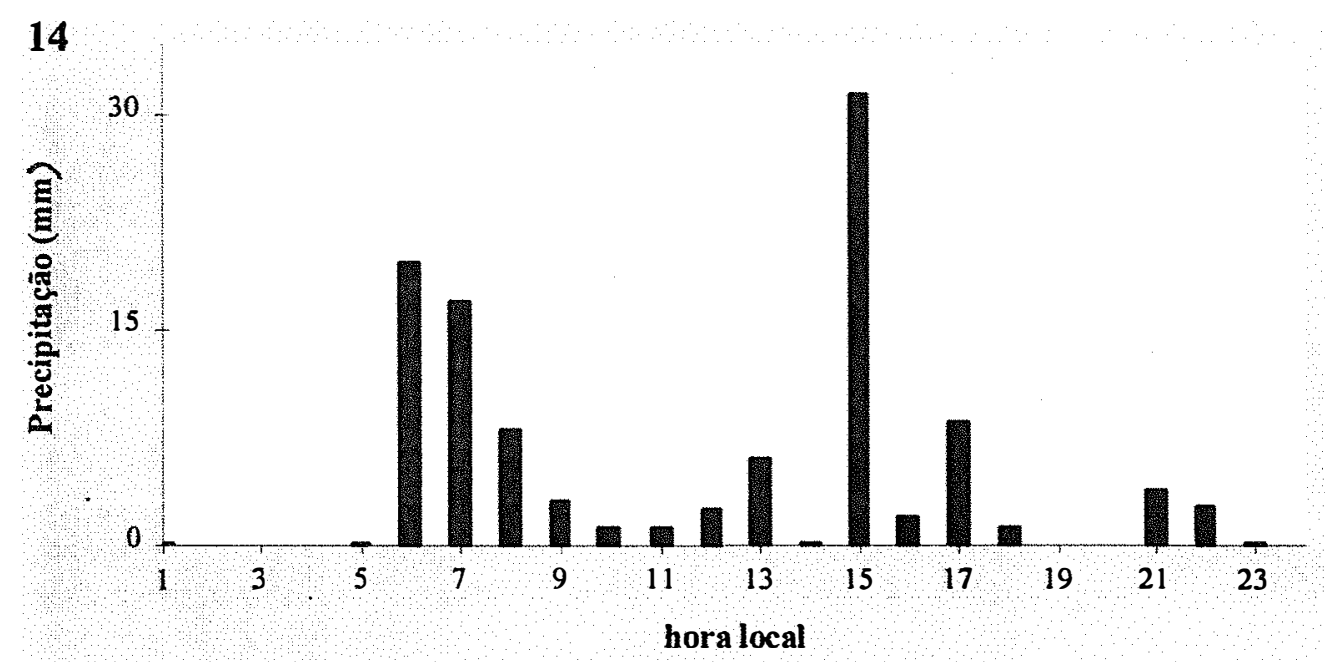

Figura 14 Ciclo diário da precipitação no período chuvoso.

A importância da chuva para as atividades fotossintéticas da vegetação foi destacada por Pielke et al. (1998) (ver item 2.4). Por outro lado, quando da ausência de precipitação na gênese de um estresse hídrico, segundo Tardieu \& Davies (1992) uma ação hormonal induziria o fechamento estomático, que preservaria certa quantidade de 
ação hormonal induziria o fechamento estomático, que preservaria certa quantidade de água armazenada, porém, restringiria a absorção de carbono pela vegetação (ver item 2.4).

Os valores de precipitação registrados em ambos os períodos analisados, neste trabalho, não apresentaram expressivos coeficientes de determinação $\left(R^{2}\right)$ nas correlação com os fluxos de $\mathrm{CO}_{2}$. Para a época chuvosa, no seqüestro de carbono coeficiente foi de 0,37 , enquanto que na emissão foi de 0,36 . Para o período seco foi 0,79 na emissão e 0,73 na absorção de $\mathrm{CO}_{2}$, mas a quantidade de dados nesta época foi muito reduzida para ser significativa. Porém, este fato não reduz a importância da chuva. Ela influenciará nas oscilações de diversas variáveis meteorológicas e fisiológicas que serão analisadas no decorrer deste estudo.

\subsection{Fluxos de $\mathrm{CO}_{2}$}

$\mathrm{O}$ padrão de variação do fluxo de $\mathrm{CO}_{2}$ no ciclo diário foi bem definido durante os períodos analisados neste trabalho. Houve um fluxo positivo, que é a maior liberação de carbono pelo sistema solo-planta para a atmosfera, desde o final das tardes até às primeiras horas das manhãs após o nascer do sol. Com a incidência dos raios solares mais acentuada sobre a floresta ocorreu um fluxo negativo, que representa o predomínio da absorção de $\mathrm{CO}_{2}$ pela vegetação, atingindo por volta da metade do dia a máxima absorção, diminuindo de intensidade no decorrer da tarde, até passar novamente para valores positivos, reiniciando a emissão para a atmosfera (Figura 15a). Esta variação seguiu o mesmo modelo apresentado, entre outros por: Goulden et al. (1996) e Grecco \& Baldochi (1996), para florestas de regiões de clima temperado do Hemisfério Norte, Fan et al. (1990), Grace et al. (1996), Culf et al. (1997) e Malhi et al. (1998) entre outros para floresta tropical.

Durante o período seco, a emissão de $\mathrm{CO}_{2}$ para a atmosfera teve valor médio $\mathrm{de}+3,4 \mu \mathrm{mol} \mathrm{m} \mathrm{m}^{-2} \mathrm{~s}^{-1}$. Pela manhã às $8 \mathrm{~h}$ o fluxo médio foi de $+12,9 \mu \mathrm{mol} \mathrm{m}^{-2} \mathrm{~s}^{-1}$ (Figura $15 \mathrm{~b})$, este valor mais elevado foi proporcionado pela ocorrência de fluxos da ordem de $+25 \mu \mathrm{mol} \mathrm{m} \mathrm{m}^{-2}$ nos dias 26 e 27 , sendo este último claramente influenciado pela 
ocorrência de chuva (Figura 16a). Como o fluxo positivo de carbono para a atmosfera se iniciou, em média às $18 \mathrm{~h}$ no período seco do ano, possivelmente uma parte do carbono liberado pelo solo e pelas camadas mais baixas da vegetação se acumulou nos níveis mais altos do dossel durante todo a noite. Após o alvorecer, o fluxo sofreu um incremento provocado pela liberação daquele carbono aprisionado na copa das árvores, atingindo valores mais elevados.

A absorção de $\mathrm{CO}_{2}$ da atmosfera pela floresta, ou seja o fluxo negativo, iniciou em média às $9 \mathrm{hs}$ com um valor médio de $-9,1 \mu \mathrm{mol} \mathrm{m} \mathrm{m}^{-2} \mathrm{~s}^{-1}$, estendendo-se até às $17 \mathrm{~h}$ no período seco. $\mathrm{O}$ pico da retirada de $\mathrm{CO}_{2}$ pela vegetação ocorreu às $12 \mathrm{hs}$, com uma taxa média de $-14,5 \mu \mathrm{mol} \mathrm{m} \mathrm{m}^{-2} \mathrm{~s}^{-1}$ (Figura 15b). Os valores diários apresentaram absorções de aproximadamente $-20 \mu \mathrm{mol} \mathrm{m} \mathrm{m}^{-2} \mathrm{~s}^{-1}$ nos dias 21,26 e 27 ocorrendo entre 11 e $13 \mathrm{~h}$ (Figura 15a).

Dos oito dias analisados no período seco, seis apresentaram balanço de carbono negativo, isto é, a floresta retirou mais carbono da atmosfera do que liberou naqueles dias. A menor taxa diária de seqüestro de carbono pela floresta foi de aproximadamente $-11 \mathrm{~kg} \mathrm{C} \mathrm{ha}^{-1} \mathrm{dia}^{-1}$ ocorrida no dia 27 de outubro de 1995. Este dia registrou ocorrência de chuva da ordem de $4,6 \mathrm{~mm}$ (cerca de $37 \%$ do total do período) que intensificou a liberação de $\mathrm{CO}_{2}$ para a atmosfera (Figura 16a). A radiação solar incidente integrada para o dia 27 foi de $12,2 \mathrm{MJ} \mathrm{m}^{-2} \mathrm{dia}^{-1}$, a temperatura média do ar foi de $25,5^{\circ} \mathrm{C}$ e o déficit de pressão de vapor médio foi de $0,55 \mathrm{kPa}$. O dia 25 foi no qual ocorreu a maior taxa de seqüestro de carbono da atmosfera pela floresta no período, com um valor de $-32,5 \mathrm{~kg} \mathrm{C} \mathrm{ha}^{-1} \mathrm{dia}^{-1}$. Houve um registro mínimo de chuva de $0,2 \mathrm{~mm}$ neste dia, porém, provavelmente existiu uma nebulosidade considerável. A radiação solar incidente integrada no dia foi de $17,8 \mathrm{MJ} \mathrm{m}^{-2} \mathrm{dia}^{-1}$, enquanto que o máximo diário foi de aproximadamente $22 \mathrm{MJ} \mathrm{m}^{-2} \mathrm{dia}^{-1}$ registrado no dia 26 sem ocorrência de chuva. A temperatura média do ar no dia 25 também foi menor, da ordem de $24,6{ }^{\circ} \mathrm{C}$, enquanto que o déficit de pressão de vapor foi de $0,49 \mathrm{kPa}$. 

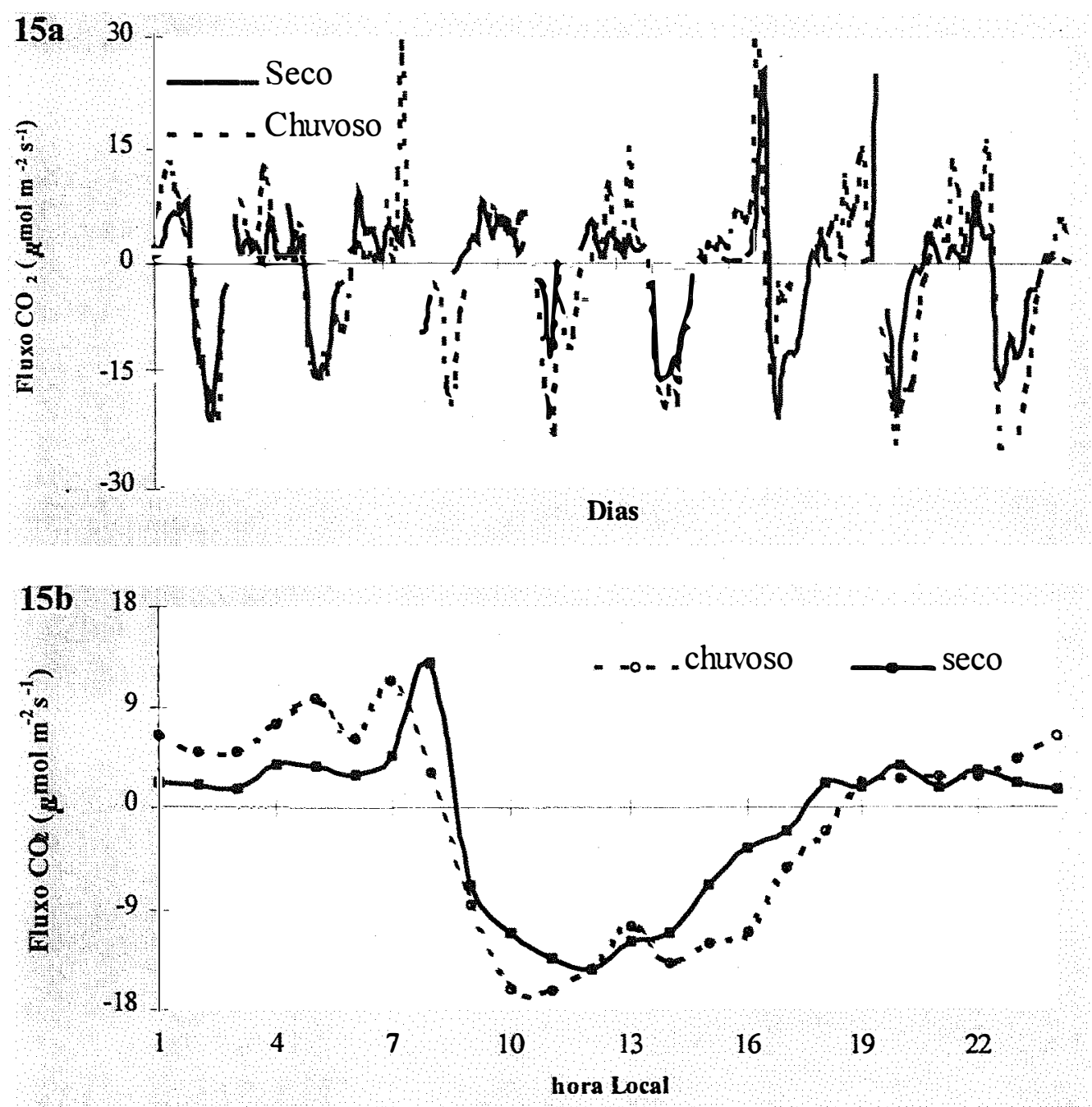

Figuras 15 Fluxos de $\mathrm{CO}_{2}$ : a) valores horários; b) ciclo médio diário

Para os dois dias do período seco nos quais o balanço de carbono foi positivo, isto é, houve liberação de $\mathrm{CO}_{2}$ da floresta para a atmosfera, as taxas foram de $+6,9 \mathrm{~kg} \mathrm{C}^{-1} \mathrm{dia}^{-1}$ no dia $24 \mathrm{e} \mathrm{de}+12,5 \mathrm{~kg} \mathrm{C}^{-1} \mathrm{dia}^{-1}$ no dia 23 . Ambos os dias registraram ocorrência de chuva, 6,4 e 1,4mm respectivamente. No dia 23 foi registrado o menor valor integrado de radiação solar incidente no período seco, com 7,3 $\mathrm{MJ} \mathrm{m}^{-2}$ dia $^{-1}$ enquanto que a temperatura média do ar foi de $23,7{ }^{\circ} \mathrm{C}$ e o déficit de pressão de vapor foi de $0,13 \mathrm{kPa}$. 

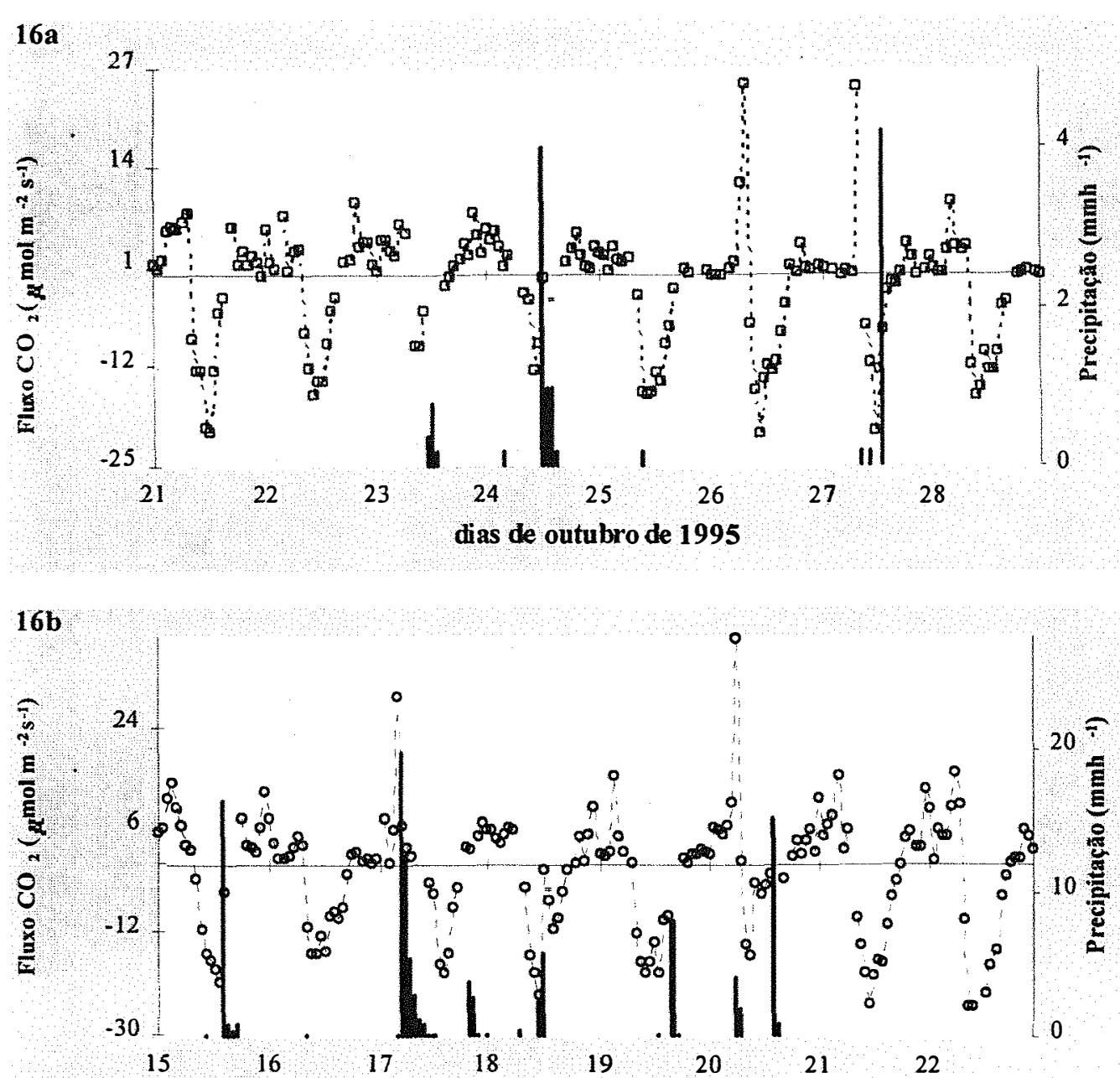

dias de fevereiro de 1996

Figuras 16 Fluxos horários de $\mathrm{CO}_{2}\left(\mathrm{em} \mu \mathrm{mol} \mathrm{m}^{-2} \mathrm{~s}^{-1}\right.$, escala da esquerda) e os valores de precipitação (em $\mathrm{mm} \mathrm{h}^{-1}$, escala da direita): a) período seco com chuvas significativas nos dias 24 e 27 de outubro. b) período chuvoso quando vários dias apresentaram chuvas intensas.

No período seco, a emissão de carbono para a atmosfera foi na média de +21 $\mathrm{kg} \mathrm{C} \mathrm{ha} \mathrm{dia}^{-1}$, enquanto que o seqüestro de carbono pela floresta foi de $-35,4 \mathrm{~kg} \mathrm{C} \mathrm{ha}^{-1}$ $\mathrm{dia}^{-1}$. O balanço médio de carbono na época seca foi de $-13,6 \mathrm{~kg} \mathrm{C} \mathrm{ha}^{-1} \mathrm{dia}^{-1}$, indicando que a floresta retirou mais carbono da atmosfera pela fotossíntese do que emitiu (Figura 17a). 
Durante o período chuvoso, o valor médio da emissão de $\mathrm{CO}_{2}$ da floresta para a atmosfera foi de $+5,3 \mu \mathrm{mol} \mathrm{m}^{-2} \mathrm{~s}^{-1}$. Os fluxos atingiram aproximadamente $+11 \mu \mathrm{mol} \mathrm{m} \mathrm{s}^{-1}$, em média, às $7 \mathrm{~h}$. Os valores máximos alcançaram cerca de $+29 \mu \mathrm{mol}$ $\mathrm{m}^{-2} \mathrm{~s}^{-1} \mathrm{e}+39 \mu \mathrm{mol} \mathrm{m}^{-2} \mathrm{~s}^{-1}$ nos dias 17 e 20 de fevereiro de 1996, respectivamente (Figura 15a). No dia 17 às $5 \mathrm{~h}$ e no dia 20 às $7 \mathrm{~h}$ tiveram início eventos de precipitação (Figura 16b). Como nestes horários ocorreu, em geral, um acúmulo de carbono nos níveis mais elevados do dossel, a presença de chuva, possivelmente, provocou uma expulsão do $\mathrm{CO}_{2}$ contido nos poros do solo, que se somou ao já existente no dossel elevando as taxas de fluxo.

A absorção de $\mathrm{CO}_{2}$ atmosférico pela floresta na época chuvosa foi, em média, das 9 às $18 \mathrm{~h}$, com um valor médio de $-11,2 \mu \mathrm{mol} \mathrm{m}^{-2} \mathrm{~s}^{-1}$. As maiores taxas de seqüestro de $\mathrm{CO}_{2}$ foram entre -24 e $-25 \mu \mathrm{mol} \mathrm{m}^{-2} \mathrm{~s}^{-1}$, nos dias 21 e 22 de fevereiro (Figura 15a). Nestes dias não foram registrados eventos de precipitação. O ciclo diário médio do período chuvoso (Figura 15b) mostrou absorção de $\mathrm{CO}_{2}$ maior nos horários entre 10 e $12 \mathrm{~h}$, sendo a maior taxa de $-16,4 \mu \mathrm{mol} \mathrm{m}^{-2} \mathrm{~s}^{-1}$ às $11 \mathrm{~h}$. Fan et al. (1990), realizando medidas na Reserva Ducke distante cerca de $50 \mathrm{~km}$ do local das medidas utilizadas neste trabalho, durante doze dias entre abril e maio de 1987, encontraram fluxos de $\mathrm{CO}_{2}$ da ordem de $+5,9 \mu \mathrm{mol} \mathrm{m}^{-2} \mathrm{~s}^{-1}$ à noite e de $-18 \mu \mathrm{mol} \mathrm{m}^{-2} \mathrm{~s}^{-1}$ das 9 às $13 \mathrm{~h}$. Grace et al. (1996a), em estudos realizados na Reserva Jarú em Rondônia (cerca de 850 $\mathrm{km}$ distante de Cuieiras) mediram fluxos de $\mathrm{CO}_{2}$ variando de $+6 \mathrm{a}+7 \mu \mathrm{mol} \mathrm{m} \mathrm{m}^{-2} \mathrm{~s}^{-1}$ durante a noite e entre $-14 \mathrm{e}-17 \mu \mathrm{mol} \mathrm{m}^{-2} \mathrm{~s}^{-1}$ por volta das $11 \mathrm{~h}$ nos meses de maio e junho de 1993.

Nos oito dias estudados para a época chuvosa, cinco apresentaram a floresta como sumidouro de $\mathrm{CO}_{2}$ da atmosfera, pois seus balanço diários de carbono foram negativos. A maior taxa diária de seqüestro de carbono foi registrada no dia 19 , com uma retirada de $-32,7 \mathrm{~kg} \mathrm{Cha}^{-1} \mathrm{dia}^{-1}$, enquanto que a menor absorção diária ocorreu em 18 de fevereiro com $-14,4 \mathrm{~kg} \mathrm{C} \mathrm{ha}^{-1} \mathrm{dia}^{-1}$. Em ambos os dias houve a presença de chuva com intensidade aproximadas de 8,6 e $8,8 \mathrm{~mm}$, respectivamente. Entretanto, esta diferença no seqüestro diário de carbono pode ser explicada pelo horário de ocorrência 
das chuvas. No dia 19 a chuva foi registrada no final da tarde e início da noite entre 17 e 18 h, Figura 15a, horário no qual a fotossíntese já está normalmente menos intensa, portanto não alterando significativamente o balanço diário. Já no dia 18 a chuva foi no início da manhã e durante a tarde, principalmente às 12 e $13 \mathrm{~h}$, horário normalmente de fotossíntese mais intensa, afetando substancialmente o balanço diário de carbono. Tanto a chuva como as condições atmosféricas que a propiciaram, causaram alterações significativas em outras variáveis. A radiação solar incidente integrada no período das 7 às $18 \mathrm{~h}$ foi de $8,9 \mathrm{MJ} \mathrm{m}^{-2} \mathrm{dia}^{-1}$ para o dia 18 , representando cerca de $42 \%$ da registrada no dia 19 que foi de de $21,4 \mathrm{MJ} \mathrm{m}^{-2} \mathrm{dia}^{-1}$ (o seqüestro de carbono no dia 18 foi de aproximadamente $44 \%$ do ocorrido no dia 19). A energia armazenada na biomassa no dia 18 foi em média de $0,55 \mathrm{Wm}^{-2}$, cerca de $21 \%$ da média do dia 19 que foi de 2,63 $\mathrm{Wm}^{-2}$. O déficit de pressão de vapor apresentou valores de $0,11 \mathrm{kPa}$ no dia 18 , cerca de $22 \%$ da média do dia 19 de $0,50 \mathrm{kPa}$.

Durante o período chuvoso, a emissão média de carbono para a atmosfera foi $\mathrm{de}+32,3 \mathrm{~kg} \mathrm{C} \mathrm{ha}^{-1} \mathrm{dia}^{-1}$, sendo que no mesmo período o seqüestro médio foi de $-48,2 \mathrm{~kg}$ $\mathrm{C} \mathrm{ha} \mathrm{dia}^{-1}$. O balanço de carbono na época chuvosa foi de $-15,9 \mathrm{~kg} \mathrm{C} \mathrm{ha}^{-1} \mathrm{dia}^{-1}$, mostrando que a floresta foi sumidouro de carbono da atmosfera, durante o período estudado (Figura 17a).

As informações coletadas nos meses de outubro de 1995 e fevereiro de 1996, mostraram claramente a sazonalidade existente na intensidade dos fluxos de $\mathrm{CO}_{2}$ na floresta tropical.

$\mathrm{Na}$ análise do ciclo diário médio dos fluxos de $\mathrm{CO}_{2}$ (Figura 15b), observouse que durante o período seco (outubro) a intensidade média dos fluxos positivos foi de $+3,4 \mu \mathrm{mol} \mathrm{m}{ }^{-2} \mathrm{~s}^{-1}$, sendo menor que a obtida para o período chuvoso (fevereiro) quando foi registrado um fluxo médio de $+5,3 \mu \mathrm{mol} \mathrm{m} \mathrm{m}^{-2} \mathrm{~s}^{-1}$. Durante o dia, o fluxo negativo de $\mathrm{CO}_{2}$, ou o seqüestro de carbono da atmosfera pela vegetação, foi de $-9,1 \mu \mathrm{mol} \mathrm{m}^{-2} \mathrm{~s}^{-1}$ no período seco e $-11,2 \mu \mathrm{mol} \mathrm{m}^{-2} \mathrm{~s}^{-1}$ para a época chuvosa. Estes dados determinaram que a floresta tropical na Amazônia central liberou menos $\mathrm{CO}_{2}$ para a atmosfera durante $o$ período seco do que no período chuvoso. No balanço médio de cada fase, a emissão de 
$\mathrm{CO}_{2}$ em outubro foi de $+21,8 \mathrm{~kg} \mathrm{C}^{-1} \mathrm{dia}^{-1}$, enquanto em fevereiro foi de $+32,3 \mathrm{~kg} \mathrm{C}$ $\mathrm{ha}^{-1} \mathrm{dia}^{-1}$.

A absorção de carbono pela floresta também foi menor no período seco com $-35,4 \mathrm{~kg} \mathrm{C} \mathrm{ha}^{-1} \mathrm{dia}^{-1}$ do que na fase chuvosa com $-48,2 \mathrm{~kg} \mathrm{C} \mathrm{ha}^{-1} \mathrm{dia}^{-1}$ (Figura 17a). Em geral, as informações analisadas neste trabalho mostraram que a floresta tropical na região central da Amazônia, foi um sorvedouro de carbono presente na atmosfera durante as duas épocas estudadas. A extrapolação dos valores obtidos para cada etapa, sugere que, com as taxas de absorção de carbono do período seco a floresta seqüestraria cerca de $-5 \mathrm{Mg} \mathrm{C} \mathrm{ha}^{-1} \mathrm{ano}^{-1}$, enquanto que na fase chuvosa a retirada seria de até $-5,8$ $\mathrm{Mg} \mathrm{C}$ ha $^{-1}$ ano $^{-1}$ aproximadamente (Figura 17b). Os fluxos extrapolados para um ano mostraram que a floresta tropical no centro da Amazônia, retiraria na época chuvosa cerca de $16 \%$ a mais carbono da atmosfera do que no período seco. Fan et al. (1990) calcularam que a floresta amazônica absorveria cerca de $-2,2 \mathrm{Mg} \mathrm{C}^{-1} \mathrm{ano}^{-1}$. Grace et al. (1996a) modelaram matematicamente que a floresta seqüestraria aproximadamente $-1,1 \mathrm{Mg} \mathrm{C} \mathrm{ha}{ }^{-1}$ ano $^{-1}$. Estas diferenças podem ser justificadas pelas características de cada local pesquisado ou época e duração das medidas. Vários trabalhos em florestas de clima temperado mostraram taxas de seqüestro de carbono da atmosfera bastante variadas. Wofsy et al. (1993) calcularam cerca de $-2,2 \mathrm{Mg} \mathrm{C}^{-1} \mathrm{ano}^{-1}$, Valentini et al. (1996) apresentaram aproximadamente $-4,7 \mathrm{Mg} \mathrm{C}^{-1} \mathrm{ano}^{-1}$, Goulden et al. (1996), em torno de $-2,1 \mathrm{Mg} \mathrm{C}$ ha $^{-1}$ ano $^{-1}$ e Grecco \& Baldochi (1996) mostraram uma retirada de até $-5,2 \mathrm{Mg} \mathrm{C}^{-1} \mathrm{ano}^{-1}$.

Dos dezesseis dias analisados neste estudo, cinco foram qualificados como fonte de $\mathrm{CO}_{2}$ para a atmosfera (31\%), enquanto que onze dias (69\%) foram sumidouros de $\mathrm{CO}_{2}$. Grace et al. (1995b), em 44 dias medidos qualificaram 11 dias (25\%) como fonte e 33 dias $(75 \%)$ como sorvedouros de $\mathrm{CO}_{2}$. 


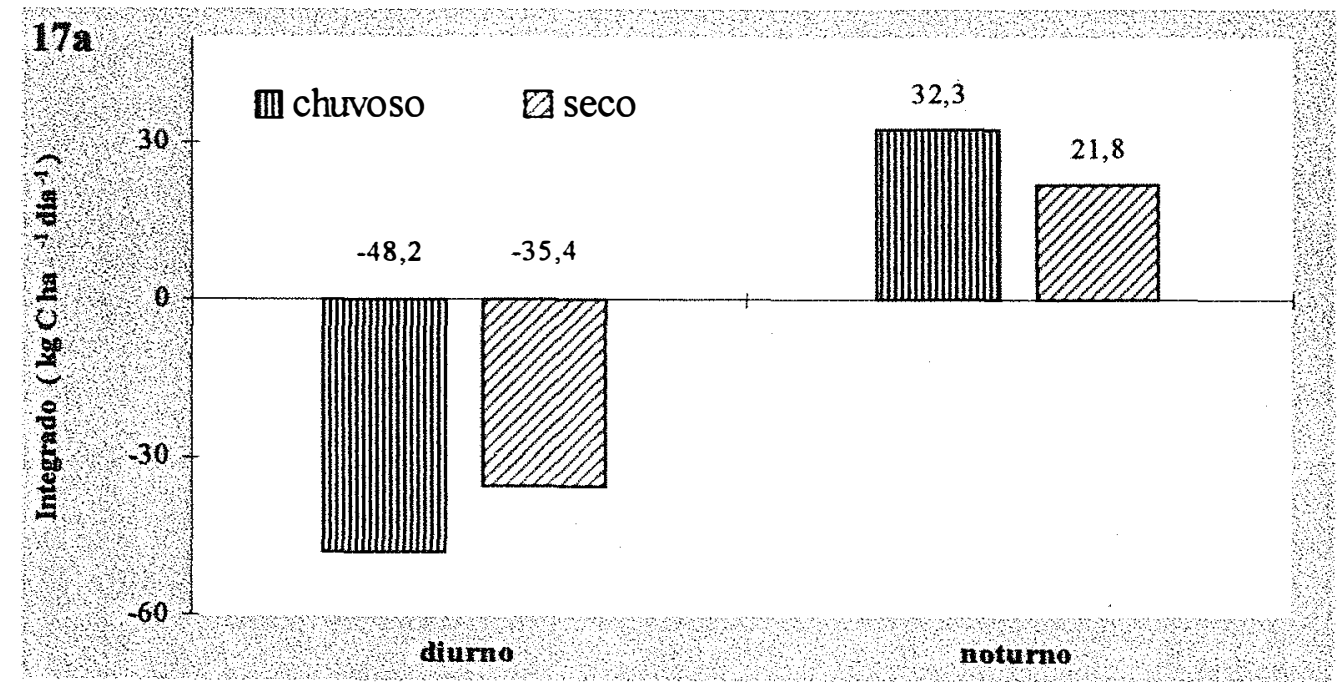

Figura 17a Fluxos de $\mathrm{CO}_{2}$ integrados em dois períodos nas épocas chuvosa e seca.

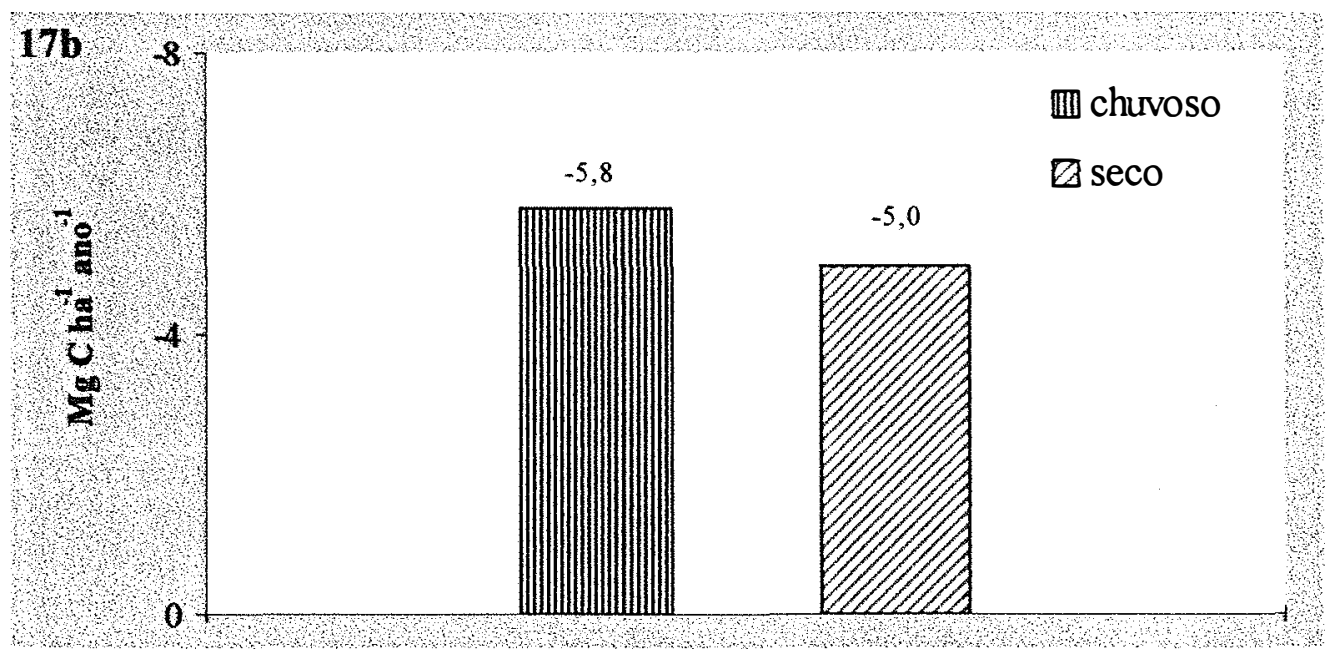

Figura 17b Carbono retirado pela floresta. nos períodos seco e chuvoso.

\subsection{Concentrações de $\mathrm{CO}_{2}$}

As medidas de concentrações de $\mathrm{CO}_{2}$ realizadas no alto da torre micrometeorológica na altura de $46,5 \mathrm{~m}$ indicaram uma variação bastante regular nos dois períodos de estudo.

A variação temporal dos valores de concentração de $\mathrm{CO}_{2}$ (Figura 18a) registrou os mais elevados conteúdos durante as últimas horas da noite e as primeiras 
horas da manhã, enquanto que os menores foram registrados no final das tardes, tanto para a época seca como para a chuvosa. Grace et al. (1996a) sugeriram que os valores máximos no início da manhã seriam devido à retenção pela parte superior do dossel, do carbono liberado pelo solo e pelos níveis mais baixos da vegetação.

Durante o período seco, a maior concentração de $\mathrm{CO}_{2}$ registrada foi de 445 ppmv às $7 \mathrm{~h}$ do dia 25 de outubro. Esta concentração de $\mathrm{CO}_{2}$ foi a mais elevada registrada nos dois períodos da pesquisa. Também no dia 25 foi determinada a mais baixa concentração da etapa seca, 345 ppmv às $16 \mathrm{~h}$. A diferença de $100 \mathrm{ppmv}$ representou uma amplitude (diferença entre a máxima e a mínima) de aproximadamente $29 \%$. A concentração média no período seco foi de 387 ppmv.

Para o período chuvoso, a variação da concentração de $\mathrm{CO}_{2}$ registrou o mais alto valor às 6 hs do dia 16 de fevereiro, com 420 ppmv. Enquanto que a menor taxa de concentração de $\mathrm{CO}_{2}$ foi de 341 ppmv medida no dia 17 às $18 \mathrm{~h}$. Esta foi a menor taxa registrada nos dois períodos do trabalho. A amplitude na época chuvosa foi de $79 \mathrm{ppmv}$, ou cerca de $23 \%$. A média concentração de $\mathrm{CO}_{2}$ neste período foi de $370 \mathrm{ppmv}$.

$\mathrm{O}$ ciclo diário médio das concentrações de $\mathrm{CO}_{2}$ acima do dossel (Figura 18b) registrou que durante a época seca o menor valor foi de 363 ppmv medido às $12 \mathrm{hs,}$ enquanto que o máximo foi de 418 ppmv às $7 \mathrm{~h}$, com amplitude de $55 \mathrm{ppmv}$, cerca de $15 \%$. Para o período chuvoso, a concentração de $\mathrm{CO}_{2}$ mínima foi de $351 \mathrm{ppmv}$ registrada às $17 \mathrm{~h}$, enquanto que o valor máximo foi de $394 \mathrm{ppmv}$ ocorrido às $5 \mathrm{~h}$, com uma diferença entre os valores extremos de 43 ppmv, aproximadamente $12 \%$. Fan et al. (1990) relataram concentrações de cerca de 370 ppmv medidas ao alvorecer, e aproximadamente 340 ppmv à tarde. Grace et al. (1996a) encontraram valores oscilando entre 357 e 453 ppmv.

A diferença sazonal das concentrações médias foi de 17 ppmv. Determinando que as concentrações foram cerca de $4,6 \%$ maiores no período seco do que no chuvoso. $\mathrm{O}$ valor médio das concentrações de $\mathrm{CO}_{2}$ durante os dois períodos analisados foi de 379 ppmv. 

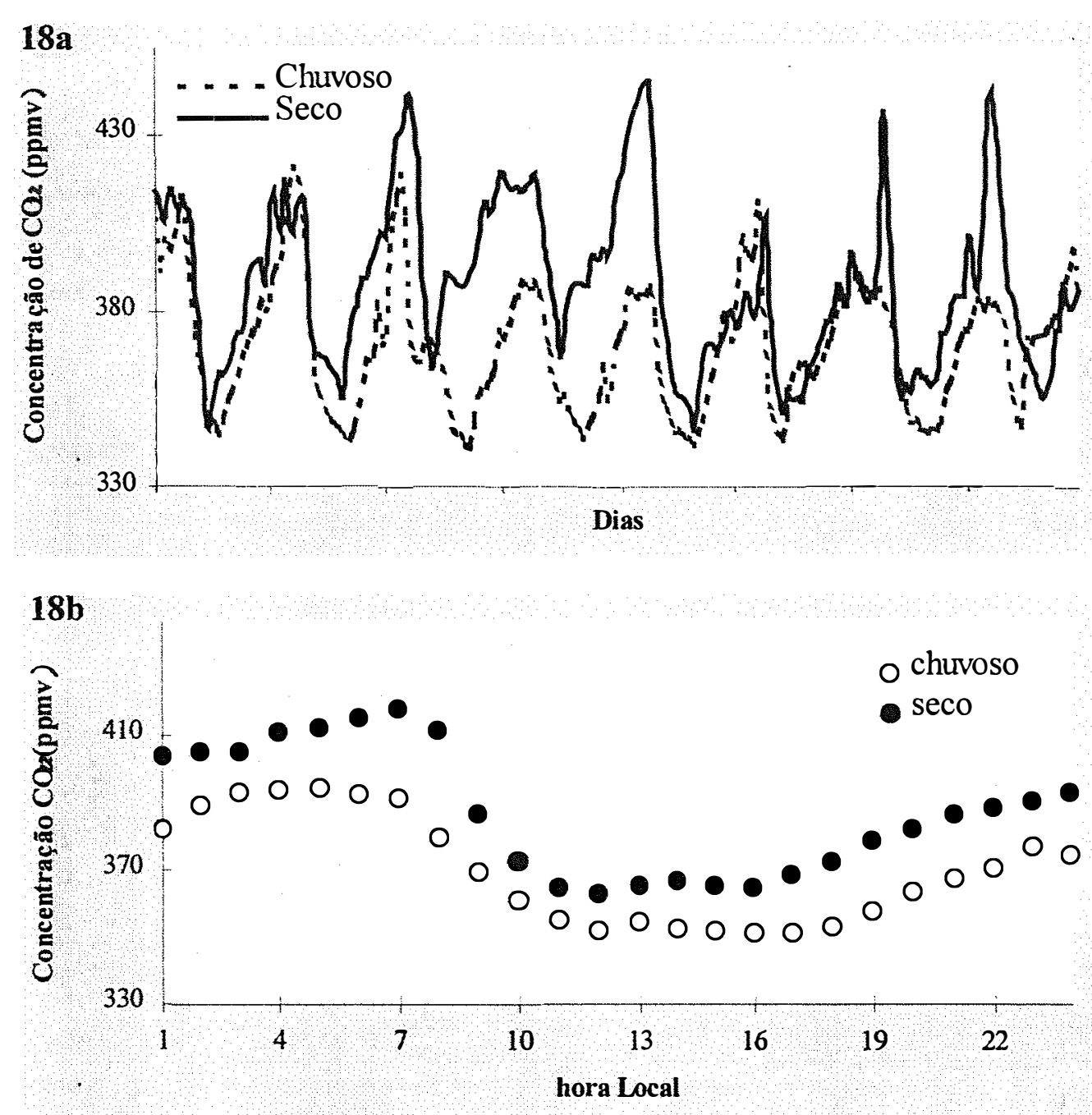

Figuras 18 Concentração de $\mathrm{CO}_{2}$ acima do dossel florestal (46,5m): a) valores horários b) ciclo médio diário. Período seco média de $387 \mathrm{ppmv}$, o período chuvoso média de 370 ppmv.

\subsection{Perfis de concentrações de $\mathrm{CO}_{2}$}

Durante a época seca foram realizadas medidas de concentrações de $\mathrm{CO}_{2}$ em seis diferentes níveis de altura, dentro e acima da vegetação. Os dados foram coletados nas alturas de $1 ; 9 ; 17,4 ; 25,3 ; 33,3$ e 46,5m, em intervalos de dez minutos, no período de 21 a 28 de outubro de 1996. 
As variações das concentrações de $\mathrm{CO}_{2}$ analisadas nos dados de dez minutos (Figura 19) oscilaram entre os valores mínimos de 340 ppmv nos níveis de $25,3 \mathrm{~m}$ e $33,3 \mathrm{~m}$ e de $341 \mathrm{ppmv}$ para as demais alturas até os máximos de 543 ppmv medidos em 9 m e 536 ppmv em $1 \mathrm{~m}$. Para a altura de 17,4m o máximo foi de 530 ppmv, enquanto que em 25,3m foi de 508 ppmv. Nos perfis de $33,3 \mathrm{~m}$ e 46,5 m os máximos foram de 486 e 453 ppmv, respectivamente. Algumas medidas realizadas por Grace et al. (1995b) indicaram concentrações de $\mathrm{CO}_{2}$ variando entre 350 e 500 ppmv, nos meses de maio e junho, período transitório entre as épocas chuvosa e seca.

A amplitude da concentração de $\mathrm{CO}_{2}$ no nível de $1 \mathrm{~m}$ foi de 195 ppmv, cerca de 57\%. Em 9m esta diferença aumentou para 202 ppmv aproximadamente $60 \%$. Acima desta altura, as amplitudes foram reduzindo gradativamente. Em 17,4m foi de $56 \%$ ou 189 ppmv. No nível de 25,3m diminuiu para 49\%, cerca de 167 ppmv, alcançando em $33,3 \mathrm{~m}$ os $146 \mathrm{ppmv}$ (aproximadamente $43 \%$ ) e por último, $112 \mathrm{ppmv}$, cerca de $33 \%$ em $46,5 \mathrm{~m}$.

Durante o período iniciado na manhã do dia 23 e prolongado até o final da tarde do dia 25, houve uma homogeneização do ambiente dentro da floresta. Com uma mistura mais acentuada na atmosfera, a concentração de $\mathrm{CO}_{2}$ variou pouco em todos os níveis de medidas. $\mathrm{O}$ registro foi de aproximadamente $400 \mathrm{ppmv}$, inclusive no topo da torre acima do dossel. Este equilíbrio esteve relacionado os eventos de chuva ocorridos nos dias 23, 24 e 25 que influenciaram em outras variáveis. A radiação solar incidente no dia 23 foi a menor registrada no período, cerca de 7,3 $\mathrm{MJ} \mathrm{m}^{-2} \mathrm{dia}^{-1}$ para os valores integrados das 7 às $18 \mathrm{~h}$, enquanto que no dia 24 foi de $8,1 \mathrm{MJ} \mathrm{m}^{-2} \mathrm{dia}^{-1}$, a segunda menor taxa determinada na fase seca. A redução na radiação solar incidente alterou a atividade fotossintética reduzindo a absorção de $\mathrm{CO}_{2}$, fazendo com que os dias 23 e 24 de outubro tenham sido qualificados no balanço diário como fonte de $\mathrm{CO}_{2}$ para a atmosfera. A velocidade de friç̧ão ( $\mathrm{u}^{*}$ ) alcançou $0,83 \mathrm{~m} \mathrm{~s}^{-1}$ às $13 \mathrm{~h}$ do dia 24 , sendo o mais alto valor registrado no período, representando, aproximadamente o dobro do valor médio para este horário na época analisada. No dia 23 às $12 \mathrm{~h}$ foi registrado o segundo maior valor de $\mathrm{u}^{*} \operatorname{com} 0,66 \mathrm{~m} \mathrm{~s}^{-1}$ mais que o dobro da média da hora. Quanto maior for o valor de $\mathrm{u}^{*}$ mais misturada estará a atmosfera ambiente. 
$\mathrm{O}$ ciclo diário médio das concentrações de $\mathrm{CO}_{2}$ nos diversos perfis para o período analisado (Figura 20) mostrou que os valores máximos foram registrados no alvorecer, entre 6 e $7 \mathrm{~h}$. Enquanto que as menores concentrações de $\mathrm{CO}_{2}$ foram às $12 \mathrm{e}$ $13 \mathrm{~h}$. No nível de $1 \mathrm{~m}$ a máxima concentração foi de 473 ppmv e a mínima de 365 ppmv com uma amplitude de 108 ppmv, representando 29,6\%. Em 9m a máxima foi de 477 ppmv, a maior do período, com a mínima de 363 ppmv e amplitude de $114 \mathrm{pmv}$ $(31,4 \%)$. Para o perfil de $17,4 \mathrm{~m}$ o valor máximo foi de 470 ppmv com o mínimo de 363 ppmv e amplitude de 107 ppmv, cerca de $29,5 \%$. Na altura de $25,3 \mathrm{~m}$ o maior valor de concentração de $\mathrm{CO}_{2}$ foi de 451 ppmv e o menor 363 ppmv com uma diferença entre os extremos de $24,3 \%$ ( $88 \mathrm{ppmv}$ ). Para o perfil de $33,3 \mathrm{~m}$ a concentração máxima foi de 431 ppmv e a mínima de 361 ppmv sendo esta a menor do período, com a amplitude de 70 ppmv (19,4\%). O nível de 46,5m já acima do dossel, registrou o valor máximo de 418 ppmv e o menor de 363 ppmv, com 55 ppmv de amplitude representando cerca de $15 \%$.

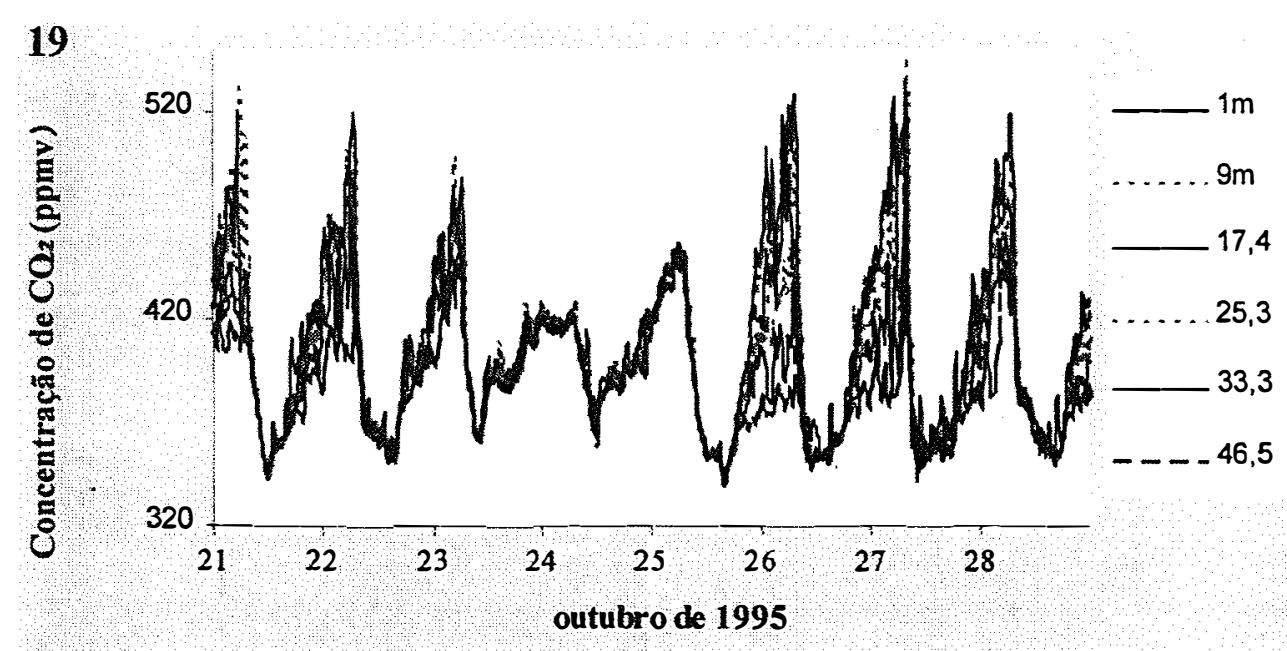

Figura 19 Perfis da concentração de $\mathrm{CO}_{2}$ em seis diferentes alturas: 1; 9; 17,4; 25,3; 33,3 e 46,5m, no período de 21 a 28 de outubro de 1995. 


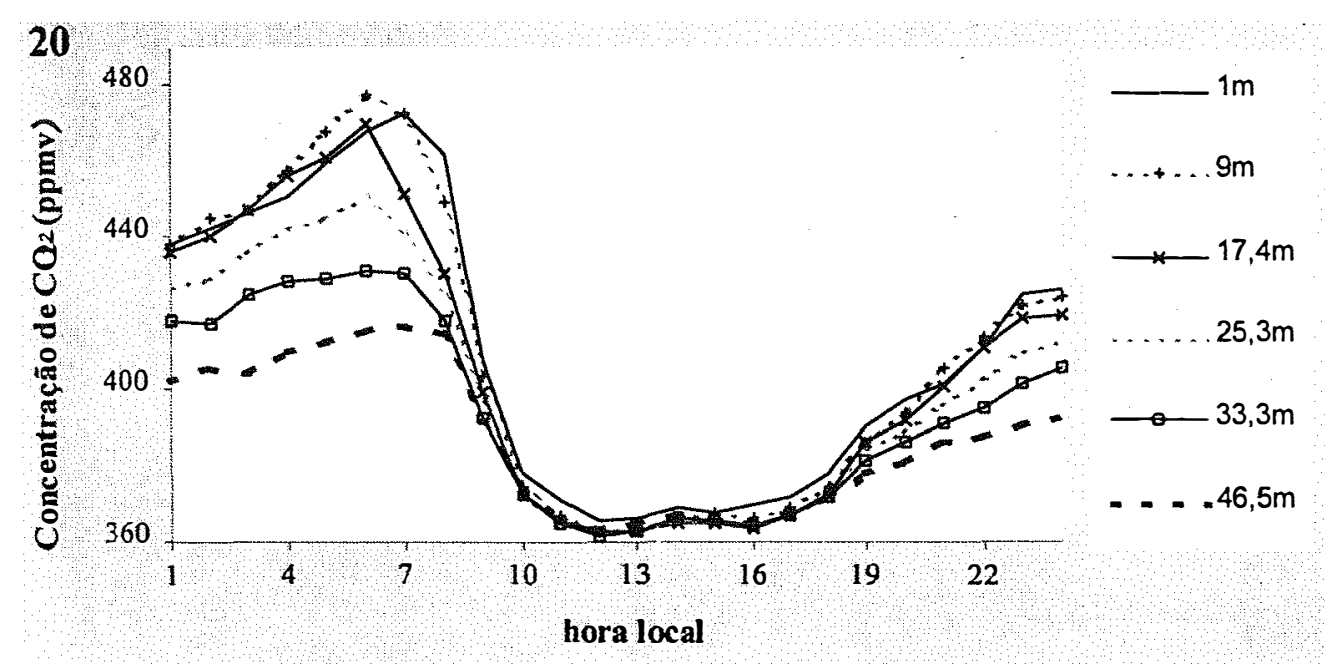

Figura 20. Variabilidade média diária da concentração de $\mathrm{CO}_{2}$ em diferentes alturas no período de 21 a 28 de outubro de 1995.

Os valores diários médios das concentrações de $\mathrm{CO}_{2}$ (Figura 21) revelaram que as maiores concentrações foram nos níveis inferiores. No dia 21 de outubro as menores concentrações registradas entre 1 e $8 \mathrm{~h}$ com média de $426 \mathrm{ppmv}$, quando as emissões são intensas, influenciaram a média do dia que ficou em 400 ppmv, em outros dias as médias foram de 470 ppmv no dia $22(+9,4 \%), 488$ ppmv no dia $26(+12,7 \%)$ e 468 ppmv dia $28(+8,9 \%)$, no mesmo intervalo de tempo. Não foi encontrada uma explicação para esta variação diferenciada, observada neste fase do dia 21. As médias diárias sofreram alterações durante o período de 23 a 25 , quando a ocorrência de chuvas modificou as condições atmosféricas dentro da floresta. Uma pequena diferença foi registrada nos valores das concentrações entre os níveis nesta fase. No dia 23 esta diferença foi de 13 ppmv, dia 24 somente 6 ppmv, enquanto que no dia 25 alcançou 12 ppmv. As maiores diferenças entre os níveis foram no dia 26 com 45 ppmv e no dia 27 com 39 ppmv, na média as diferenças entre os níveis foram de cerca de 24 ppmv.

A concentração média de $\mathrm{CO}_{2}$ para cada nível de medida, durante o período analisado (Figura 22) mostrou que os maiores valores foram encontrados nos níveis mais baixos, cerca de 410 e 409 ppmv nos níveis de 1 e 9m, respectivamente. Esta maior concentração média de $\mathrm{CO}_{2}$ nestes níveis foi devido à liberação de $\mathrm{CO}_{2}$ do solo, que foi 
produzido pela respiração das raízes, microorganismos e pela fauna existente no solo. Segundo Meir et al. (1996), as variações térmicas nas regiões tropicais fazem da respiração do solo uma componente altamente responsável pelo ciclo de carbono terrestre.

As concentrações foram diminuindo inversamente com a altura do perfil, atingindo cerca de 405 ppmv em 17,4m, aproximadamente 399 e 394 ppmv nos perfis de $25,3 \mathrm{~m}$ e $33,3 \mathrm{~m}$, respectivamente. Finalmente, registraram aproximadamente $387 \mathrm{ppmv}$ na altura de 46,5 m, já acima do dossel. A concentração média de $\mathrm{CO}_{2}$ foi cerca de 5,5\% maior nos níveis inferiores em relação às medidas acima da floresta.

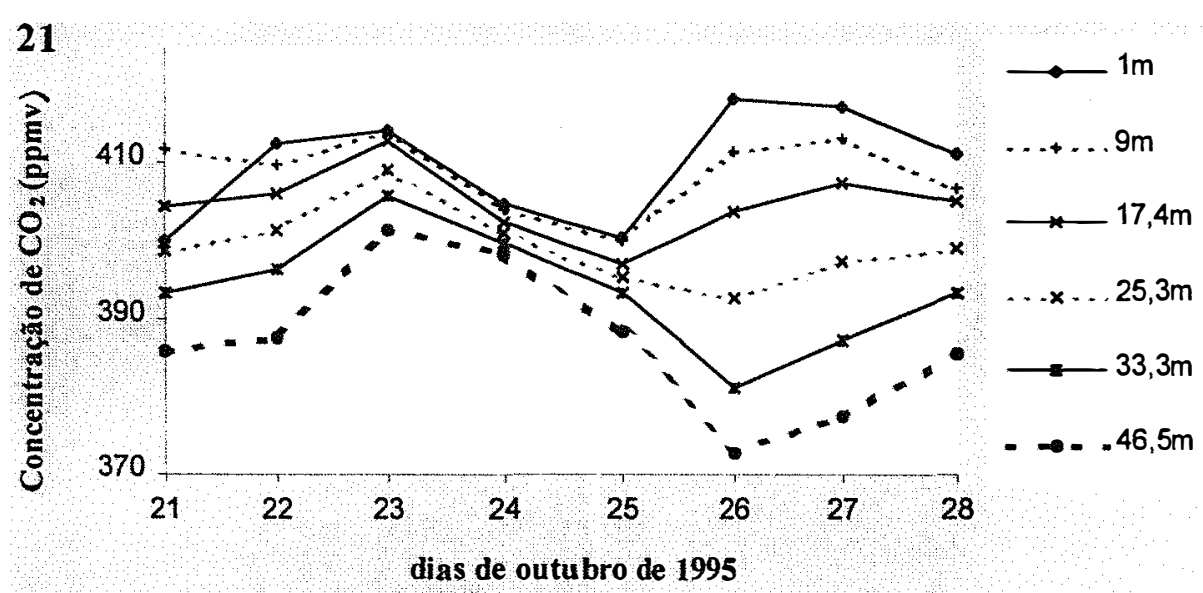

Figura 21 Valores diários médios da concentração de $\mathrm{CO}_{2}$ para diferentes alturas.

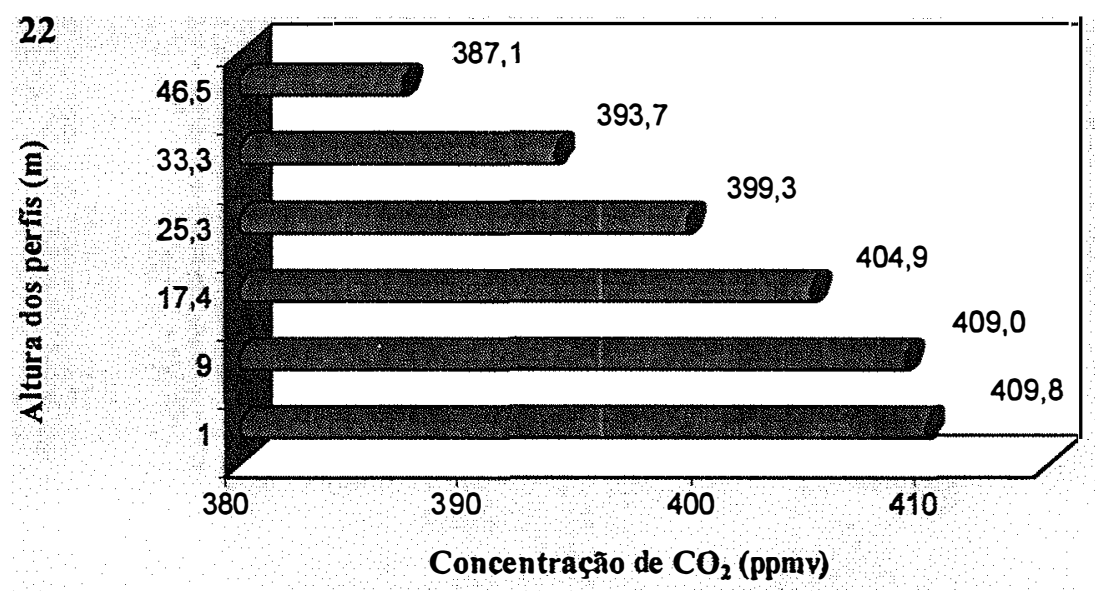

Figura 22 Concentração média de $\mathrm{CO}_{2}$ em seis diferentes alturas: $1 ; 9 ; 17,4 ; 25,3 ; 33,3$ e 46,5m. Os valores são médias do período de 21 a 28 de outubro de 1995. 


\subsection{Radiação solar incidente $(S)$}

A radiação solar é a fonte de energia que cria os processos que dão sustentabilidade à vida na Terra. A porção que incide sobre a superfície terrestre está na origem das atividades fisiológicas e meteorológicas, e torna possível a presença dos seres vivos no planeta.

A variação temporal de $S$ com dados horários (Figura 23a) na época seca, oscilou entre o máximo de $938 \mathrm{~W} \mathrm{~m}^{-2}$ às $12 \mathrm{~h}$ do dia 21 de outubro, e o menor pico dos máximos diários, que foi de $433 \mathrm{~W} \mathrm{~m}^{-2}$ às $10 \mathrm{~h}$ do dia 23 . Os valores registrados no dia 23 foram mais baixos devido à ocorrência de chuva entre 12 e 14 h, esta alteração provocou a menor taxa de $S$ integrada das 7 às $18 \mathrm{~h}$ de todo o período seco, que foi de 7,3 $\mathrm{MJ} \mathrm{m}^{-2} \mathrm{dia}^{-1}$. Outro dia que apresentou um valor abaixo da média do período na $S$ integrada foi o $24 \mathrm{com} 8,1 \mathrm{MJ} \mathrm{m}^{-2} \mathrm{dia}^{-1}$, a pesar de ter atingido um pico máximo horário de $736 \mathrm{~W} \mathrm{~m}^{-2}$ às $12 \mathrm{~h}$. Entretanto, a chuva ocorrida a partir das $13 \mathrm{~h}$ indo até às $16 \mathrm{~h}$, reduziu drasticamente a intensidade de $S$ sobre a floresta. A média horária de $S$, no intervalo das 13 às $18 \mathrm{~h}$ no dia 24 foi abaixo de $40 \mathrm{~W} \mathrm{~m}^{-2}$, enquanto que a média do período seco no mesmo intervalo de tempo foi de $256 \mathrm{~W} \mathrm{~m}^{-2}$. No dia 23 foi de $46 \mathrm{~W} \mathrm{~m}^{-2}$ e no dia 26 foi de aproximadamente $460 \mathrm{~W} \mathrm{~m}^{-2}$. O dia 26 foi o que apresentou o maior valor integrado de $S \operatorname{com} 21,7 \mathrm{MJ} \mathrm{m}^{-2} \mathrm{dia}^{-1}$.

Durante o período chuvoso, o máximo valor de $S$ foi de $1088 \mathrm{Wm}^{-2}$ registrado no dia 19 às $14 \mathrm{~h}$ (Figura 23a). O segundo maior pico horário ocorreu às $13 \mathrm{~h}$ do dia 21 sendo de $953 \mathrm{Wm}^{-2}$. Nos dias 21 e 22 não ocorreu chuva, entretanto não tiveram os maiores valores de $S$ integrada das 7 às $18 \mathrm{~h}$. Isso foi alcançado no dia 19 com 21,4 $\mathrm{MJ} \mathrm{m}^{-2} \mathrm{dia}^{-1}$, enquanto que nos dia 21 e 22 foram registrados 19,3 e 20,8 $\mathrm{MJ}$ $\mathrm{m}^{-2} \operatorname{dia}^{-1}$, respectivamente. $\mathrm{O}$ dia 19 mesmo tendo de ocorrência de chuvas só às registrou significativamente às $17 \mathrm{~h}$, quando a incidência da radiação solar já é mais atenuada pela camada atmosférica mais espessa pela qual atravessa. $\mathrm{O}$ menor pico horário ocorreu no dia 20 sendo de $399 \mathrm{Wm}^{-2}$ às $10 \mathrm{~h}$, este dia apresentou a ocorrência de chuva desde as $7 \mathrm{~h}$ prolongando-se de forma intermitente até quase o final da tarde. 
Este fato fez com que no dia 20 fosse registrado o menor valor de $S$ integrado, sendo de apenas 5,5 $\mathrm{MJ} \mathrm{m}^{-2} \mathrm{dia}^{-1}$. Este foi o menor valor obtido nos dois periodos de pesquisa.

Para os valores médios de $S$ calculados para as duas etapas do trabalho, o período chuvoso apresentou o máximo de $555 \mathrm{Wm}^{-2}$ às $14 \mathrm{~h}$. Enquanto que na fase seca o máximo às $11 \mathrm{~h}$ sendo $S$ de $688 \mathrm{Wm}^{-2}$ (Figura 23b). Feitosa et al. (1998) mostraram valores para o sudoeste da Amazônia da ordem de $680 \mathrm{Wm}^{-2}$ e $721 \mathrm{Wm}^{-2}$ para as épocas chuvosa e seca, respectivamente. A diferença entre os dois trabalhos foi de menos de $5 \%$ no período seco, enquanto no chuvoso foi de aproximadamente $23 \%$, sendo explicada pela alta variabilidade da nebulosidade existente na região amazônica durante a época das chuvas. Os valores médios integrados nos dois periodos foram de 14,4 e $15,2 \mathrm{MJ} \mathrm{m}^{-2}$ dia $^{-1}$, respectivamente para o chuvoso e no seco. Os dados apresentados por Feitosa et al. op.cit. foram cerca de $16 \%$ diferentes, da ordem de 17,1 e $18,3 \mathrm{MJ} \mathrm{m}^{-2} \mathrm{dia}^{-1}$, respectivamente.

A radiação solar incidente foi a variável que apresentou o melhor coeficiente de determinação da correlação $\left(R^{2}\right)$ com os fluxos de $\mathrm{CO}_{2}$. Estas correlações foram significativas na fase de seqüestro de $\mathrm{CO}_{2}$ pela vegetação, quando o fluxo de $\mathrm{CO}_{2}$ é negativo. Para os ajustes nas correlações polinomiais, durante o período seco o coeficiente foi de 0,86 (Figura 23c). Para a época chuvosa $R^{2}=0,72$ (Figura 23d). Estes bons ajustes nas correlações eram esperados, pois, parte da $S$ (aproximadamente 50\%) é utilizada nos processos fisiológicos da vegetação como radiação fotossinteticamente ativa RFA (ver item 2.4, Figura 6). Desta forma, a fotossintese é diretamente dependente da quantidade de radiação solar incidente. Durante a fase de emissão de $\mathrm{CO}_{2}$ para a atmosfera, que ocorre principalmente à noite, as correlações como seria esperado, não apresentaram coeficientes significativos. 

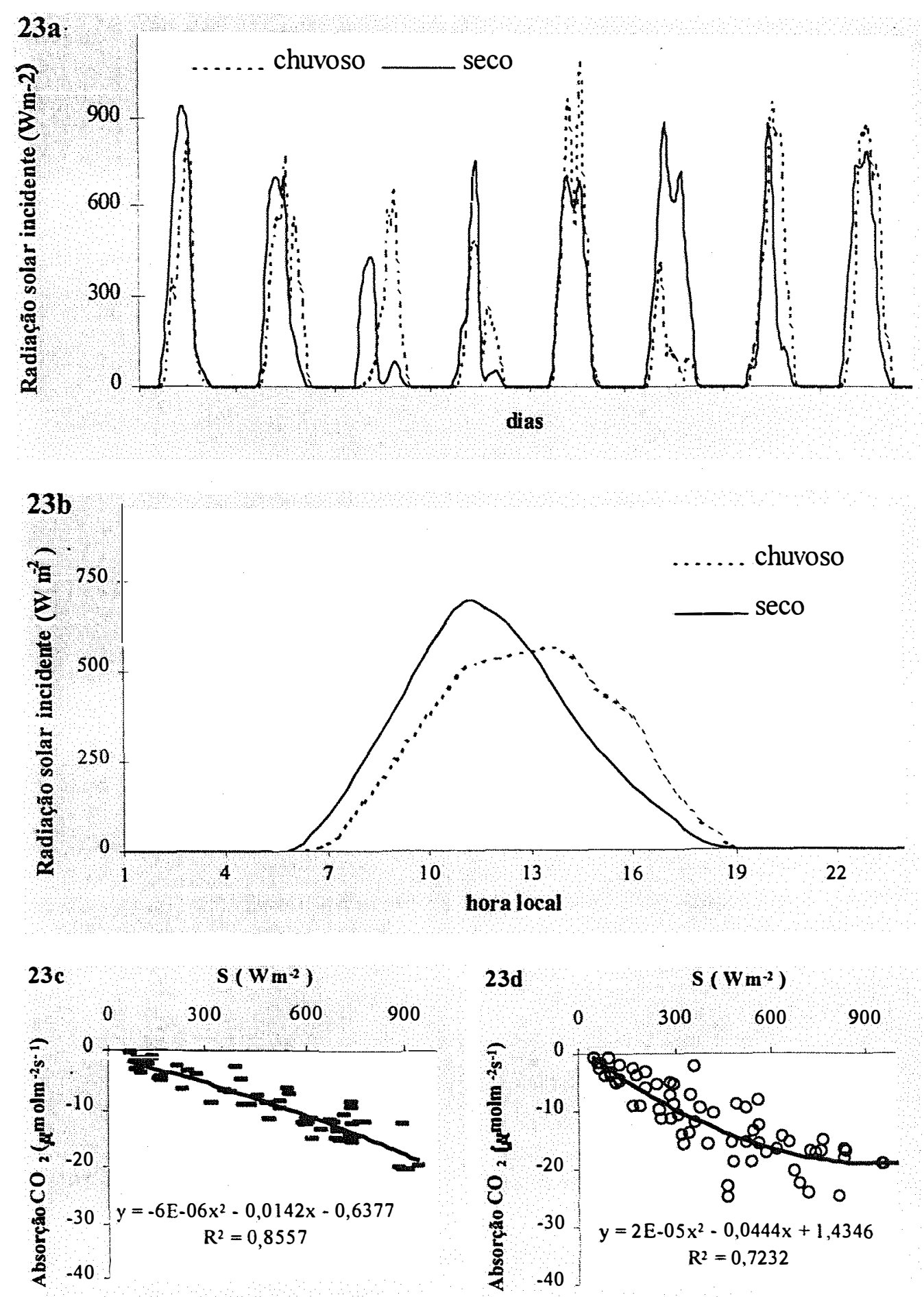

Figuras 23 Radiação solar incidente( $\boldsymbol{S}$ ): a) variação horária; b) ciclo médio diário; c) correlação de $S$ com absorção de carbono no período seco; d) correlação de $S$ com absorção de carbono no período chuvoso. 


\subsection{Radiação solar refletida $(S r)$}

A radiação solar refletida pela superficie $(S r)$ teve uma variação temporal que registrou o máximo de $122 \mathrm{~W} \mathrm{~m}^{-2}$ às $14 \mathrm{~h}$ do dia 19 de fevereiro (período chuvoso), cerca de $10 \%$ da radiação solar incidente $(S)$. Para o período seco o máximo foi de 115 $\mathrm{W} \mathrm{m}^{-2}$ ocorrido no dia 26 de outubro às $11 \mathrm{~h}$, aproximadamente $13 \%$ de $S$ (Figura 24a).

Durante a fase chuvosa, os máximos diários de $S r$ foram registrados em uma faixa horária ampla, indo desde as $10 \mathrm{~h}$ com $50 \mathrm{~W} \mathrm{~m}^{-2}$ no dia 20 até as $16 \mathrm{~h}$ no dia 17 com $80 \mathrm{~W} \mathrm{~m}^{-2}$. Esta amplitude do horário de ocorrência dos picos máximos diários durante o período chuvoso, esteve associada à grande variabilidade de existência de nebulosidade, pois as chuvas ocorrem em praticamente todos os horários (ver item 4.1., figura 14)

Para o período seco, os valores mais elevados de $S r$ diários ocorreram entre $10 \mathrm{~h}$ nos dias 22, 23, 25 e 28, e $12 \mathrm{~h}$ para os dias 21,24 e 27 . Novamente a amplitude de ocorrência dos máximos esteve vinculada às chuvas, que no período ocorreram mais significativamente a partir das $13 \mathrm{~h}$, afetando diretamente a radiação solar incidente e por relação a radiação refletida.

Os valores médios de $\mathrm{Sr}$ atingiram no período chuvoso o máximo de $66 \mathrm{~W}$ $\mathrm{m}^{-2}$ às $12 \mathrm{~h}$, cerca de $12 \%$ de $S$ e durante o período seco atingiu $88 \mathrm{~W} \mathrm{~m}^{-2}$ às $11 \mathrm{~h}$, aproximadamente $13 \%$ de $S$ (Figura 24b). A integração de $S r$ no intervalo de 7 às $18 \mathrm{~h}$ registrou 1,7 e $2,0 \mathrm{MJ} \mathrm{m}^{-2} \mathrm{dia}^{-1}$ nos períodos chuvoso e seco, respectivamente, representando 12 e $13 \%$ do total da radiação solar incidente nos dois períodos.

As correlações polinomiais entre $\mathrm{Sr}$ e os fluxos de $\mathrm{CO}_{2}$ apresentaram bons coeficientes quando da fase de absorção de $\mathrm{CO}_{2}$ pela floresta (fluxos negativos). Para a época seca $R^{2}=0,83$ (Figura $24 \mathrm{c}$ ), enquanto que no período chuvoso $R^{2}=0,73$ (Figura 24d). 

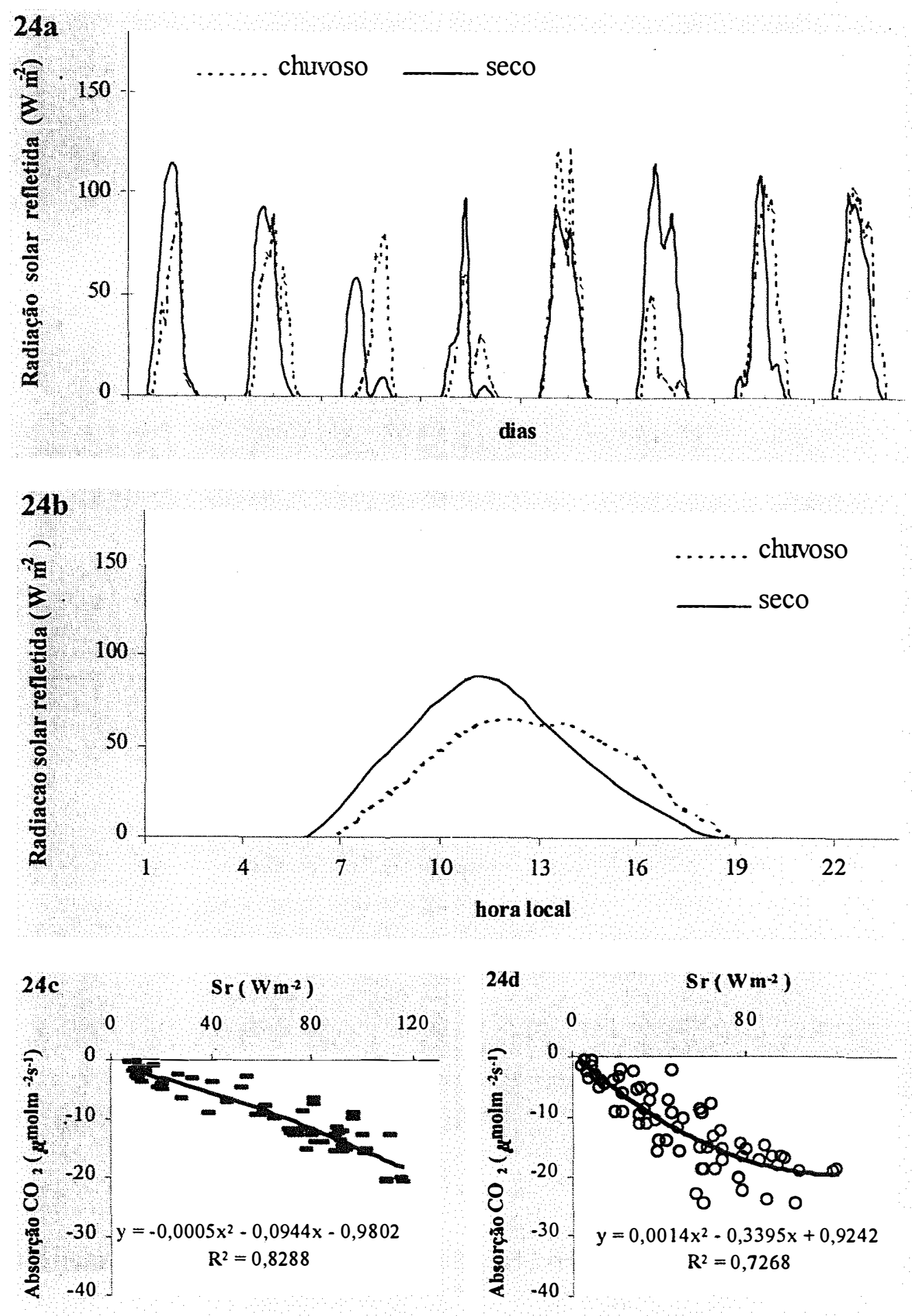

Figuras 24 Radiação solar refletida (Sr): a) variação horária; b) ciclo médio diário; c) correlação de $S r$ com absorção de carbono no período seco; d) correlação de $\mathrm{Sr}$ com absorção de carbono no período chuvoso. 


\subsection{Saldo de radiação $(R n)$}

A variação do saldo de radiação $(R n)$ ou radiação líquida, durante o período chuvoso apresentou o maior valor diário $\left(940 \mathrm{~W} \mathrm{~m}^{-2}\right)$ às $14 \mathrm{~h}$ do dia 19 de fevereiro, representanto cerca de $86 \%$ da radiação solar incidente $(S)$ neste dia (Figura 25a). Nesta etapa, os picos máximos diários de $R n$ ocorreram principalmente às $13 \mathrm{~h}$ registrados em quatro dos oito dias analisados. O menor desses picos diários foi registrado às $10 \mathrm{~h}$ do dia 20 , sendo de $331 \mathrm{~W} \mathrm{~m}^{-2}$. Os máximos diários foram medidos entre 10 e $16 \mathrm{~h}$. No período seco, o máximo diário foi de $731 \mathrm{~W} \mathrm{~m}^{-2}$ às $12 \mathrm{~h}$ do dia 21 (cerca de $78 \%$ de $S$ neste dia), vindo em seguida $717 \mathrm{~W} \mathrm{~m}^{-2}$ e $691 \mathrm{~W} \mathrm{~m}^{-2}$ às $12 \mathrm{~h}$ do dia 27 e às $11 \mathrm{~h}$ do dia 26 , respectivamente. $\mathrm{O}$ menor pico diário foi de $344 \mathrm{~W} \mathrm{~m}^{-2}$ registrado no dia 23 às $10 \mathrm{~h}$.

Para os valores médios de $R n$, no período chuvoso o máximo ocorreu às $13 \mathrm{~h}$ com $487 \mathrm{~W} \mathrm{~m}^{-2}$ aproximadamente $88 \%$ de $S$ (Figura 25b). No intervalo das 7 às $18 \mathrm{~h} \mathrm{o}$ valor integrado de $R n$ no período chuvoso foi de $11,9 \mathrm{MJ} \mathrm{m}^{-2} \mathrm{dia}^{-1}$ representando cerca de $83 \%$ da radiação solar incidente no período. Para a época seca, o $R n$ máximo foi de $541 \mathrm{~W} \mathrm{~m}^{-2}$ às $11 \mathrm{~h}$, equivalente a aproximadamente $79 \%$ de $S$, sendo que o valor de $R n$ integrado das 7 as $18 \mathrm{~h}$ foi de $11,5 \mathrm{MJ} \mathrm{m}^{-2} \mathrm{dia}^{-1}$, aproximadamente $76 \%$ de $S$ nesta fase de medidas.

O saldo de radiação apresentou bons coeficientes nas correlação com os fluxos negativos de $\mathrm{CO}_{2}$, o seqüestro de carbono da atmosfera pela vegetação. As regressões polinomiais determinaram um $R^{2}=0,75$ durante o período chuvoso (Figura 25c). Para a época seca o $R^{2}=0,85$ no seqüestro de $\mathrm{CO}_{2}$, sendo este o segundo melhor coeficiente entre todas as variáveis analisadas e os fluxos de $\mathrm{CO}_{2}$ na floresta (Figura $25 d)$. 

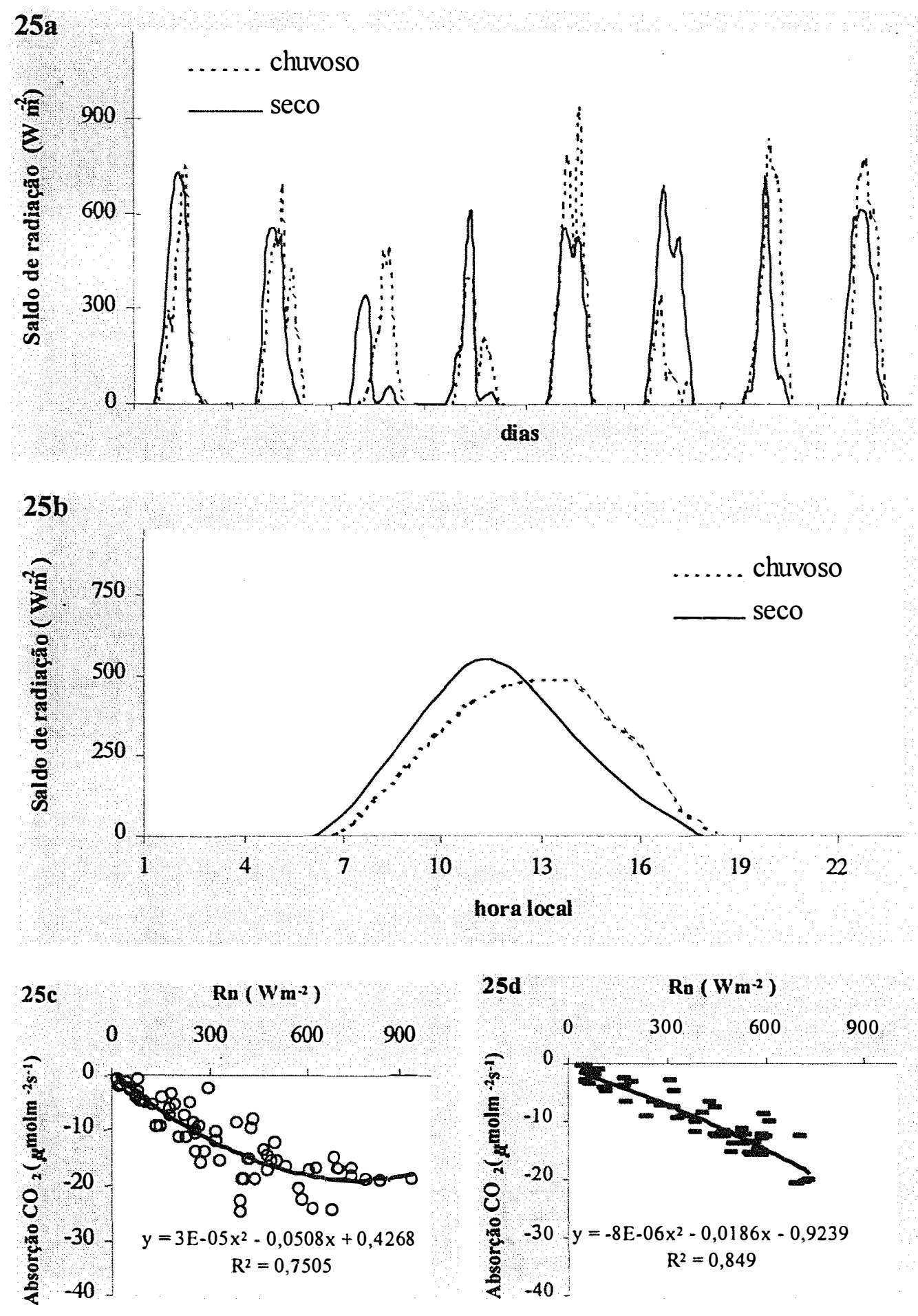

Figuras 25 Saldo de radiação ( $R \boldsymbol{n}$ ): a) variação horária; b) ciclo médio diário; c) correlação de $R n$ com absorção de carbono no período chuvoso; d) correlação de $R n$ com absorção de carbono no período seco. 


\subsection{Fluxo de calor sensível $(H)$}

O fluxo de calor sensível $(H)$, que é parte da energia utilizada no aquecimento atmosférico, apresentou variabilidade temporal (Figura 26a) oscilando na época chuvosa entre o máximo de $255 \mathrm{Wm}^{-2}$ registrado às $11 \mathrm{~h}$ do dia 19 de fevereiro, representando cerca de $32 \%$ do saldo de radiação $(R n)$ nesta hora, e o menor pico diário de $61 \mathrm{Wm}^{-2}$ às $10 \mathrm{~h}$ do dia 20. Os valores máximos diários ocorreram entre $10 \mathrm{e} 16 \mathrm{~h}$. Para o período seco, os máximos diários foram registrados entre 9 e $13 \mathrm{~h}$, sendo o maior de $305 \mathrm{Wm}^{-2}$ registrado às $13 \mathrm{~h}$ do dia 21 de outubro, aproximadamente $44 \%$ do valor de $R n$ neste horário, seguido de $210 \mathrm{Wm}^{-2}$ às $12 \mathrm{~h}$ do dia 27 . Os menores picos diários

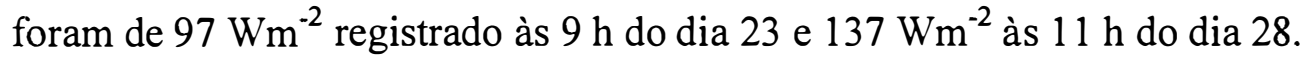

Para os valores médios de $H$ os registros máximos foram de $116 \mathrm{Wm}^{-2}$ às 12 h no período chuvoso (aproximadamente $24 \%$ de $R n$ ), e no período seco foi de $143 \mathrm{Wm}^{\text {- }}$ ${ }^{2}$ também às $12 \mathrm{~h}$, cerca de $26 \%$ de $R n$ (Figura 26b). Os valores integrados (das 7 às 18 h) foram de 2,3 e 2,5 $\mathrm{MJ} \mathrm{m}^{-2} \mathrm{dia}^{-1}$ para os períodos chuvoso e seco, respectivamente, representando cerca de $19 \%$ de $R n$ no período chuvoso e aproximadamente $22 \%$ de $R n$ durante a época seca.

As correlações entre $H$ e os fluxos negativos do $\mathrm{CO}_{2}$ foram de $R^{2}=0,77$ na época seca (Figura 26c), enquanto no período chuvoso $R^{2}=0,69$ (Figura 26d).

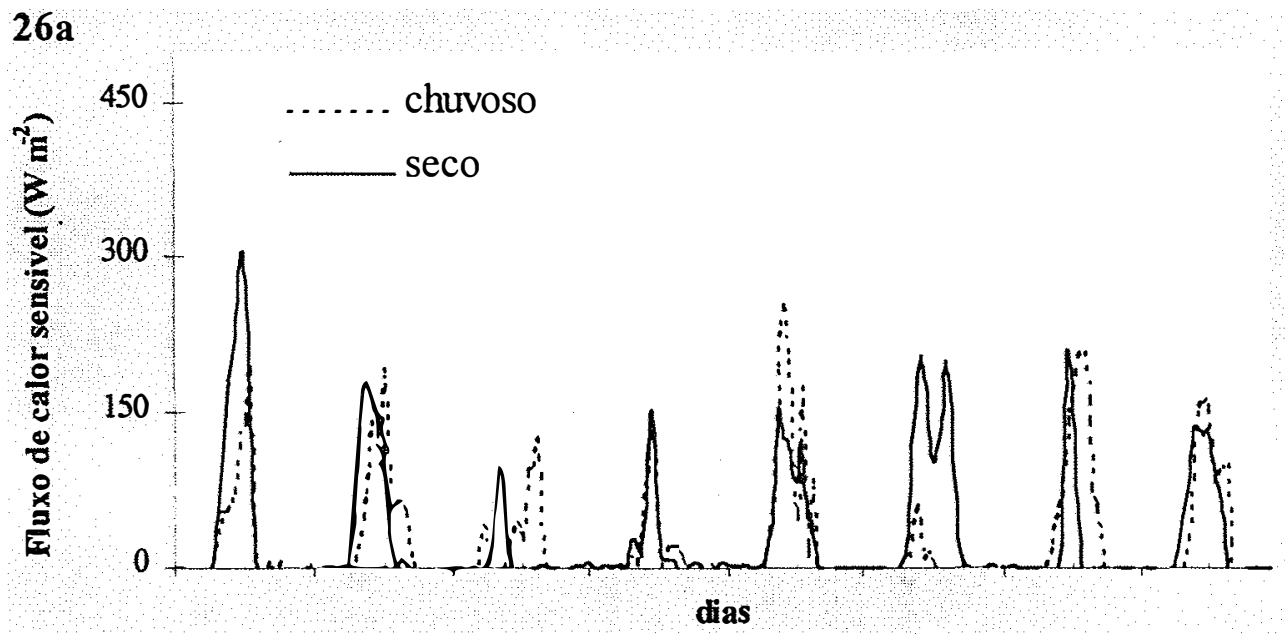

Figura 26a Variação horária do fluxo de calor sensível $(H)$. 

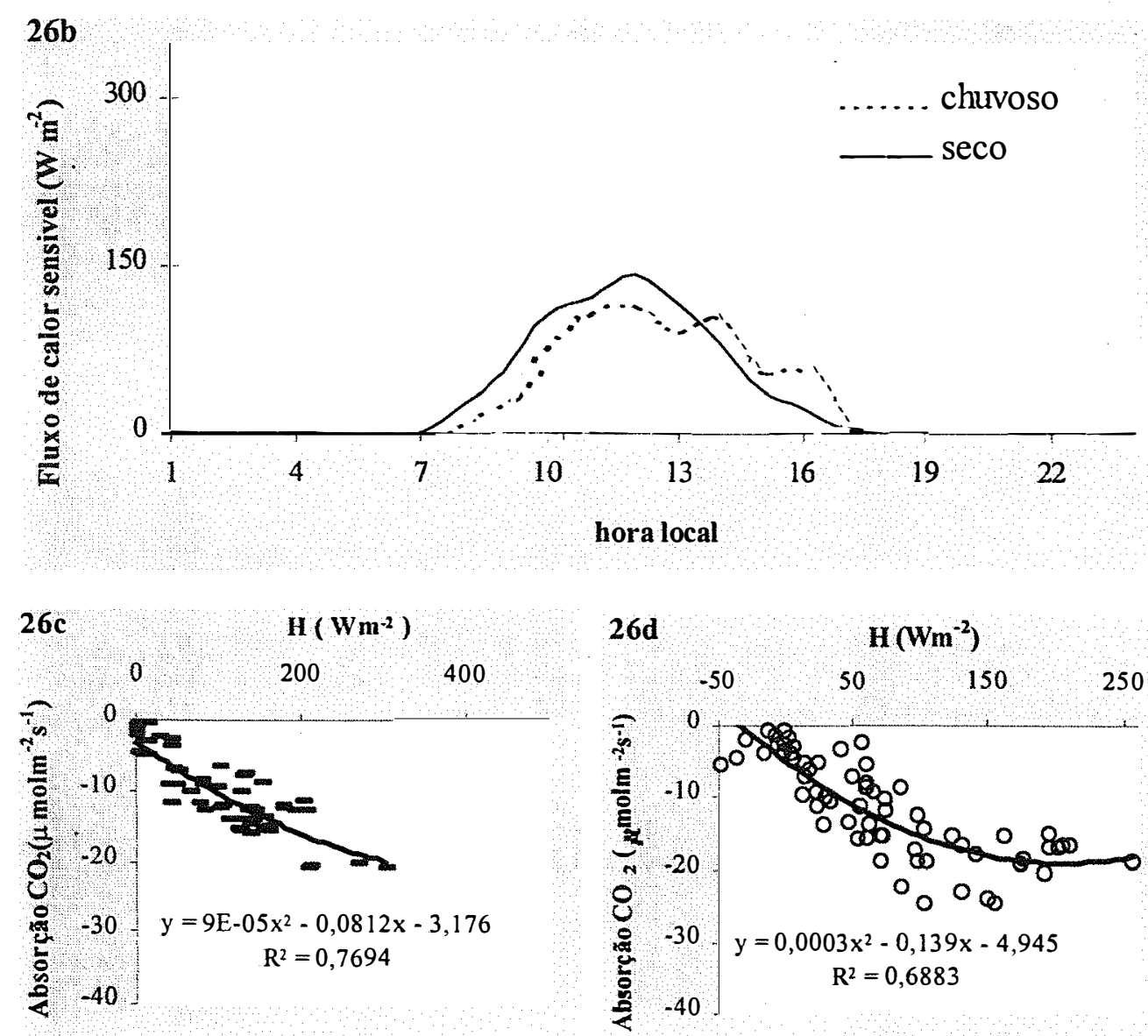

Figuras 26 Fluxo de calor sensível $(\boldsymbol{H})$ : b) ciclo médio diário; c) correlação de $H$ com absorção de carbono no período seco; d) correlação de $H$ com absorção de carbono no período chuvoso.

\subsection{Fluxo de calor latente $(L E)$}

O fluxo de calor latente $(L E)$ é a parte da energia utilizada no processo de evapotranspiração da umidade disponível no ambiente. Como seria esperado, durante a época chuvosa os valores de $L E$ foram superiores aos registrados no período seco, pois existe maior quantidade de água presente no solo. A variação temporal registrou o valor máximo diário foi de $476 \mathrm{~W} \mathrm{~m}^{-2}$ às $14 \mathrm{~h}$ do dia 22 de fevereiro, cerca de $81 \%$ do valor do saldo de radiação $(R n)$ (Figura 27a). Outros valores máximos foram de $457 \mathrm{~W} \mathrm{~m}^{-2}$ às $14 \mathrm{~h}$ do dia $19,412 \mathrm{~W} \mathrm{~m}^{-2}$ às $15 \mathrm{~h}$ do dia $21 \mathrm{e} 297 \mathrm{~W} \mathrm{~m}^{-2}$ às $13 \mathrm{~h}$ do dia 16 . Os menores 
picos diários foram de $137 \mathrm{~W} \mathrm{~m}^{-2}$ no dia 20 às $10 \mathrm{~h}$ e de $190 \mathrm{~W} \mathrm{~m}^{-2}$ às $12 \mathrm{~h}$ do dia 18 . No período chuvoso, o maior valor integrado de 7 às $18 \mathrm{~h}$ foi de $8,7 \mathrm{MJ} \mathrm{m}^{-2} \mathrm{dia}^{-1}$ no dia 19 , enquanto que o menor foi de $1,4 \mathrm{MJ} \mathrm{m}^{-2} \mathrm{dia}^{-1}$ no dia 20 .

Para a época seca, os máximos diários foram de $420 \mathrm{~W} \mathrm{~m}^{-2}$ às $13 \mathrm{~h}$ do dia 21 , cerca de $60 \%$ de $R n$ e de $406 \mathrm{~W} \mathrm{~m}^{-2}$ às $11 \mathrm{~h}$ do dia 26 de outubro. Os picos máximos diários com menores valores ocorreram às $10 \mathrm{~h}$ do dia $23 \mathrm{com} 77 \mathrm{~W} \mathrm{~m}^{-2} \mathrm{e}$ às $12 \mathrm{~h}$ do dia 24 com $159 \mathrm{~W} \mathrm{~m}^{-2}$. O dia 26 de outubro apresentou o maior valor integrado de $L E$, sendo de $8,0 \mathrm{MJ} \mathrm{m}^{-2} \mathrm{dia}^{-1}$, seguido do dia 21 quando atingiu 6,2 $\mathrm{MJ} \mathrm{m}^{-2} \mathrm{dia}^{-1}$. Os dias 23 e 24 registraram os menores valores integrados, sendo de 1,1 e $1,3 \mathrm{MJ} \mathrm{m}^{-2} \mathrm{dia}^{-1}$, respectivamente.

Para o ciclo diário médio, no período chuvoso o $L E$ máximo foi às $14 \mathrm{~h}$ com $251 \mathrm{~W} \mathrm{~m}^{-2}$, cerca de $52 \%$ de $R n$, enquanto que o período seco registrou o maior valor às $12 \mathrm{~h}$ sendo de $219 \mathrm{~W} \mathrm{~m}^{-2}$, aproximadamente $41 \%$ de $R n$ (Figura 27b). Os valores médios de $L E$ integrados das 7 às $18 \mathrm{~h}$ foram de $4,2 \mathrm{MJ} \mathrm{m}^{-2} \mathrm{dia}^{-1}$ no período seco, representando cerca de $37 \%$ de $R n$ no período. Enquanto que na época chuvosa, o valor médio foi de $5,2 \mathrm{MJ} \mathrm{m}^{-2} \mathrm{dia}^{-1}$, aproximadamente $24 \%$ acima do período seco e cerca de $44 \%$ de $R n$.

As correlações polinomiais entre os fluxos de $\mathrm{CO}_{2}$ e $L E$ apresentaram valores de $R^{2}=0,70$ na fase de absorção de carbono pela floresta na época seca (Figura $27 \mathrm{c}$ ) e de $R^{2}=0,67$ também para absorção durante a fase chuvosa (Figura 27d).

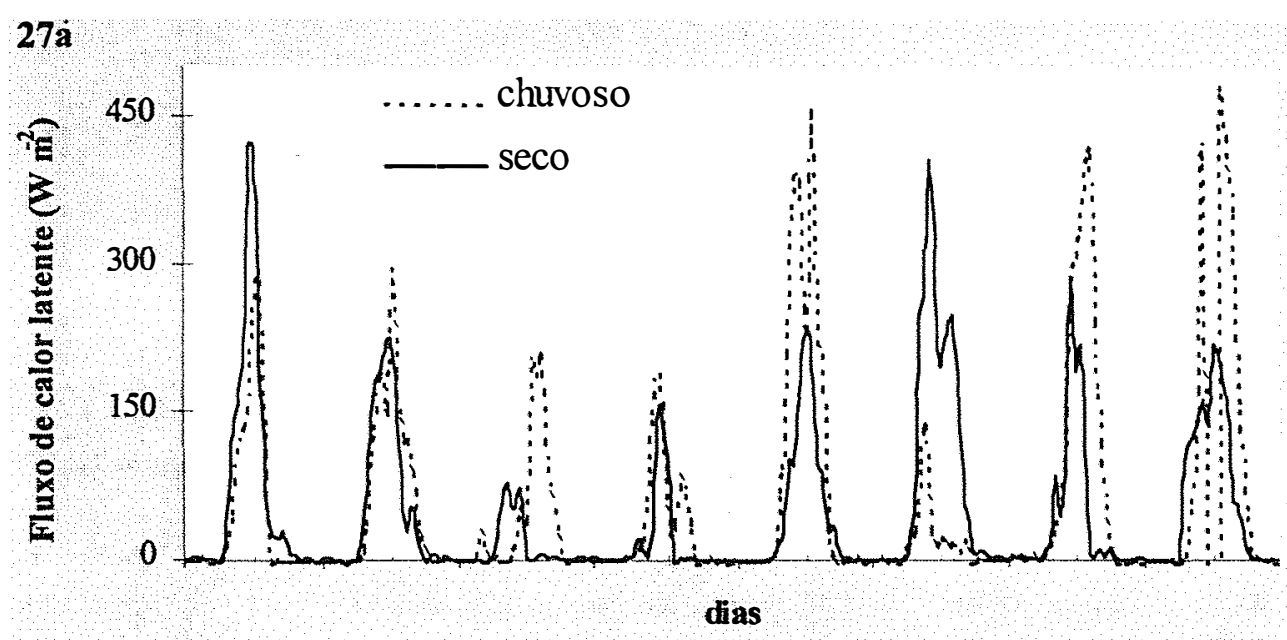

Figura 27a Variação horária do fluxo de calor latente $(\boldsymbol{L E})$. 

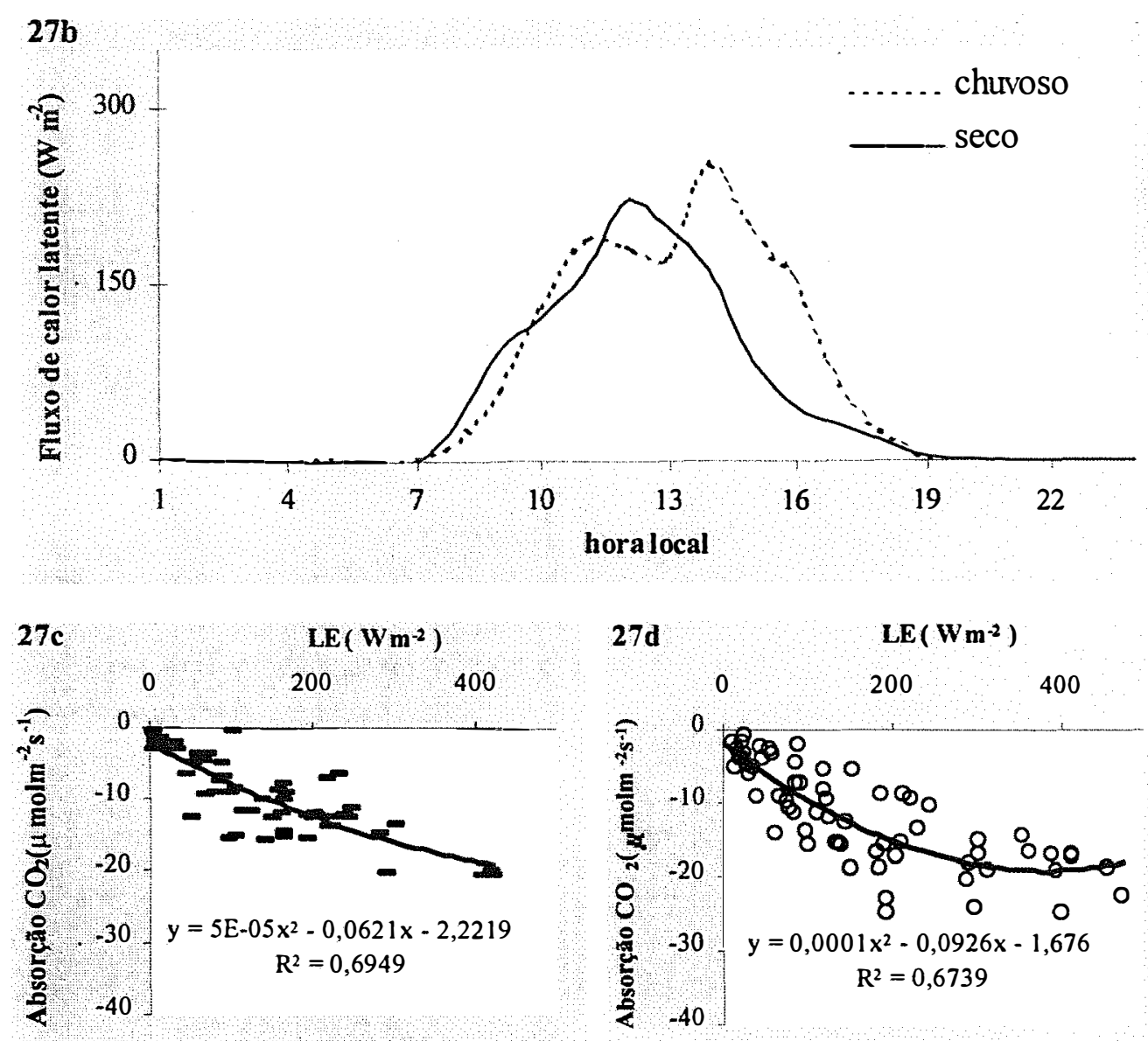

Figuras 27 Fluxo de calor latente $(\boldsymbol{L E})$ : b) ciclo médio diário; c) correlação de $L E$ com absorção de carbono no período seco; d) correlação de $L E$ com absorção de carbono no período chuvoso.

\subsection{Velocidade de friç̧ão $\left(u^{*}\right)$}

A velocidade de friç̧ão $\left(u^{*}\right)$ atingiu, durante a fase chuvosa $0,70 \mathrm{~m} \mathrm{~s}^{-1}$ às 11 $\mathrm{h}$ do dia 22 de fevereiro, sendo este o valor máximo diário do período. Nesta época do ano, os máximos diários oscilaram em torno de $0,50 \mathrm{~m} \mathrm{~s}^{-1}$, geralmente entre $11 \mathrm{e} 15 \mathrm{~h}$. Para o período seco, o maior valor diário de $u^{*}$ alcançou $0,83 \mathrm{~m} \mathrm{~s}^{-1}$ às $13 \mathrm{~h}$ do dia 24 , sendo o mais alto registrado no período e representando quase o dobro do valor médio para este horário $\left(0,43 \mathrm{~m} \mathrm{~s}^{-1}\right)$ na época analisada. No dia 27 às $9 \mathrm{~h}$ foi registrado o valor de $0,77 \mathrm{~m} \mathrm{~s}^{-1}$ pouco mais que o triplo da média da hora $\left(0,25 \mathrm{~m} \mathrm{~s}^{-1}\right)$, e no dia 23 às $12 \mathrm{~h}$ 
foi registrado o valor de $0,66 \mathrm{~m} \mathrm{~s}^{-1}$ mais que o dobro da média $\left(0,32 \mathrm{~m} \mathrm{~s}^{-1}\right)$ (Figura 28a). Quanto maior for o valor de $u^{*}$, mais misturada estará a atmosfera ambiente.

No ciclo diário médio (Figura 28b) os valores máximos de $u^{*}$ foram de 0,43 $\mathrm{m} \mathrm{s}^{-1}$ às $13 \mathrm{~h}$ durante o período seco, e $0,38 \mathrm{~m} \mathrm{~s}^{-1}$ às $14 \mathrm{~h}$ na fase chuvoso. A média do período seco foi de $0,15 \mathrm{~m} \mathrm{~s}^{-1}$, aproximadamente $71 \%$ da média do período chuvoso que foi de $0,21 \mathrm{~m} \mathrm{~s}^{-1}$.

A velocidade de friç̧ão foi a variável que apresentou correlação linear com os fluxos positivos de carbono (a emissão de $\mathrm{CO}_{2}$ para a atmosfera). Como os fluxos positivos são majoritariamente noturnos, as variáveis que são diretamente dependentes da radiação solar incidente só apresentaram correlações satisfatórias durante o período diurno (quando ocorrem os fluxos negativos de $\mathrm{CO}_{2}$ ) na fase de absorção de $\mathrm{CO}_{2}$ pela floresta. No caso de $u^{*}$, esta dependência direta não prevaleceu, possibilitando a correlação com a emissão de $\mathrm{CO}_{2}$. Durante o período seco o coeficiente de determinação foi de 0,27 o maior para as emissões de $\mathrm{CO}_{2}$ nesta época do ano. Para a época chuvosa $R^{2}=0,34$ (Figura 28c), o segundo melhor do período chuvoso nas emissões, ficando atrás somente da correlação com a precipitação, que também não foi dependente somente da radiação solar ocorrendo praticamente durante todo o dia.

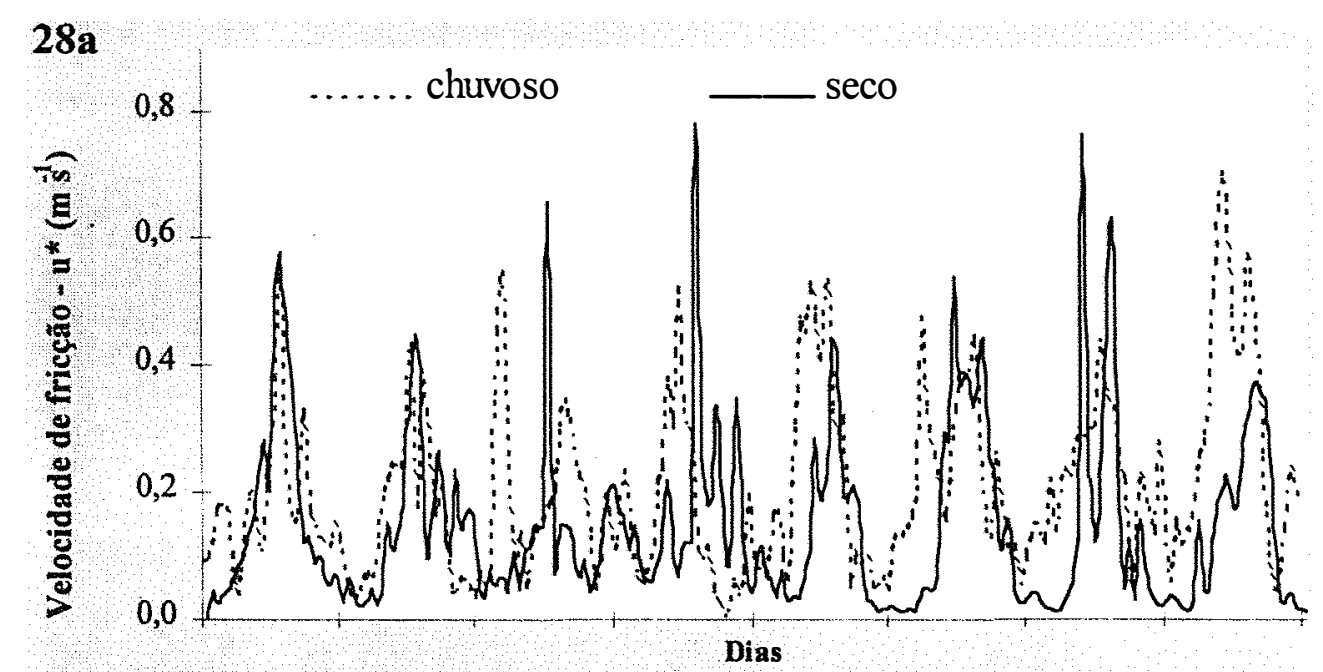

Figura 28a Variação horária da Velocidade de friç̧ão $\left(\boldsymbol{u}^{*}\right)$. 

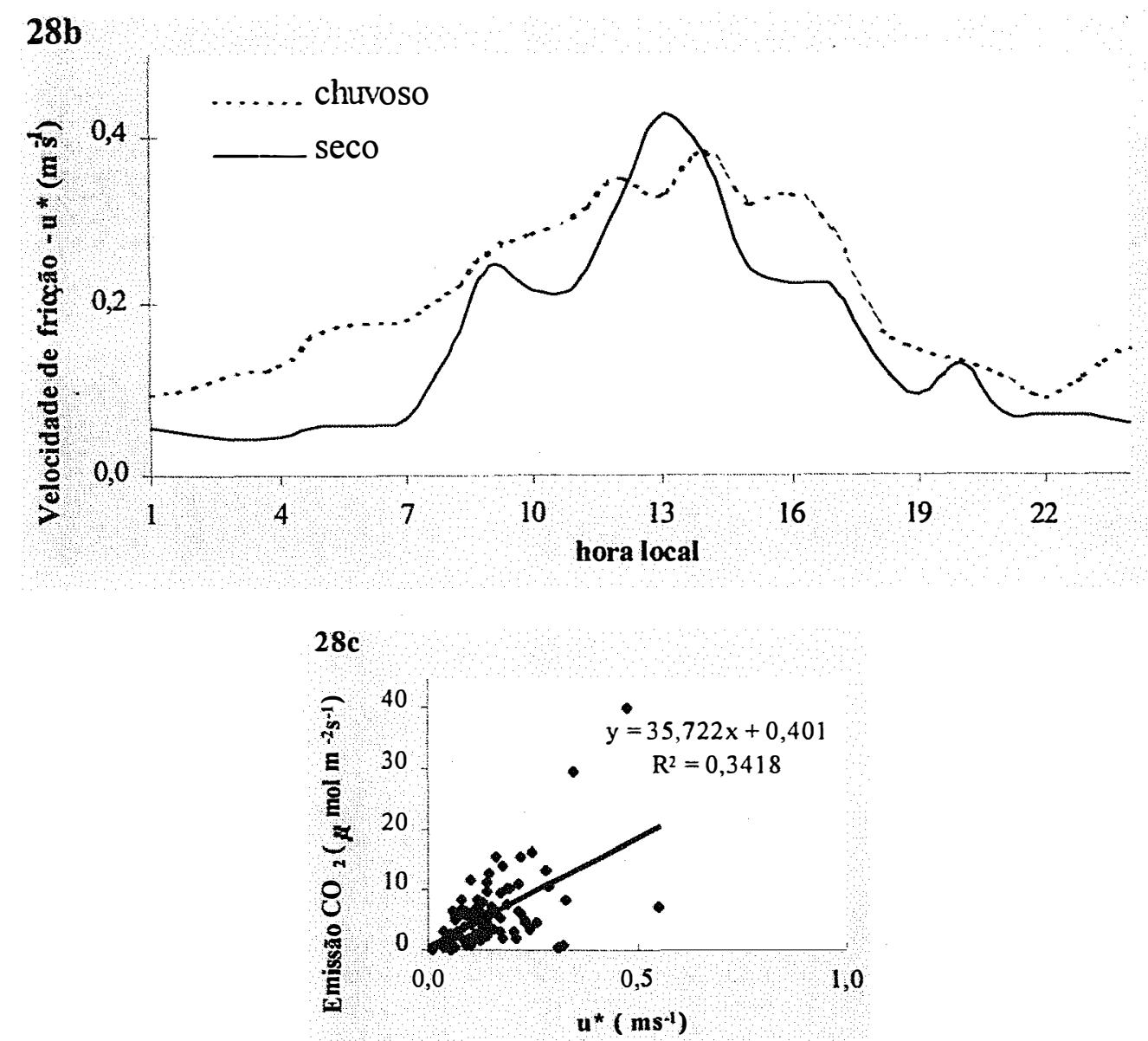

Figuras 28 Velocidade de fricção $\left(\boldsymbol{u}^{*}\right)$ : b) ciclo médio diário; c) correlação linear com os fluxos positivos de carbono (emissão) no período chuvoso.

\subsection{Temperatura do ar (Ta)}

A variação temporal da temperatura do ar $(T a)$ apresentada na Figura 29a., registrou o pico máximo diário às $15 \mathrm{~h}$ do dia 26 de outubro, período seco, sendo de 32,6 ${ }^{\circ} \mathrm{C}$. Os máximos diários neste período ocorreram entre 11 e $16 \mathrm{~h}$, sendo na média de 30,5 ${ }^{\circ} \mathrm{C}$. Os valores mínimos de $\mathrm{Ta}$ neste período foram registrados principalmente entre 5 e 7 $\mathrm{h}$ com o menor valor às $6 \mathrm{~h}$ do dia $25 \operatorname{com} 20,2^{\circ} \mathrm{C}$. As amplitudes térmicas diárias foram, em média, de $8,2{ }^{\circ} \mathrm{C}$ no período seco, sendo que o maior valor ocorreu dia 25 $\operatorname{com} 10,1^{\circ} \mathrm{C}$. 
Para o chuvoso, o máximo valor de $T a$ foi registrado às $15 \mathrm{~h}$ do dia 22 de fevereiro com $31,1^{\circ} \mathrm{C}$. O menor valor foi de $21,4^{\circ} \mathrm{C}$ registrado às $6 \mathrm{~h}$ do dia 21 . No dia 21 também foi determinada a maior amplitude térmica diária, sendo de $8,3^{\circ} \mathrm{C}$. A média das amplitudes, neste período, foi de $6,5^{\circ} \mathrm{C}$.

O ciclo médio (Figura 29b) no período chuvoso apresentou a Ta máxima de $27,2{ }^{\circ} \mathrm{C}$ às $14 \mathrm{~h}$. No período seco o máximo valor de $\mathrm{Ta}$ foi de $29,4^{\circ} \mathrm{C}$ às $12 \mathrm{~h}$ cerca de $8 \%$ a mais que no chuvoso. As mínima foram de 22,2 e $22,5^{\circ} \mathrm{C}$, respectivamente. As amplitudes médias foram de 5 e $6,9^{\circ} \mathrm{C}$ para o chuvoso e seco, respectivamente.

A $T a$ apresentou na época seca $R^{2}=0,31$ e na época chuvosa $R^{2}=0,18$, ambos na fase de absorção de $\mathrm{CO}_{2}$ da atmosfera (fluxos negativos).

29a
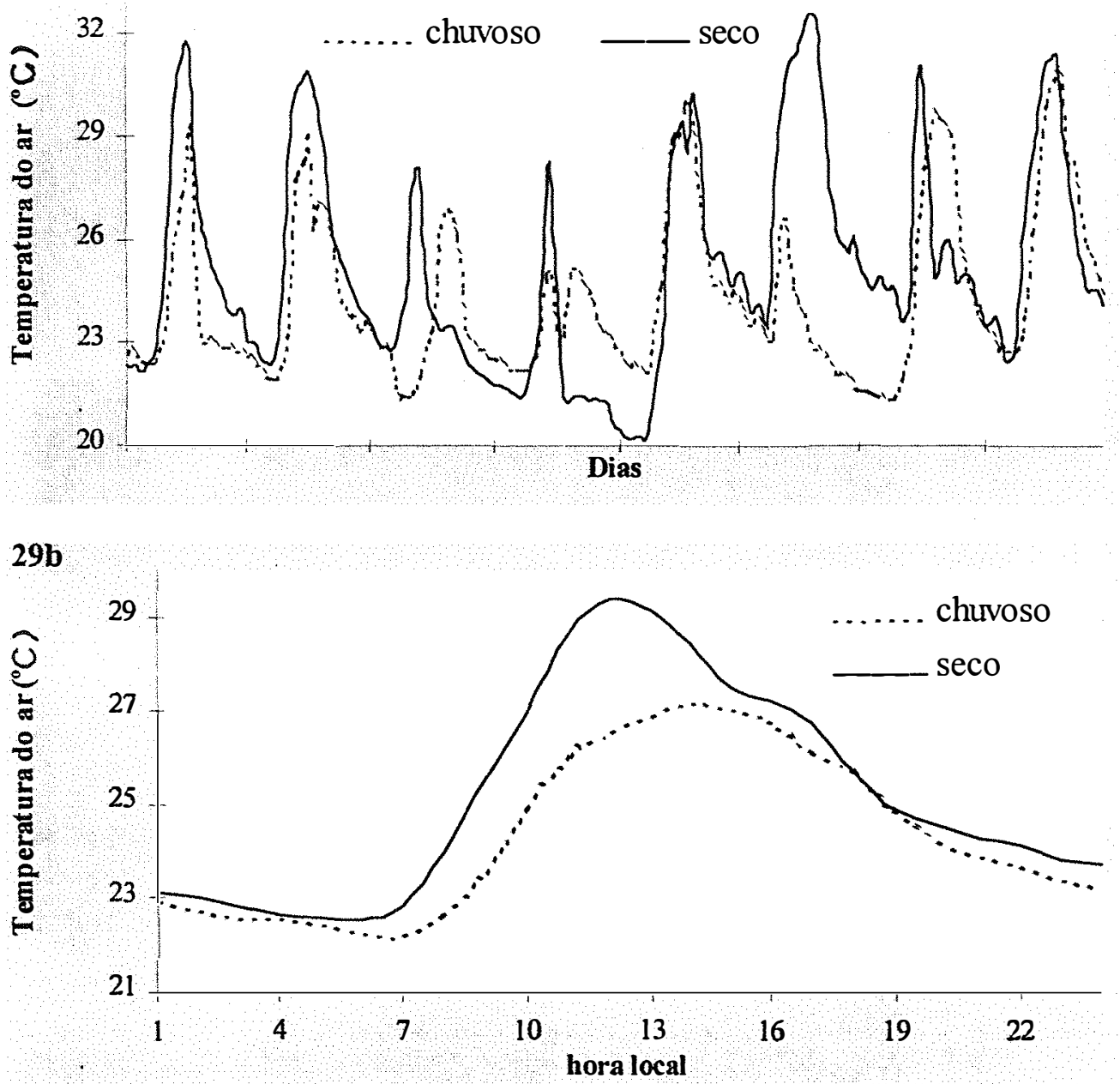

Figuras 29 Temperatura do ar (Ta): a) variação horária; b) ciclo médio diário. 


\subsection{Temperatura do solo $(T s)$}

A temperatura do solo $(T s)$ medida a $5 \mathrm{~cm}$ de profundidade apresentou variabilidade durante o período seco entre $26,7^{\circ} \mathrm{C}$ às $14 \mathrm{~h}$ do dia 21 e $22,8^{\circ} \mathrm{C}$ às $7 \mathrm{~h}$ do dia 25 (Figura 30a), os valores máximos diários foram registrados entre $11 \mathrm{e} 17 \mathrm{~h}$. Durante o período chuvoso a máxima $T s$ foi de $25,7^{\circ} \mathrm{C}$ às $16 \mathrm{~h}$ do dia 22 de fevereiro. Durante esta época os máximos diários oscilaram entre 13 e 19 h. O registro de menor valor foi de $22,5^{\circ} \mathrm{C}$ ocorrido às $9 \mathrm{~h}$ do dia 17 . As amplitudes de $T s$ foram entre $0,7{ }^{\circ} \mathrm{C} \mathrm{e}$ $2{ }^{\circ} \mathrm{C}$ durante o período chuvoso e entre $1,4^{\circ} \mathrm{C}$ e $2,9^{\circ} \mathrm{C}$ na época seca.

Para o ciclo médio diário os valores máximos de $T s$ foram de $24,7^{\circ} \mathrm{C}$ no período chuvoso, e de $25,7^{\circ} \mathrm{C}$ na época seca, aproximadamente $4 \%$ mais quente que no período chuvoso. Estes registros ocorreram às 15 e 14 hs respectivamente (Figura 30b).

O melhor coeficiente obtido nas correlações polinomiais entre $T s$ e os fluxos de $\mathrm{CO}_{2}$ fai 0,07 na fase de emissão de $\mathrm{CO}_{2}$ para a atmosfera durante o período chuvoso, mostrando que não houve correlação. Este resultado contrariou as expectativas de uma boa correlação entre a $T s$ e a liberação de carbono pelo solo (respiração), pois, Meir et al. (1996) consideraram as oscilações térmicas (ar e solo) nos trópicos importantes na respiração do solo e conseqüentemente no ciclo do carbono terrestre. Desta forma, sugere-se que seja feito um estudo mais detalhado sobre o assunto.

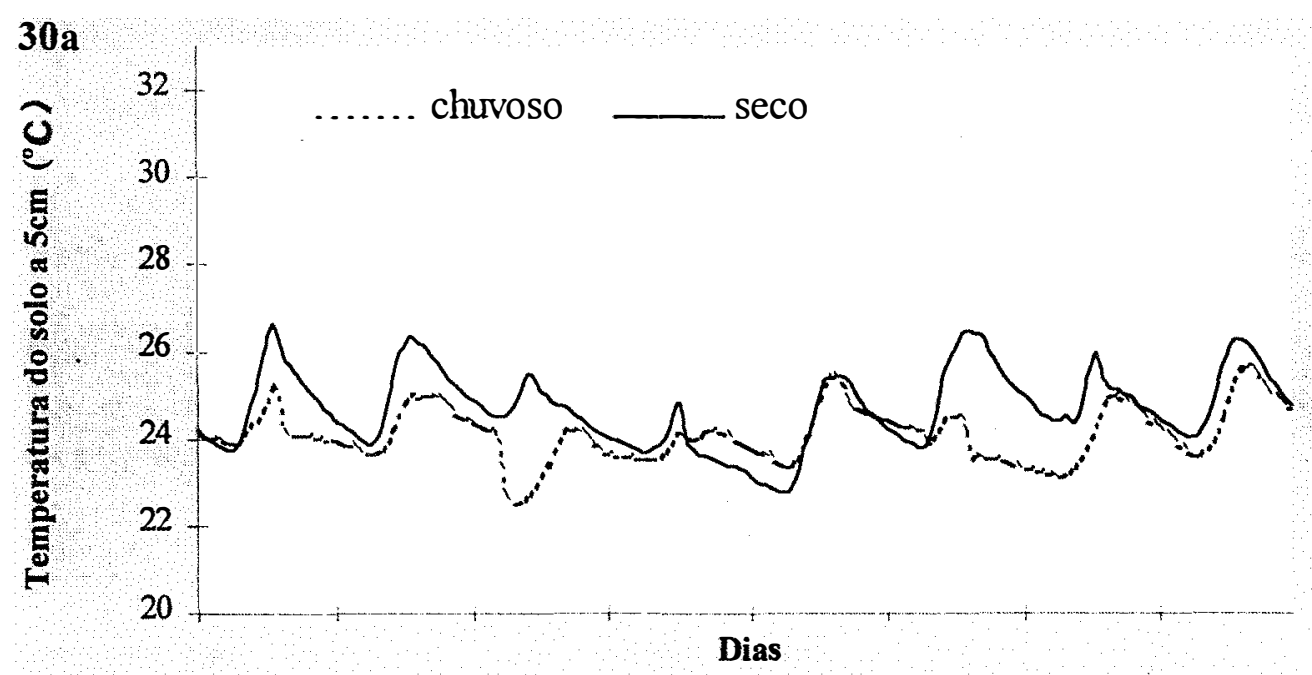

Figura 30a Variação horária da Temperatura do solo a $5 \mathrm{~cm}$ de profundidade $(\boldsymbol{T} \boldsymbol{s})$ 


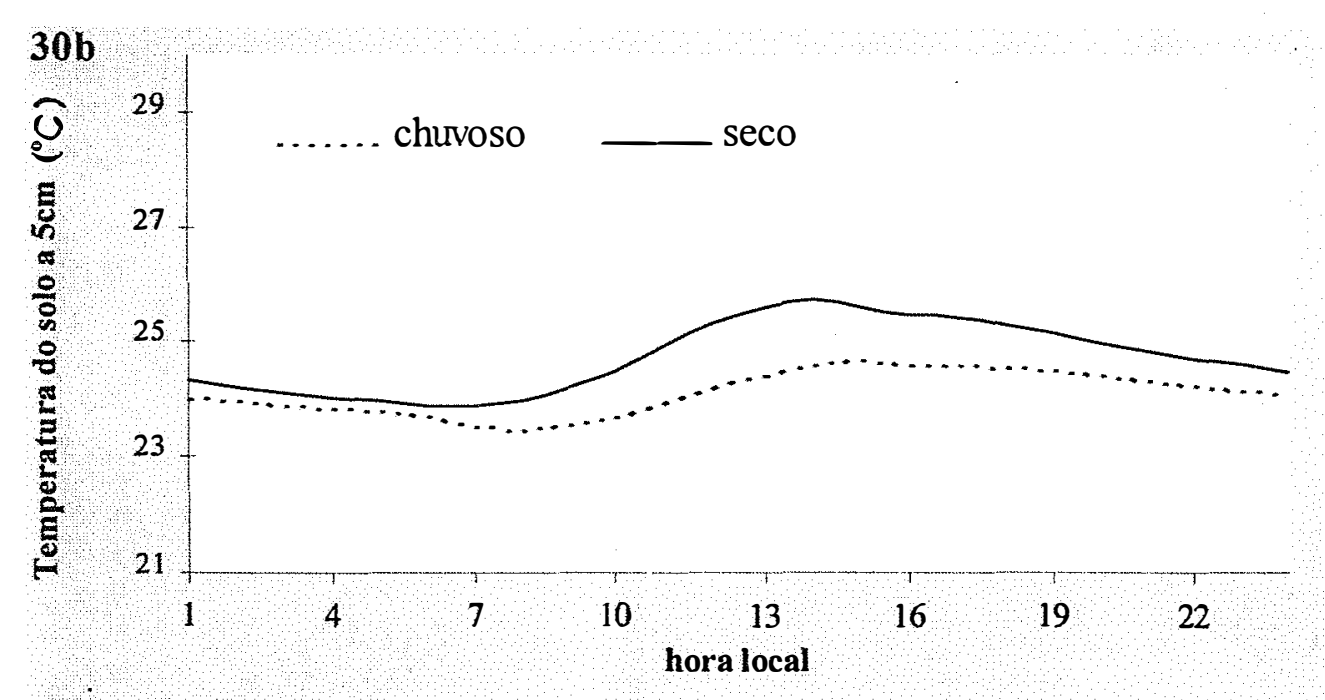

Figuras 30b Ciclo médio diário da Temperatura do solo a $5 \mathrm{~cm}$ de profundidade $(T s)$.

\subsection{Déficit de pressão de vapor $(\Delta e)$}

O déficit de pressão de vapor $(\Delta e)$ variou durante o período chuvoso com picos máximos de $1,96 \mathrm{kPa}$ às $15 \mathrm{~h}$ do dia 22 de fevereiro. Os maiores valores horários ocorreram com freqüência entre 13 e $16 \mathrm{~h}$, enquanto que o menor pico ocorreu às $16 \mathrm{~h}$ do dia 18 com $0,38 \mathrm{kPa}$ (Figura $31 \mathrm{a}$ ). Como seria esperado, durante a época seca os valores de $\Delta e$ foram tipicamente maiores que durante o período chuvoso. Os máximos foram de 2,38 kPa, $1,95 \mathrm{kPa}$ e $1,94 \mathrm{kPa}$, registrados nos dias 26 às $16 \mathrm{~h}$, dia 28 às $15 \mathrm{~h}$ e no dia 21 às $13 \mathrm{~h}$.

Os valores médios de $\Delta e$ nos períodos foram de $1,31 \mathrm{kPa}$ às $13 \mathrm{~h}$ na época seca e de $0,91 \mathrm{kPa}$ às $15 \mathrm{~h}$ no período chuvoso, com uma sazonalidade de aproximadamente $30 \%$, e de $0,11 \mathrm{kPa}$ às $6 \mathrm{~h}$ no período seco e de $0,02 \mathrm{kPa}$ às $3 \mathrm{~h}$ no período chuvoso (Figura $31 \mathrm{~b}$ ). A média de $\Delta e$ foi de $0,33 \mathrm{kPa}$ no período chuvoso, cerca de $62 \%$ da média da fase seca que foi de $0,53 \mathrm{kPa}$.

As correlações polinomiais entre $\Delta e$ e os fluxos de $\mathrm{CO}_{2}$ apresentaram $R^{2}=$ 0,22 no período chuvoso e $R^{2}=0,31$ na época seca, ambos na fase de seqüestro de $\mathrm{CO}_{2}$ da atmosfera. 


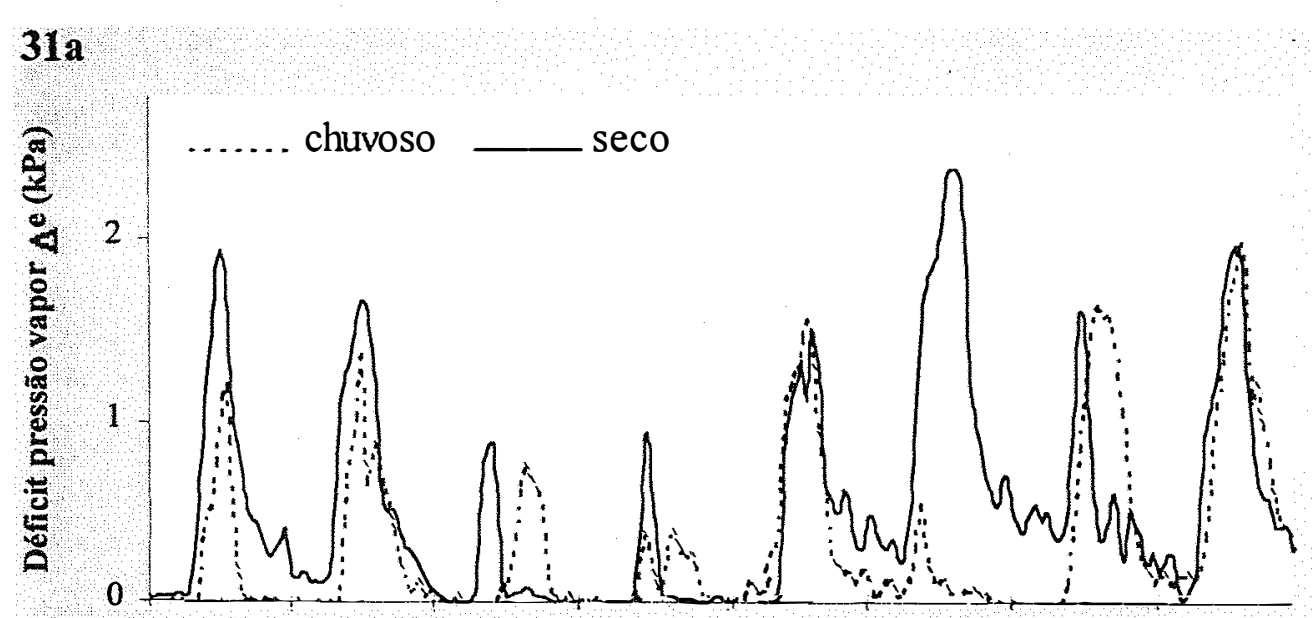

Dias

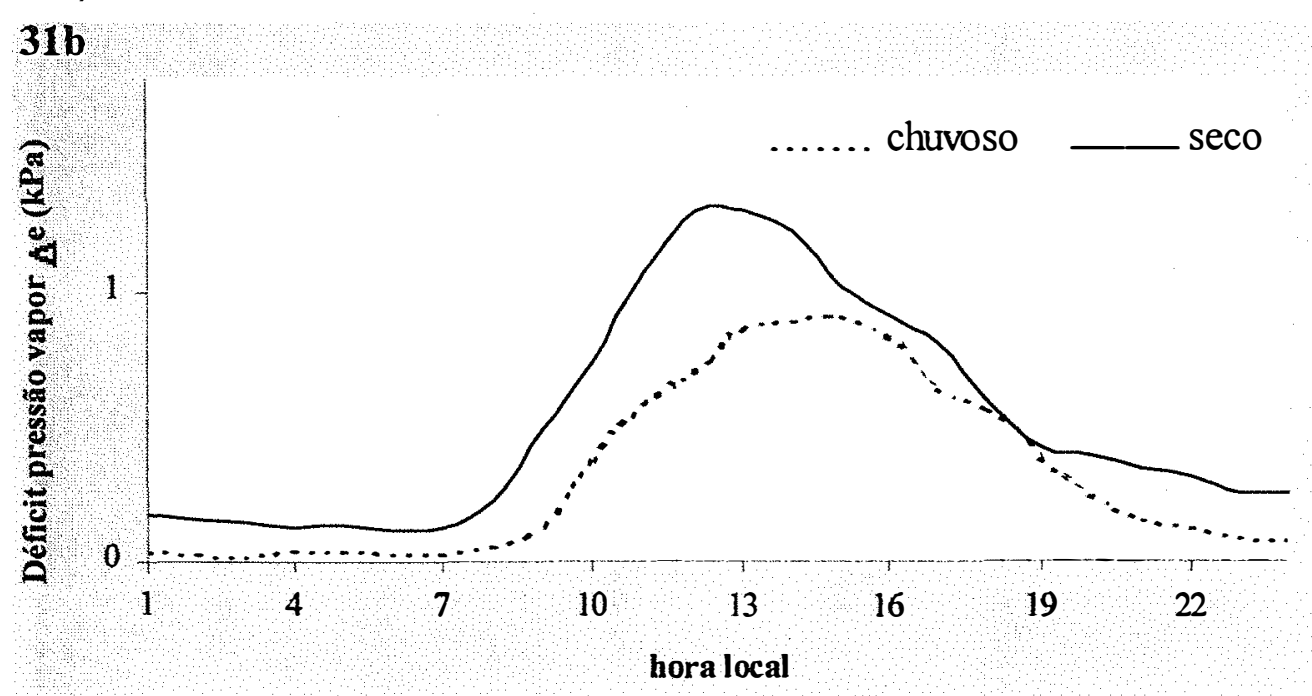

Figuras 31 Déficit de pressão de vapor ( $\Delta e)$ : a)variação horária, b) ciclo médio diário.

\subsection{Umidade relativa do ar (UR)}

$\mathrm{Na}$ região central da Amazônia, a umidade relativa do ar (UR) freqüentemente alcança valores próximos de $100 \%$, quando há a condensação da umidade disponível no ambiente nos períodos noturnos, mesmo durante a épocas secas. Os valores mais baixos, naturalmente, ocorrem nos horários mais quentes dos dias.

Durante o período chuvoso o valor mínimo de $U R$ foi de $56 \%$ no dia 22,61 $\%$ no dia 21 e $63 \%$ no dia 19 , todos registrados às 15 h (Figura 32a). A menor média 
diária no período chuvoso foi de $81 \%$ no dia 22 , enquanto que a maior $U R$ foi de $97 \%$ no dia 20.

No período seco os menores valores de $U R$ foram registrados às $16 \mathrm{~h}$ do dia 26 sendo de $51 \%$, enquanto que às $15 \mathrm{~h}$ do dia 28 foi de $57 \%$ e de $59 \%$ às $13 \mathrm{~h}$ do dia 21. A média diária mais baixa no período seco foi de $74 \%$ no dia 26 e a mais elevada foi de $97 \%$ no dia 24 .

$\mathrm{Na}$ variação média horária da $U R$ apresentada na Figura $32 \mathrm{~b}$, os valores menores foram de $77 \%$ registrados às 14 e $15 \mathrm{~h}$, durante o período chuvoso. Para a época seca o registro mais baixo foi de $69 \%$ às $12 \mathrm{~h}$. As média dos períodos foram de $86 \%$ no seco e de $91 \%$ no chuvoso. A diferença entre as épocas foi de aproximadamente $6 \%$.

Os coeficientes de determinação da correlação entre $U R$ e os fluxos de $\mathrm{CO}_{2}$ foram $R^{2}=0,24$ no período chuvoso e $R^{2}=0,28$ na época seca, ambos para a fase de absorção de $\mathrm{CO}_{2}$ pela floresta.

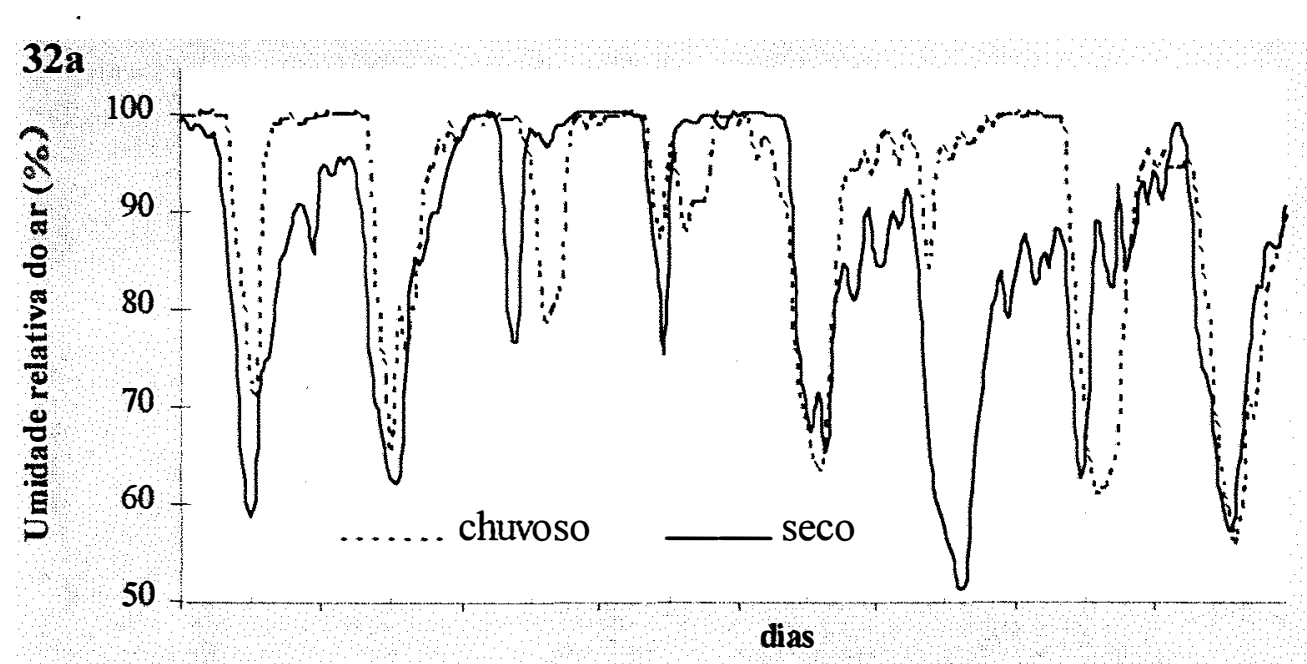

Figura 32a Variação horária da Umidade relativa do ar (UR). 


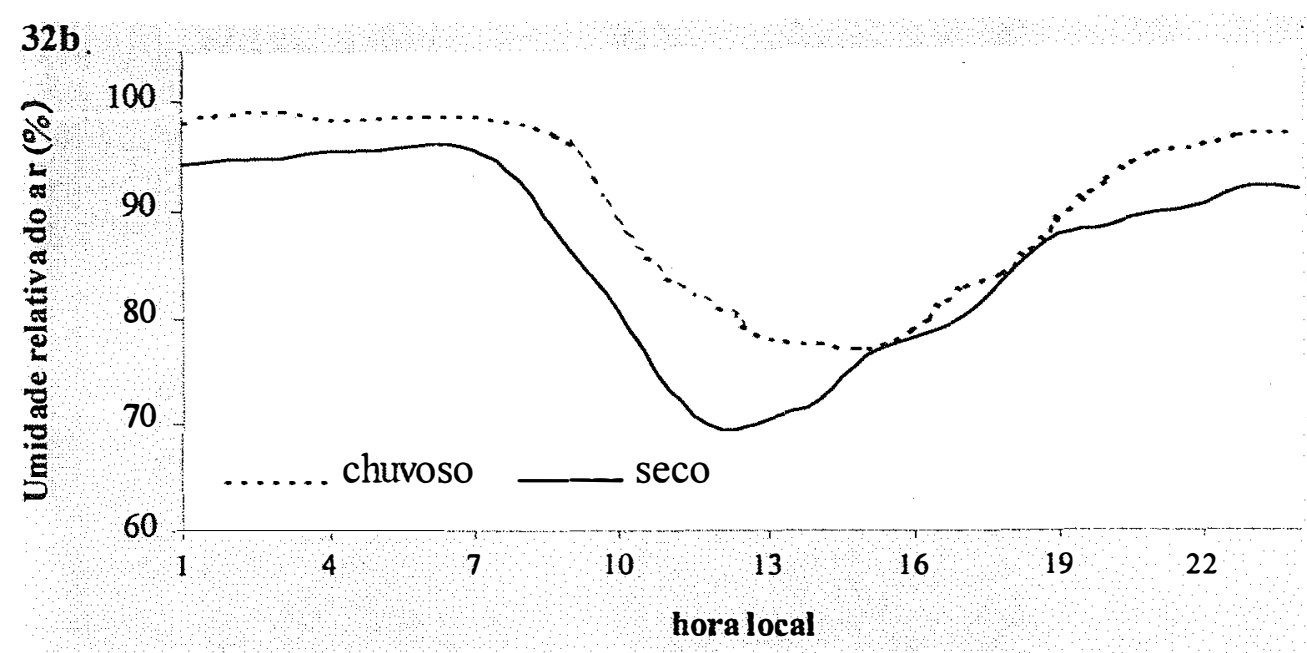

Figura 32b Ciclo médio diário da Umidade relativa do ar (UR).

\subsection{Velocidade do vento $(V v)$}

A velocidade do vento $(V v)$ acima do dossel vegetativo apresentou valores máximos de 4,2 $\mathrm{m} \mathrm{s}^{-1}$ no dia 15 de fevereiro, período chuvoso, e de $4,3 \mathrm{~m} \mathrm{~s}^{-1}$ no dia 24 de outubro, durante o período seco (Figura 33a). O ciclo médio diário registrou o máximo de $1 \mathrm{~m} \mathrm{~s}^{-1}$ às 6 e $21 \mathrm{~h}$ no período chuvoso. Enquanto que no período seco alcançou de $1,5 \mathrm{~m} \mathrm{~s}^{-1}$ às $13 \mathrm{~h}$ (Figura 33b). Sobre a floresta $V v$ foi tipicamente reduzida durante os períodos. Normalmente os valores mais elevados foram associados à presença de eventos de precipitação. A correlação entre $V v$ e os fluxos de $\mathrm{CO}_{2}$ apresentou $R^{2}=$ 0,24 na fase de emissão de $\mathrm{CO}_{2}$ para a atmosfera, durante o período chuvoso. 

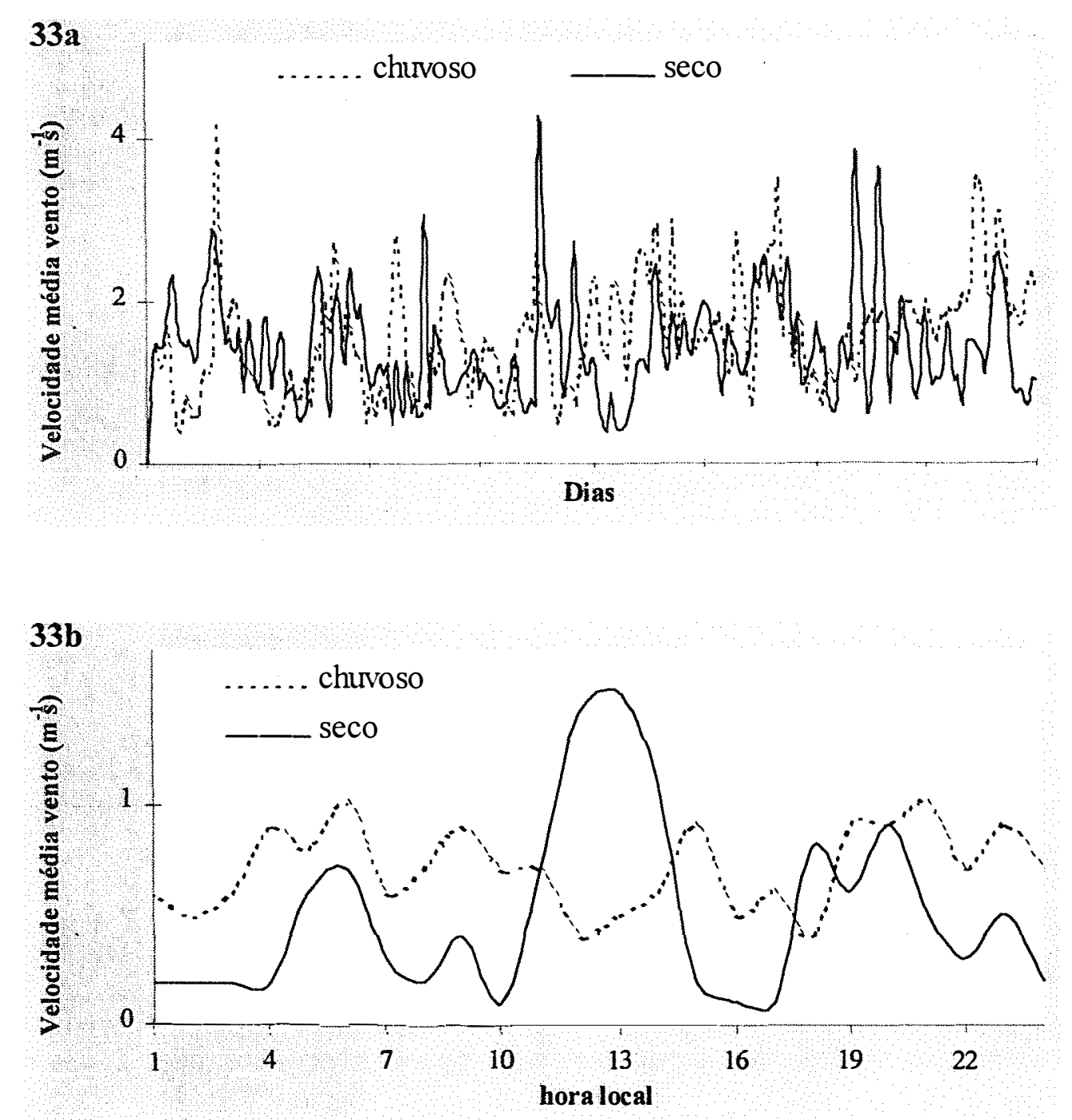

Figuras 33 Velocidade do vento $(\boldsymbol{V} \boldsymbol{v})$ : a) variação horária; b) ciclo médio diário. 


\subsection{Razão de Bowen $(\beta)$}

Os valores da razão de Bowen $(\beta)$ calculados para o período de 7 às $18 \mathrm{~h}$, apresentaram durante o período chuvoso os mínimos de -15 (valor admensional) às 8 e 9 h do dia 17, e o máximo de 8 às 16 h do dia 15 (Figura 34a). O ciclo médio apresentou valores de $\beta$ oscilando entre $-1,9$ e 3,7 no período chuvoso. Para a época seca variou de $-2,1$ e 2,5 apresentado na figura $34 \mathrm{~b}$.

$\mathrm{O}$ coeficiente de determinação da correlação entre $\beta$ e os fluxos de $\mathrm{CO}_{2}$ teve $R^{2}=0,31$ na fase de seqüestro de $\mathrm{CO}_{2}$ durante o período chuvoso.
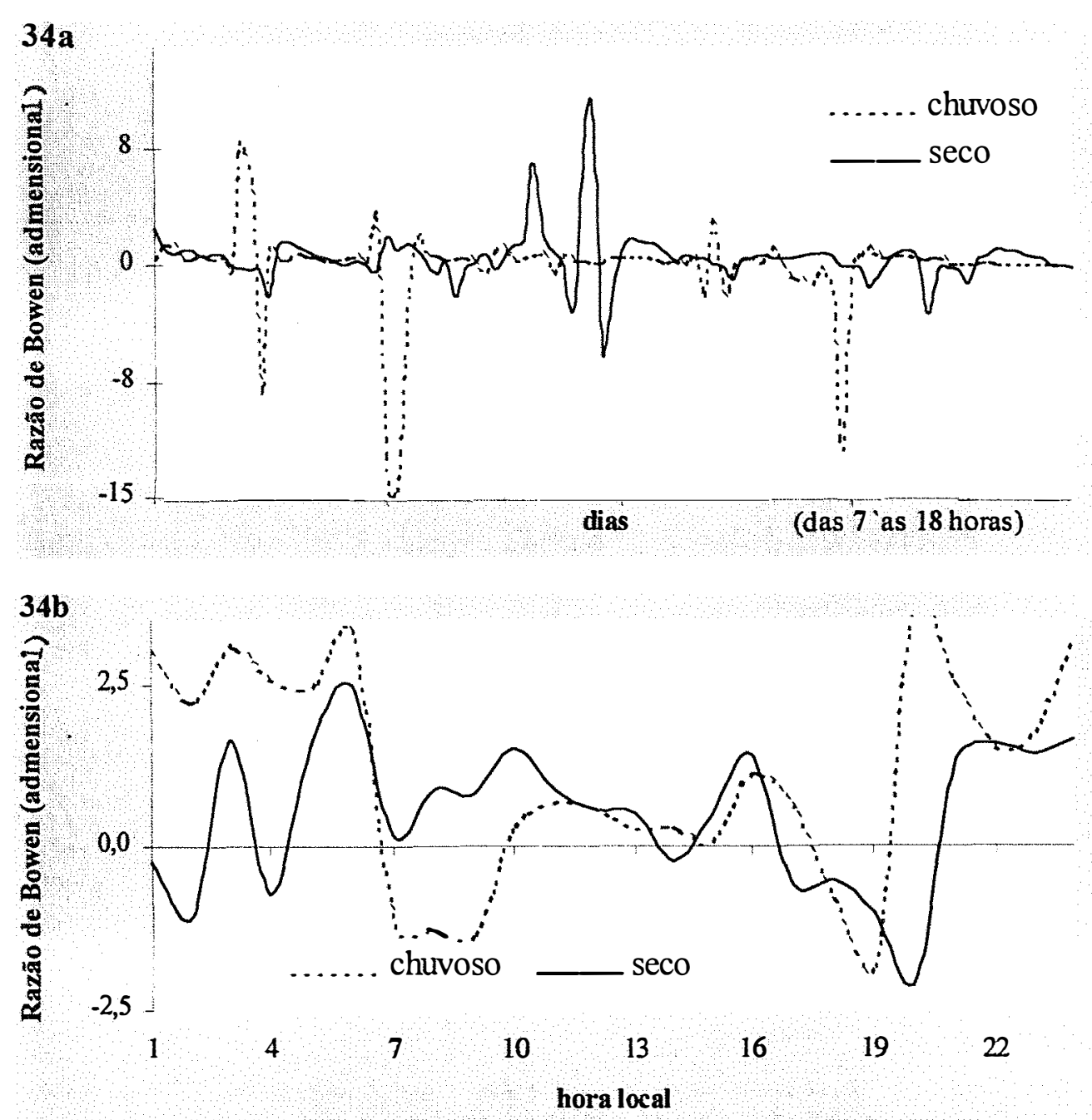

Figuras 34 Razão de Bowen ( $\beta$ ): a) variação horária; b) ciclo médio diário. 


\section{CONCLUSÕES}

As análises realizadas neste trabalho ajudaram a compreender um pouco melhor qual é a contribuição da floresta tropical amazônica no balanço global de carbono terrestre.

As informações mostram que a região possui enorme potencial de seqüestrar carbono presente na atmosfera para utilizá-lo no processo de fotossíntese. Este fato destaca que a questão da utilização da floresta precisa ser atentamente planejada e implementada. Os danos causados pela prática de manejos inadequados à Amazônia podem ser irreversíveis.

Com a destruição da floresta amazônica haverá aumento das concentrações de $\mathrm{CO}_{2}$ atmosférico de duas maneiras básicas: Primeiro, pela liberação de grande quantidade de $\mathrm{CO}_{2}$ armazenada atualmente como biomassa que intensificaria o chamado efeito estufa, e segundo, pela diminuição do potencial de retirar carbono da atmosfera.

O balanço médio de carbono durante a época seca (21 a 28 de outubro de 1995) foi de $-13,6 \mathrm{~kg} \mathrm{C} \mathrm{ha}^{-1} \mathrm{dia}^{-1} \mathrm{e}$ para o período chuvoso (15 a 22 de fevereiro de 1996) foi de $-15,9 \mathrm{~kg} \mathrm{Cha}^{-1} \mathrm{dia}^{-1}$.

A floresta retiraria da atmosfera aproximadamente $-5 \mathrm{MgC} \mathrm{ha}^{-1} \mathrm{ano}^{-1} \mathrm{com}$ as taxas de seqüestro obtidas no período seco, e cerca de $-5,8 \mathrm{Mg} \mathrm{C} \mathrm{ha}^{-1}$ ano $^{-1}$ com os valores da época chuvosa. Representando aproximadamente $16 \%$ mais carbono absorvido pela vegetação na época chuvosa do que no período seco.

A floresta retirou mais $\mathrm{CO}_{2}$ da atmosfera do que liberou, considerado fluxo negativo, em média entre 9 e $18 \mathrm{~h}$ na época chuvosa e 9 e $17 \mathrm{~h}$ no período seco. No restante do dia o fluxo tornou-se positivo, significando que a liberação de $\mathrm{CO}_{2}$ pelo sistema solo-planta para a atmosfera predominou em relação a absorção. 
Na época seca o pico da emissão de $\mathrm{CO}_{2}$ foi de $+12,9 \mu \mathrm{mol} \mathrm{m}^{-2} \mathrm{~s}^{-2}$ às $8 \mathrm{~h}$, enquanto que o máximo seqüestro de $\mathrm{CO}_{2}$ foi de $-14,5 \mu \mathrm{mol} \mathrm{m} \mathrm{m}^{-2} \mathrm{~s}^{-2}$ às $12 \mathrm{~h}$.

$\mathrm{Na}$ época chuvosa o máximo de liberação de $\mathrm{CO}_{2}$ foi de $+11,4 \mu \mathrm{mol} \mathrm{m} \mathrm{m}^{-2} \mathrm{~s}^{-2}$ às $7 \mathrm{~h}$. $\mathrm{O}$ pico da absorção de $\mathrm{CO}_{2}$ foi de $-16,4 \mu \mathrm{mol} \mathrm{m} \mathrm{m}^{-2} \mathrm{~s}^{-2}$ registrado às $11 \mathrm{~h}$.

As concentrações de $\mathrm{CO}_{2}$ acima do dossel foram de cerca de 4,6 \% maiores no período seco do que no chuvoso. As concentrações médias de $\mathrm{CO}_{2}$ foram de 387 ppmv no período seco e de 370 ppmv no chuvoso. A média geral da concentração de $\mathrm{CO}_{2}$ foi de aproximadamente 379 ppmv.

As máximas concentrações de $\mathrm{CO}_{2}$ foram de 445 ppmv no período seco e 420 ppmv na fase chuvosa. As mínimas foram de 345 ppmv na época seca e 341 ppmv no período chuvoso.

Os perfis de concentração de $\mathrm{CO}_{2}$ dentro da floresta mostraram que, em média, os valores foram 5,5\% maiores nos níveis mais baixos da vegetação, 1 e 9m, em relação ao nível mais elevado de $46,5 \mathrm{~m}$. As concentrações máximas registradas nos níveis de $\mathrm{i}$ e $9 \mathrm{~m}$, foram em torno de 540 ppmv em outubro de 1995.

As concentrações atingiram os valores máximos entre 6 e $7 \mathrm{~h}$, enquanto que os mínimos foram registrados entre 12 e 13 h. Neste ciclo diário, as diferenças médias foram de aproximadamente 30 a $32 \%$ nos níveis mais baixos, e menos que $20 \%$ nas camadas superiores.

A radiação solar incidente $(S)$ foi a variável analisada que apresentou o melhor coeficiente nas correlação com os fluxos negativos de $\mathrm{CO}_{2}$ (absorção pela floresta) no período seco com $R^{2}=0,86$. No período chuvoso o melhor coeficiente foi obtido pela correlação com o saldo de radiação $(R n)$ quando o $R^{2}=0,75$.

As correlações com os fluxos positivos de $\mathrm{CO}_{2}$ (emissão para a atmosfera) apresentaram os melhores coeficientes com as variáveis que não dependiam diretamente da radiação solar incidente; a precipitação $(P)$ quando o $R^{2}=0,36$ e a velocidade de friç̧ão $\left(u^{*}\right)$ com $R^{2}=0,34$ ambos na época chuvosa.

A taxa média de seqüestro de carbono pela vegetação obtida neste trabalho, de aproximadamente $-5,4 \mathrm{Mg} \mathrm{C} \mathrm{ha}^{-1} \mathrm{ano}^{-1}$, se expandida para a área total da Amazônia $\left(\sim 5 \times 10^{8}\right.$ ha $)$ atingiria a marca de $-2,7 \mathrm{Pg} \mathrm{C}$ ano $^{-1}$. Uma mitigação de carbono atmosférico 
desta proporção, ajudaria a explicar, em parte, o chamado carbono desaparecido "missing carbon" apresentado nos balanços globais. Como a floresta amazônica é considerada de crescimento estável e não estaria aumentando de tamanho, este carbono seria usado principalmente na reposição de galhos e folhas depostos sobre o solo, passando a fazer parte de um estoque com longo período de armazenamento. Uma parte do carbono sob ação das chuvas seria drenada pelos cursos d'água e despejada nos ecossistemas de manguezais na foz do rio Amazonas no litoral do Pará e Amapá, favorecendo a elevação do volume dos fitoplânctons nesta região do oceano Atlântico. Isto por sua vez interage com cadeia trófica marinha, sendo posteriormente depositado como sedimentos no fundo do oceano e tornando integrante da parte dos estoques de carbono que sofre uma troca muito lenta com o meio, demorando um enorme intervalo de tempo para retornar à atmosfera. 


\section{REFERÊNCIAS BIBLIOGRÁFICAS}

ANDREAE, M.O.; BROWELL, E.V.; GARSTANG, M.; GREGORY, G.L.; HARRISS, R.C.; HILL, G.F.; JACOB, D.J.; SACHSE, G.W.; SETZER, A.W.; SILVA DIAS, P.L.; TALBOT, R.W.; TORRES, A.L.; WOFSY, S.C. Biomass burning emissions and associated haze layers over Amazonia. Journal of Geophysical Research, v.93, n.D2, p.1509-1527, 1988.

ANDRES, R. J.; MARLAND, G.; FUNG, I.Y.; MATTHEWS, E. A $1 \times 1$ distribution of carbon dioxide emissions from fossil fuel consumption and cement manufacture, 1950-90. Global biogeochemical cycles, v. 10, p. 419-429, 1996.

AUCLAIR, A.; BEDFORD, J. News perspectives on the terrestrial carbon flux: importance to the policy debate. In: AUCLAIR, A; BEDFORD, J. (Eds.). ORD EPA Technical Briefing. Environmental Protection Agency, Berkeley, 1993.

BALDOCCHI, D.; HICKS, B.B.; MEYERS, T.P. Measuring biosphere-atmosphere exchanges of biologically reated gases with micrometeorological methods. Ecology, v.69, p.1331-1340, 1988.

BALDOCCHI, D.; VALENTINI, R.; RUNNING, S.; OECHEL, W.; DAHLMAN, R. Strategies for measuring and modelling carbon dioxide and water vapor fluxes over terrestrial ecossystems. Global change biology. v.2, p.159-168, 1996.

BARNOLA, J.M.; ANKLIN, M.; PORCHERON, J.; RAYNAOD, D.; SCHWANDER, J; STAUFFER, B. $\mathrm{CO}_{2}$ evolution during the last milennium as recorded by antarctic and greenland ice. Tellus, v. 47, n. B, p. 264-272, 1995.

BRADLEY, R.S.; JONES, P.D. 'Little ice age' summer temperature variations: Their nature and relevance global warming trends. The holocene, v.3, p. 367-376, 1993.

CERRI, C.C.; VOLKOFF, B.; ANDREUX, F. Nature and behaviour of organic matter in soils under natural forest, and after deforestation, burning and cultivation, near Manaus. Forest ecology and management, v.38, p. 247-257,1991. 
CHAUVEL, A.; GRIMALDI, M.; TESSIER, D. Changes in soil pore-space distribution following deforestation and vegetation: na example from the central Amazon basin, Brazil. Forest ecology and management, v.38, p. 259-271,1991.

CONWAY, T. J., TANS, P. P., WATERMAN, L. S., THONING, K. W., KITZIS, D. R., MASARIE, K.; ZHANG, N. Evidence for interannual variability of the carbon cycle from NOAA/CMDL global sampling network. Journal of Geophysical Research, v.99, p.22831-22855, 1994.

CONWAY, T.J.; TANS, P.P. Atmospheric carbon dioxide mixing ratios from the NOAA climate monitoring and diagnostics laboratory cooperative flask sampling network, 1963-1993. Oak Ridge, National Laboratory / Carbon Dioxide Information Analysis Center (ORNL/CDIAC)-73, Tennessee, 202 p., 1996. http://cdiac.esd.ornl.gov

CORREA, J.C. Características físico hídricas dos solos latossolo amarelo, podzólico vermelho amarelo e podzólico hidromófico do estado do amazonas. Pesquisa agropecuária brasileira, v.20, p.1317-1322, 1984.

CULF, A. D., FISCH, G., HODNETT, M. G. The albedo of Amazonian forest and ranchland. Journal of climate, v.8, n.6, p.1544-1554, 1995.

CULF, A. D., FISCH, G., MALHI, Y., FERREIRA DA COSTA, R., NOBRE, A .D., MARQUES FILHO, A. O., GASH, J., GRACE, J. Carbon dioxide measurements in the nocturnal boundary layer over Amazonian forest. Hydrology and Earth System Science, v.3, n.1, p.39-53, 1999.

CULF, A. D.; FISCH, G.; MALHI, Y.; NOBRE, C. A. Influence of the boundary layer on carbon dioxide concentrations over a tropical forest. Agricultural and forest meteorology, v.85, p.149-158, 1997.

CULF, A. D.;ESTEVES, J. L.; MARQUES FILHO, A. O.; ROCHA, H. R. Radiation, temperature and humidity over forest and pasture in Amazonia. In: GASH, J.H.C.; NOBRE, C.A.; ROBERTS, J.M.; VICTORIA, R.L.(Eds.). Amazonian deforestation and climate. Chichester, John Willey \& Sons, 1996, p.175-190. 
DAI, A.; FUNG, I.Y. Can climate variability contribute to the "missing" $\mathrm{CO}_{2}$ sink? Global biogeochemical cycles, v. 7, p. 599-610, 1993.

DELMAS, R.A.; SERVANR, J.; THATY, J.P.; CROS, B.; LABAT, M. Sources and sinks of methane and carbon dioxide exchanges in mountain forest in equatorial Africa. Journal of Geophysical Research, v.97, n.D6, p.6169-6179, 1992.

DIXON, R. K.; BROWN, S; HOUGHTON, R. A. Carbon pools and flux of global forest ecossystems. Science, v.263, p. 185-190, 1994.

EAMUS, D.; JARVIS, P. G. The direct effects of increase in the global atmospheric $\mathrm{CO}_{2}$ concentration on natural and commercial temperature trees and forest. Advances in ecological research, v.19, p.1-55, 1989.

EPRON, D.; DREYER, E. Photosyntesis of oak leaves and water stress maintenance of high photochemical efficiency of photosystem II and occurrence of non-uniform $\mathrm{CO}_{2}$ assimilation. Tree physiology, v.13, p.107-117, 1993.

ETHERIDGE, D.M.; STELLE, L.P.; LANGELFELDS, R.L.; FRANCEY, R.J.; BARNOLA, J.M.; MORGAN, V.L. Natural and antropogenic changes in atmospheric $\mathrm{CO}_{2}$ over the last 1000 years from air antarctic ice. Journal of Geophysical Research, v.101, p.411 5-4128, 1996.

FAN, S.M.; WOFSY, S.C.; BAKWIN, P.S.; JACOBS, B.J. Atmosphere-biosphere exchange of $\mathrm{CO}_{2}$ and $\mathrm{O}_{3}$ in the central Amazon forest. Journal of Geophysical Research, v.95, n.D10, p.16851-16864, 1990.

FEITOSA, J. R. P., FERREIRA DA COSTA, R., FISCH, G., SOUZA, S. S., e NOBRE, C. A . Radiação solar global em áreas de floresta e pastagem na Amazônia. Revista Brasileira de Agrometeorologia, v.6, n.1, p.1-7, 1998.

FERREIRA DA COSTA, R., FEITOSA, J. R. P., FISCH, G., SOUZA, S. S., e NOBRE, C. A . Variabilidade diária da precipitação em regiões de floresta e pastagem na Amazônia. Acta Amazonica, v.28, n.4, p.395-408, 1998. 
FISCH, G. Camada limite amazônica: Aspectos observacionais de modelagem. São José dos Campos, 1996. 171p. Tese (Doutorado) - Instituto Nacional de Pesquisas Espaciais.

FLAVIN, C. World carbon emission fall. http://www.worldwatch.org/worldwatch/newsbrief 99$5,1999$.

FRIEDLINGTEIN, P.; FUNG, I.Y.; HOLLAND, E.; JOHN, J.; BRASSEUER, G.; ERICKSON, D.; SCHIMEL, D. On the contribution of $\mathrm{CO}_{2}$ fertilization to the missing biospheric sink. Global biogeochemical cycles, v. 9, p. 541-556, 1995.

FUNG, I. Y.; TUCKER, C. J.; PRENTICE, K. C. Application of advanced very high resolution radiometer vegetation index to study atmosphere-biosphere exchange of $\mathrm{CO}_{2}$. Journal of Geophysical Research, v.92, p.2999-3015, 1987.

GIFFORD, R. M. The global carbon cycle: a viewpoint on the missing sink. Australian journal of plant physiology, v. 21, p. 1-5, 1994.

GOULDEN, M. L.; MUNGER, J. L.; FAN, S. M.; DAUBE, B. C.; WOFSY, S. C. Measurements of carbon sequestration by long-term eddy covariance: methods and a critical evaluation of accuracy. Global Change Biology, v.2, p.169-182, 1996.

GRAÇA, P.M.L.A. Conteúdo de carbono na biomassa florestal da Amazônia e alterações após à queima. Piracicaba, 1997. 105p. Dissertação (Mestrado) - Escola Superior de Agricultura "Luiz de Queiroz", Universidade de São Paulo.

GRACE, J. LLOYD, J., McINTIRE, J., MIRANDA, A., MEIR, P., MIRANDA, H., MONCRIEFF, J., MASSHEDER, J. WRIGHT, I.; GASH, J. H. C. Fluxes of carbon dioxide and water vapor over na undisturbed tropical forest in south-west Amazonia. Global Change Biology, v.1, n.1, p.1-12, 1995a.

GRACE, J. LLOYD, J., McINTIRE, J., MIRANDA, A., MEIR, P., MIRANDA, H., NOBRE, C.A.; MONCRIEFF, J.M.; MASSHEDER, J.; MALHI, Y.; WRIGHT, I.R.; GASH, J.H.C. Carbon dioxide uptake by and undisturbed tropical rainforest in southwest Amazonia. Science, v.270, p.778-780, 1995b. 
GRACE, J., LLOYD, J., McINTIRE, J., MIRANDA, A., MEIR, P., MIRANDA, H., Carbon dioxide flux over Amazon. rainforest in Rondonia. In: GASH, J.H.C.; NOBRE, C.A.; ROBERTS, J.M.; VICTORIA, R.L.(Eds.). Amazonian deforestation and climate. Chichester, John Willey \& Sons, 1996a, p.307-317.

GRACE, J., MALHI, Y., LLOYD, J., McINTIRE, J., MIRANDA, A., MEIR, P.; MIRANDA, $\mathrm{H}$. The use of eddy covariance to infer the net carbon dioxide uptake of Brazilian rain forest. Global Change Biology, v.2, p.209-217, 1996 b.

GRECCO, S.; BALDOCCI, D. D. Seasonal variations of $\mathrm{CO}_{2}$ and water vapor exchange rates over a temperate forest. Global Change Biology, v.2, p.183-197, 1996.

GRELLE, A.; LINDROTH, A. Eddy-correlation system for long-term monitoring of flux of heat, water vapor and $\mathrm{CO}_{2}$. Global Change Biology, v.2, p.297-307, 1996.

GROVE, J.M. 'The little ice age'. Methuen, New York, 498p., 1988.

HARRISS, R.C.; GARSTANG, M; WOFSY, S.C.; BECK, S.M.; BENDURA, R.J.; COELHO, J.R.B. et al. The Amazon Boundary Layer Experiment - ABLE 2a - Dry season 1985, Journal of Geophysical Research, v.93, n.D2, p.1477-1486, 1988.

HARRISS, R.C.; GARSTANG, M; WOFSY, S.C.; BECK, S.M.; BENDURA, R.J.; COELHO, J.R.B.; DREWRY, J.W. et al. The Amazon Boundary Layer Experiment ABLE 2b - Wet season 1987, Journal of Geophysical Research, v.95, n.D10, p.16721-16736, 1990.

HENDERSON-SELLERS, A.; DICKINSON, R. E.; DURBIDGE, T.B.; KENNEDY, P.J.; McGUFFLE, K.; PITMAN, A.J. Tropical deforestation: Modeling local and regional-scale climate change. Journal of Geophysical Research, v.98, n.D4, p.7289-7315, 1993.

HODNETT, M. G.; TOMASELLA, J.; MARQUES FILHO, A de O.; OYAMA, M.D. Deep water uptake by forest and pasture in central Amazonia: Precictions from longterm daily rainfall data using a simple water balance model. In: GASH, J.H.C.; NOBRE, C.A.; ROBERTS, J.M.; VICTORIA, R.L.(Eds.). Amazonian deforestation and climate. Chichester, John Willey \& Sons, 1996, p.79-99. 
HOUGHTON, R.A. The global effects of tropical deforestation. Environmental science technology, v.24, n.4, p. 414-422, 1990.

HOUGHTON, R.A. Is carbon accumulating in the northern temperate zone? Global biogeochemical cycles, v.7, p. 611-6188, 1993.

HOUGHTON, R.A.; BOONE, R.D.; FRUCCI, J.R. The flux of carbon from terrestrial ecosystems to the atmosphere in 1980 due to changes in land use: Geographic distribution of the global flux. Tellus, v.39, n.B, p. 122-139, 1987.

INDERMÜHLE, A. Long-term variations of the concentration of atmospheric $\mathrm{CO}_{2}$. Global change newsletter, IGBP, v. 37, p. 12-14, 1999.

INTERGOVERNAMENTAL PANEL ON CLIMATE CHANGE. Technical Summary. In: HOUGTON, J. T.; MEIRA FILHO, L. G.; CALLANDER, B. A.; HARRIS, N.; KATTENBERG, A. MASKELL, H.(Eds.). Climate change 1995: The science of climate change. IPCC 1996. Cambridge: Cambridge University press, 1996, p9-49.

KEELING, C.D.; WHORF, T.P. Atmospheric $\mathrm{CO}_{2}$ concentrations (ppmv) derived from in situ air samples collected at Mauna Loa observatory, Hawaii. http://www.cdiac.esd.ornl.gov/ndps/ndp001.html, 1999.

KEELING,C.D., and WHORF, T.P. Atmospheric $\mathrm{CO}_{2}$ records from sites in the SIO air sampling network. In "Trends '93: A compendium of data on global change". p.16 26, 1994.

KEIGWIN, L.D. The 'little ice age' and medieval warm period in the Sargasso Sea. Science, v.274, p.1504-1508, 1996.

KUBISKE, M. E.; ABRAMS, M. D. Ecophysiological analyses of woody species in contrasting temperate communities during wet and dry years. Oecologia. v.8, p.303$312,1994$.

LBA. O experimento de grande escala na biofera-atmosfera na Amazônia. Plano experimental conciso. Grupo de planejamento científico do LBA, CPTEC / INPE, Cachoeira Paulista, 48 p., 1996. http://yabae.cptec.inpe.br/lba 
LEEMANS, R. Land-use change and the terrestrial carbon cycle. Global change newsletter, IGBP, v. 37, p. 24-26, 1999.

LENSCHOW, D. H. Micrometeorological techniques for measuring biosphereatmosphere trace gas exchange. In: MATSON, P.; HARRISS, R.C. (Eds.). Biogenic Trace Gases : Methods in ecology. New York, 1995. 384p.

LEUNING, R.; JUDD, M. J. The relative merits of open-and-closed-path analysers for measurements of eddy fluxes. Global Change Biology, v.2, p.241-253, 1996.

LLOYD, C.R., MARQUES, A de O. Spatial variability of throughfall measurements in Amazonia rainforest. Agricultural and Forest meteorology, v.42, p.63-73, 1988.

LUCAS, R. M.; CURRAN, P. J.; HONZAK, M.; FOODY, G.M.; AMARAL, I.; AMARAL, S. Disturbance and recovery of tropical forests: balancing and carbon account. In: GASH, J.H.C.; NOBRE, C.A.; ROBERTS, J.M.; VICTORIA, R.L.(Eds.). Amazonian deforestation and climate. Chichester, John Willey \& Sons, 1996, p.383-398.

MALHI, Y., NOBRE, A.D., GRACE, J., KRUIJT, B., PEREIRA, M.G.P., CULF, A. D. and STEVE, S. Carbon dioxide transfer over a Central Amazonian rain forest. Journal of Geophysical Research, v.103, n.D24, p.31593-31612, 1998.

MANABE, S.; STOUFFER, R. J. Multiple century response of a coupled oceanatmosphere model to a increase of atmospheric carbon. Journal of Climate, v.7, p.523, 1994.

MARENGO, J.; CUlF, A. D.; NOBRE, C.A. Climatic impacts of the "friagens" in forested and deforested areas of the Amazon basin. Journal of Climate, v.36, n.11, p.1553-1566, 1997.

MARLAND, G.; BODEN, T.A.; ANDRES, R.J.; BRENKERT, A. L.; JOHNSTON, C. Global, regional and national $\mathrm{CO}_{2}$ emissions. In Trends: A compendium of data on global change. Oak Ridge, National Laboratory / Carbon Dioxide Information Analysis Center (ORNL/CDIAC), Tennessee, 1999. http://cdiac.esd.ornl.gov 
McMURTRIE, R. E.; COMINS, H. N.; KIRSCHBAUM, M. U. F.; WANG, Y.P. Modifying existing forest growth models to take account of effects of elevated $\mathrm{CO}_{2}$. Australian journal of botany, v. 40, p. 657-677, 1992.

McWILlIAM, A.-L.C.; ROBERTS, J.M.; CABRAL, O. M.; LEITÃO, M.V.B.R.; COSTA, A.C.L.; MAITELLI, G.T.; ZAMPARONI,C.A.G.P. Leaf area index and above-ground biomass of terra fire rain forest and adjacent clearings in Amazonia. Functional Ecology. v.7, p.310-317, 1993.

MEIR, P., GRACE, J., MIRANDA, A., LLOYD, J. Carbon Soil respiration in a rainforest in Amazonia and in cerrado in the central Brazil. In: GASH, J.H.C.; NOBRE, C.A.; ROBERTS, J.M.; VICTORIA, R.L.(Eds.). Amazonian deforestation and climate. Chichester, John Willey \& Sons, 1996, p.319-329.

MELliLO, J. M.; McGUIRE, A. D.; KICKLIGHTER, D. W.; MOORE, B.; VOROSMARTY, C. J.; SCHLOSS, A. L. Global climate change and terrestrial net primary productivity. Nature, v. 363, p.234-240, 1993.

MICHEL, E. Last milennium atmospheric $\mathrm{CO}_{2}$. Global change newsletter, IGBP, v. 37, p. 20-21, 1999.

MONCRIEFF, J.; MASSHEDER, J. M.; De BRUIN, H.; ELBERS, J.; FRIBORG, T.; HUESUNKVELD, B.; KABAT, P.; SCOTT, S. J.; SOERGAARD, H.; VERHOEF, A. A system to measure surface fluxes of momentum, sensible heat, water vapor and carbon dioxide. Journal of Hydrology, v.188-189, p.589-611, 1997.

MONCRIEFF, J.B.; MALHI, Y.; LEUNING, R. The propagation of errors in long-term measurements of land-atmosphere fluxes of carbon and water. Global change biology. v.2, p.231-240, 1996.

MOORE, C. J., FISCH, G. Estimating heat storage in Amazonia tropical forest. Agricultural and Forest meteorology, v.38, n. 1-3, p.147-169, 1986.

MORTATTI, J.; PROBST, J.L.; TARDY, Y. Flutuações no consumo de $\mathrm{CO}_{2}$ atmosférico pelas alterações das rochas na bacia amazônica desde 1990. Geochimicae Brasil, v.8, p.225-234,1994. 
MUSSELMAN, R. C.; FOX, D. G. A review of the role of temperate forest in the global $\mathrm{CO}_{2}$ balance. Journal of air waste management association, v. 41, p. 798-807, 1991.

NEFTEL, A.; MOOR, E.; OESCHGER, H.; STAUFFER, B. Evidence from polar ice cores for the increase in atmospheric $\mathrm{CO}_{2}$ in the past two centuries. Nature, v. 315, p.45-47, 1985.

NEPSTAD, D.C.; CARVALHO, R.C.; DAVIDSON, E.A.; JIPP, P.H.; LEFEBVRE, P.A.; NEGREIROS, G.H.; DA SILVA, E.D.; STONE, T.A.; TRUMBORE, S.E.; VIEIRA, S. The role of deep roots in the hydrological and carbon cycles of amazonian forest and pastures. Nature, v. 372, p.666-669, 1994.

NOBRE C.A. \& GASH J.H.C. Desmatamento e clima: o maior estudo já feito na Amazônia. Ciência Hoje, v.22, n.128, p.32-41, 1997

NOBRE, C.A.; GASH, J.H.C.; ROBERTS, J.M.; VICTORIA, R.L. Conclusões do Projeto ABRACOS. In: GASH, J.H.C.; NOBRE, C.A.; ROBERTS, J.M.; VICTORIA, R.L.(Eds.). Amazonian deforestation and climate. Chichester, John Willey \& Sons, 1996, p.586-595.

NOBRE, C.A.; SELLERS, P.J. and SHUKLA, J. Amazonian deforestation and regional change. Journal of Climate, v.4, p.957-988, 1991.

PEAGLE, J. Interactions between convective and large-scale motions over Amazonia.

In: DICKINSON, R.E. (Ed.) The Geophysiology of Amazonia. New york: John Willey \& Sons, 1987, p.347-387.

PENNER; J.E.; DICKINSON, R.E.; O’NEILL, C.A. Effects of aerossol from biomass burning on the global radiation budget. Science, v.256, p. 1432-1434, 1992.

PEREIRA, A. R.; Villa Nova, N. A.; SEDYAMA, G. C. Evapo(transpi)ração. Piracicaba, FEALQ, 1997, 183p.

PIELKE, R. A.; AVISSAR, R.; RAUPACH, M.; DOLMAN, A. J.; ZENG, X.; DENNING, S. Interactions between the atmosphere and terrestrial ecossystems: influence on weather and climate. Global Change Biology, v.4, p.461-475, 1998. 
ROBERTS, J.M.; CABRAL, O. M.; COSTA, J. P.; McWILLIAM, A.-L.C.; SÁ, T.D.A. An overview of the leaf area index and physiological measurements during ABRACOS. In: GASH, J.H.C.; NOBRE, C.A.; ROBERTS, J.M.; VICTORIA, R.L.(Eds.). Amazonian deforestation and climate. Chichester, John Willey \& Sons, 1996, p.287-306.

ROCHA, E.J.P. Balanço de umidade na Amazônia durante o FLUAMAZON. São Paulo, 1991. 121 p. Dissertação (Mestrado) - Instituto Astronômico e Geofísico , Universidade de São Paulo.

ROCHA, H.R. Modelagem e observações das relações da biosfera-atmosfera na região sudeste. São Paulo, 1998. 142p. Tese (Doutorado) - Instituto Astronômico e Geofísico, Universidade de São Paulo.

RUIMY, A.; KERGOAT, L.; FIELD, C. B.; SAUGIER, B. The use of $\mathrm{CO}_{2}$ flux measurements in models of the global terrestrial carbon budget. Global Change Biology, v.2, p.287-296, 1996.

SARMIENTO, J. L. Atmospheric CO $\mathrm{CO}_{2}$ stalled. Nature, v. 365, p. 607-698, 1993.

SCHIMEL, D.; ALVES, D.; ENTING, I.; HEIMANN, M.; JOOS, F.; RAYNAUD, D.; WINGLEY, T. et al., Radiative forcing of climate change. In: HOUGTON, J. T.; MEIRA FILHO, L. G.; CALLANDER, B. A.; HARRIS, N.; KATTENBERG, A. MASKELL, H.(Eds.). Climate change 1995: The science of climate change. IPCC 1996. Cambridge: Cambridge University press, 1996, cap. 2, p.65-131.

SCHINDLER, D. W.; BAYLEY, S. E. The biosphere as an increasing sink for atmospheric carbon: estimates from increased nitrogen deposition. Global biogeochemical cycles, v. 7, p. 717-734, 1993.

SCHOLES, R.J. Will the terrestrial carbon sink saturate soon? Global change newsletter, IGBP, v. 37, p. 2-3, 1999.

SEILER, W.; CRUTZEN, P.J. Estimates of gross and net fluxes of carbon between the biosphere and the atmosphere from biomass buming. Climatic Change, v.2, p.207$247,1980$. 
SHUTTLEWORTH, W.J. Evaporation from Amazonian rain forest. Proceedings of Royal Society of London, serie B, V.233, n.1272, p.321-346,1988.

SHUTTLEWORTH, W.J.; GASH, J.H.C.; LLOYD, C.R.; MOORE, C.J.; ROBERTS, J.M.; MARQUES, A. de O.; FISCH, G.; SILVA, V. de P.; RIBEIRO, M.N.G., MOLION, L.C.B.; de ABREU SÁ, L.D.; NOBRE, C.A.;CABRAL, O.M.R.; PATEL, S.R.; MORAES, J.C. Eddy correlation measurements of energy partition for Amazonian forest. Quarterly Journal of Royal Meteorological Society, v.110, n.466, p.1143-1162, 1984.

TANS, P. P., FUNG, Y. I., TAKAHASI, T. Observational constraints on the global atmospheric $\mathrm{CO}_{2}$ budget. Science, v.247, p.1431-1438, 1990.

TANS, P.P.; BAKWIN, P.S.; GUENTHER, D.W. A feasible global carbon cycle observing system: a plan to decipher today's carbon cycle based on observations. Global change biology. v.2, p.309-318, 1996.

TARDIEU, F.; DAVIES, W. J. Stomatal response to abscisic acid is a function of current plant water status. Plant physiology. v.98, p.540-545, 1992.

TOMASELLA, J.; HODNETT, M.G. Soil hydraulic properties and van Genuchten parameters for a oxisol under pasture in central amazonia. In: GASH, J.H.C.; NOBRE, C.A.; ROBERTS, J.M.; VICTORIA, R.L.(Eds.). Amazonian deforestation and climate. Chichester, John Willey \& Sons, 1996, p.101-123.

UBARANA, V. N. Observation and modelling of rainfall interception loss in two experimental sites in amazonian rainforest. In: GASH, J.H.C.; NOBRE, C.A.; ROBERTS, J.M.; VICTORIA, R.L.(Eds.). Amazonian deforestation and climate. Chichester, John Willey \& Sons, 1996, p.151-162.

VALENTINI, R.; DeANGELIS, P.; MATTEUCCI, G.; MONACO, R.; DORE, S.; SCARASCIA MUGNOZZA, G.E. Seasonal net carbon dioxide exchange of a beech forest with the atmosphere. Global change biology. v.2, p.199-207, 1996.

WILLIAMS, M.; MALHI, Y., NOBRE, A.D., RASTETTER, E. B.; GRACE, J.; PEREIRA, M.G.P. Seasonal variation in net exchang and evapotranspiration in a 
brazilian rainforest: a modelling analysis. Plant, cell and environmental, v.21, p.953-968, 1998.

WOFSY, S. C., HARRISS, R.C.; KAPLAN, W. A. Carbon dioxide in the atmosphere over the Amazon basin. Journal of Geophysical Research, v.93 n.D2, p.1377-1387, 1988.

WONG, C.S. Atmospheric input of carbon dioxide from burning wood. Science, v.200, p.197-200, 1978. 